\title{
Mali: Poverty Reduction Strategy Paper Implementation Report
}

Poverty Reduction Strategy Papers (PRSPs) are prepared by member countries in broad consultation with stakeholders and development partners, including the staffs of the World Bank and the IMF. Updated every three years with annual progress reports, they describe the country's macroeconomic, structural, and social policies in support of growth and poverty reduction, as well as associated external financing needs and major sources of financing. This country document for Mali, dated August 24, 2005, is being made available on the IMF website by agreement with the member country as a service to users of the IMF website.

To assist the IMF in evaluating the publication policy, reader comments are invited and may be sent by e-mail to publicationpolicy@imf.org.

$$
\begin{gathered}
\text { Copies of this report are available to the public from } \\
\text { International Monetary Fund • Publication Services } \\
70019^{\text {th }} \text { Street, N.W. • Washington, D.C. } 20431 \\
\text { Telephone: (202) 623-7430 • Telefax: (202) 623-7201 } \\
\text { E-mail: publications@imf.org • Internet: http://www.imf.org }
\end{gathered}
$$

Price: $\$ 15.00$ a copy

\section{International Monetary Fund Washington, D.C.}



Mali: PRSP

\section{Poverty Reduction Strategy Paper}

\section{Adopted by the Council of Ministers, August 24, 2005}

In recent years, the government of Mali expressed its determination to make the reduction of poverty its highest development priority. That determination reflects a twofold need: first, to make development efforts more effective for the poor; and second, to design new policies and instruments and take pertinent short- and medium-term measures to enable the government to make rational and effective use of domestic and external resources.

\section{PRSP IMPLEMENTATION REPORT}

2003 and 2004

August 2005 
Acronyms and abbreviations.

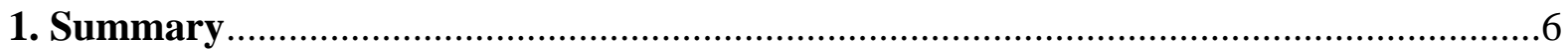

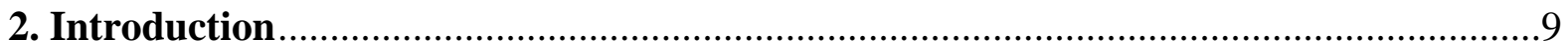

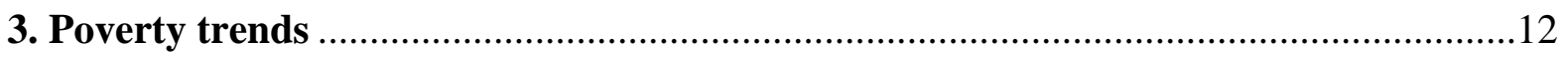

3.1 Results of the short-form integrated household survey (ELIM) ...................................12

3.2 PRSP monitoring and assessment system ..........................................................13

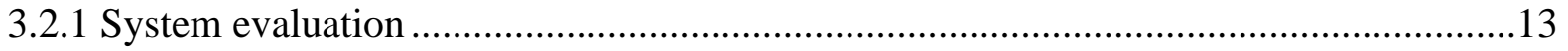

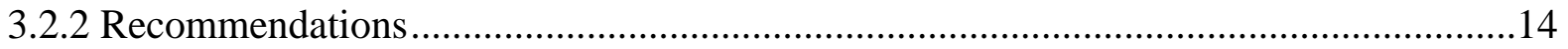

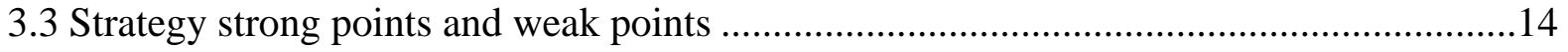

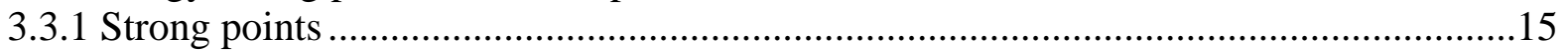

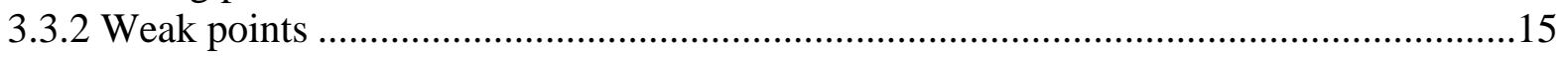

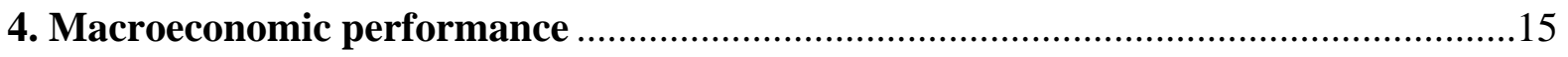

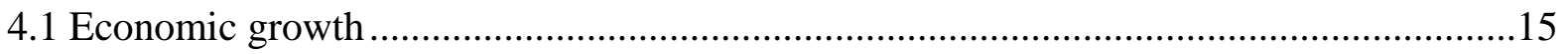

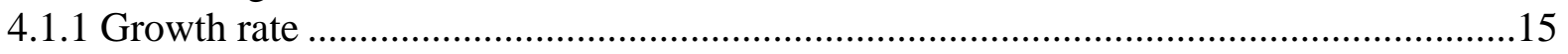

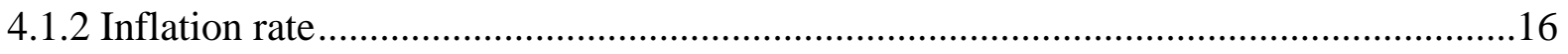

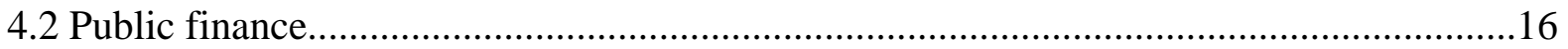

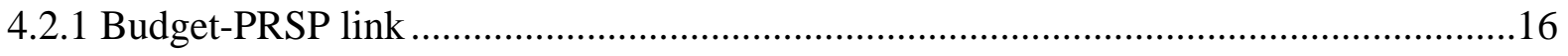

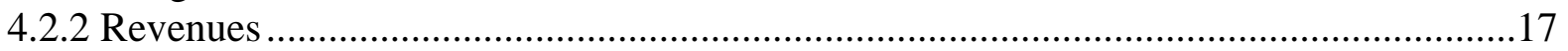

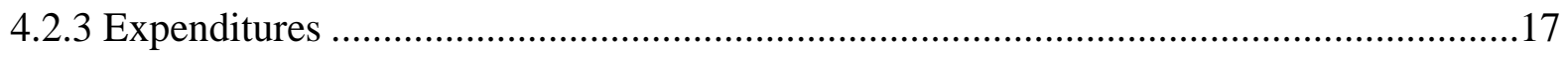

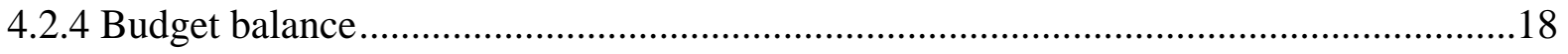

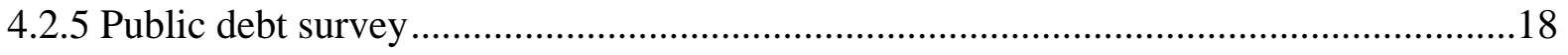

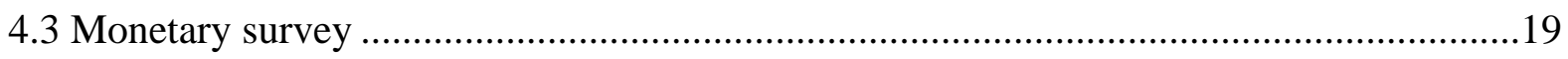

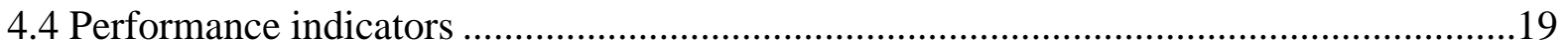

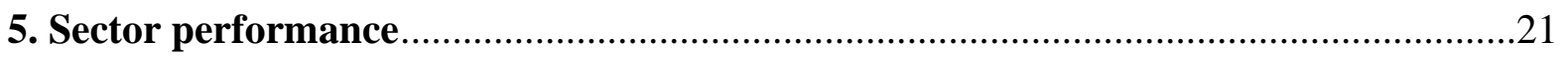

5.1 Approach 1: Ensure institutional development, improve governance and participation ...21

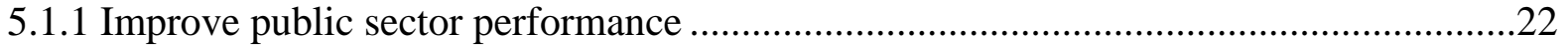

5.1.2 Strengthen national capacities for development planning and management .................22

5.1.3 Improve public expenditure management..............................................................23

5.1.4 Coordination and effectiveness of foreign assistance and the reduction of poverty.......24

5.1.5 Consolidate the democratic, participatory and decentralizing process .........................25 
5.2 Approach 2: Foster sustainable human development and strengthen access to basic social

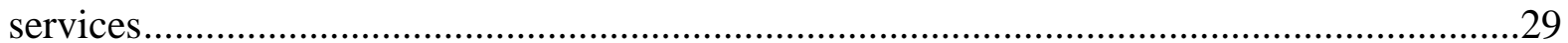

5.2.1 Strengthen health, nutrition and population services...............................................29

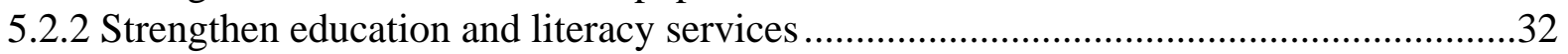

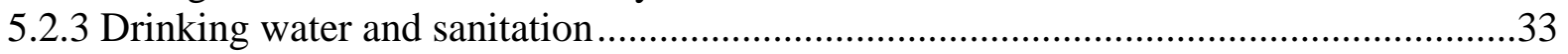

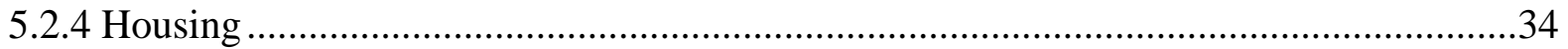

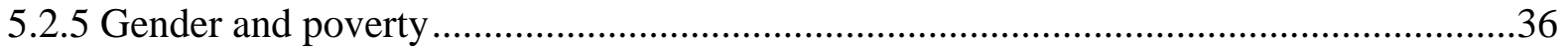

5.2.6 Improve the living conditions of children and youth.............................................37

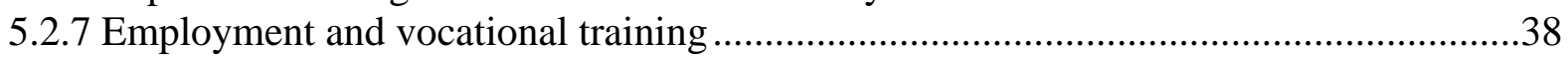

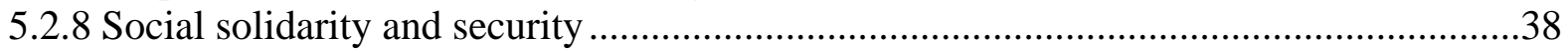

5.3 Approach 3: Develop basic infrastructure and productive sectors ................................39

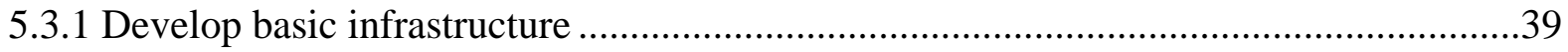

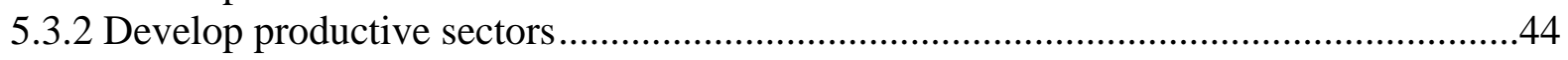

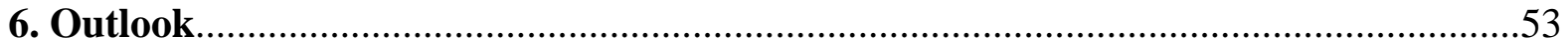

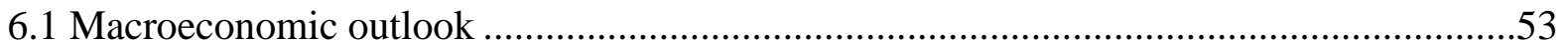

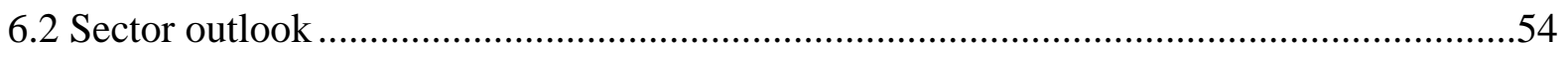

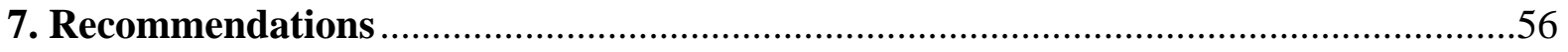

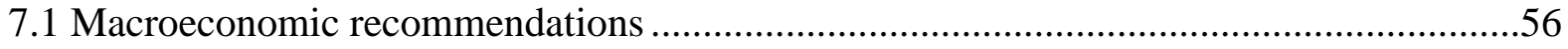

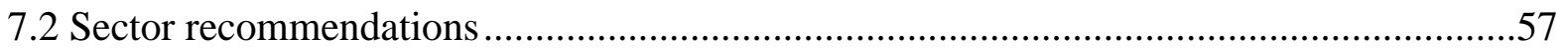

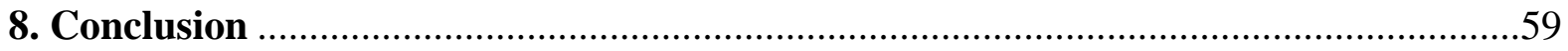

Annex 1. Macroeconomic framework for 2004-2007 …...............................................61

Annex 2. PRSP basic framework for 2002-2006.............................................................64

Annex 3. Comparative table of PRSP objectives and results .............................................66

Annex 4. Simplified diagram of the PRSP monitoring and assessment mechanism..............68

Annex 5. PRSP monitoring/assessment mechanism....................................................69

Annex 6. Trends in Mali’s major macroeconomic indicators—“more comparable” GDP

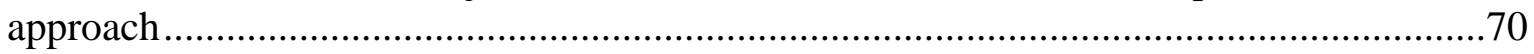

Annex 7. Structure of the "more comparable” GDP for 2000-2007....................................71

Annex 8. Limited list of PRSP monitoring/assessment indicators .....................................73

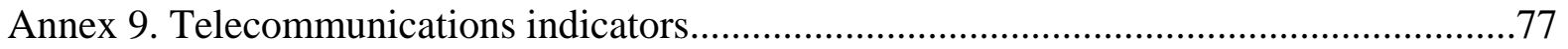

Annex 10. Trends in the budget law: distribution of revenues by budget

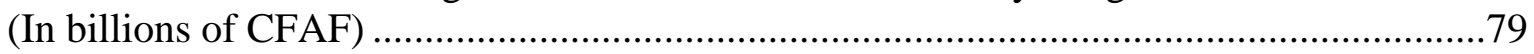

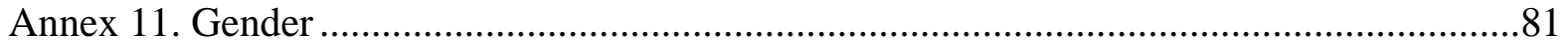

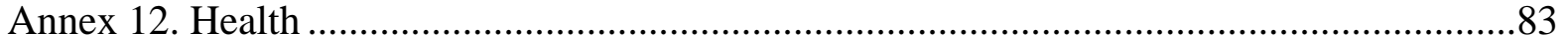

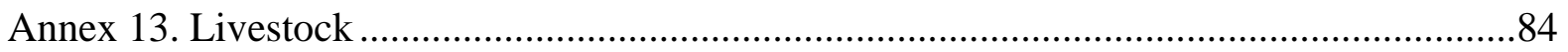

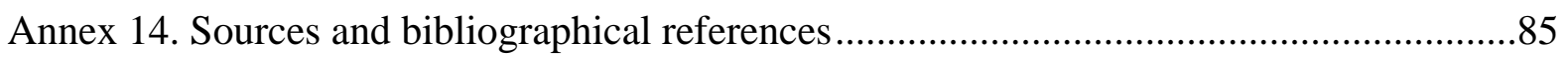




\section{Acronyms and abbreviations}

\begin{tabular}{|l|l|}
\hline ADM & Mali airports \\
\hline AGETIER & Executing agency for rural infrastructure and equipment construction \\
\hline AMADER & Malian agency for development of rural electrification \\
\hline ANICT & National investment agency for regional governments \\
\hline APD & Public development assistance \\
\hline AU & African Union \\
\hline BADEA & Arab bank for African economic development \\
\hline BSI & Special investment budget \\
\hline CADB & Basic development support unit \\
\hline CAN & Nations cup of Africa \\
\hline CAP & Privatization support unit \\
\hline CCC & Communal counseling center \\
\hline CCF & Consumption of fixed capital \\
\hline CCN & National coordination unit \\
\hline CFAF & Franc of the African financial community \\
\hline CMDT & Malian textile development company \\
\hline CNDIFE & $\begin{array}{l}\text { National center for documentation and information on women and } \\
\text { children }\end{array}$ \\
\hline CPN & Prenatal consultation \\
\hline CRT & Telecommunications regulatory committee \\
\hline DNACPN & National directorate for sanitation, pollution and noise control \\
\hline DNR & National roads directorate \\
\hline DNPD & National planning and development directorate \\
\hline DTCP3 & Diphtheria, tetanus, whooping cough, poliomyelitis 3 \\
\hline ECOWAS & Economic Community of West African States \\
\hline EDM & Malian power company \\
\hline EMEP & Malian poverty assessment survey \\
\hline ESAF & Enhanced structural adjustment facility \\
\hline FAI & Social integration support fund \\
\hline FDI & Foreign Direct Investment \\
\hline FER & Rural electrification fund \\
\hline FICT & Regional government investment fund \\
\hline GDP & Gross domestic product \\
\hline HCPI & Harmonized consumer price index \\
\hline HIPC & Highly indebted poor countries \\
\hline HUICOMA & Mali cottonseed oil company \\
\hline IDA & International Development Association \\
\hline IMF & International Monetary Fund \\
\hline MATCL & Ministry for territorial administration and local government \\
\hline
\end{tabular}




\begin{tabular}{|l|l|}
\hline MDG & Millennium development goals \\
\hline MTEF & Medium-Term Expenditure Framework \\
\hline NEPAD & New Partnership for Africa's Development \\
\hline NTIC & New technologies for information and communications \\
\hline ODHD/LCP & Sustainable human development and poverty reduction center \\
\hline OISE & Electronic monitoring/assessment organization \\
\hline PASAOP & Program of support for agricultural services and rural organizations \\
\hline PAS & Structural adjustment program \\
\hline PDDSS & Ten-year sanitation and social development program \\
\hline PDI & Institutional development program \\
\hline PISE & Education sector investment program \\
\hline PNIR & National rural infrastructure program \\
\hline PNP & National population policy \\
\hline PRODEC & Ten-year education development program \\
\hline PRODEJ & Justice development program \\
\hline PRGF & Poverty reduction and growth facility \\
\hline PRSP & Poverty reduction strategy framework \\
\hline PRSP & Poverty reduction strategy paper \\
\hline PTF & Technical and financial partner \\
\hline PTI & Three-year investment program \\
\hline SAC IV & Structural adjustment credit IV \\
\hline SDR & Roads data service \\
\hline Sinankouya & Social kinship system \\
\hline SOTELMA & Malian Telecommunications Company \\
\hline TBS & Gross rate of school attendance \\
\hline TOFE & Table of Government Finance Operations \\
\hline TOR & Terms of reference \\
\hline WAEMU & West African Economic and Monetary Union \\
\hline
\end{tabular}




\section{Summary}

1. In May 2002 Mali adopted a medium-term (2002-2006) Poverty Reduction Strategy Paper (PRSP) whose implementation is taking place in a context marked by a downward trend in Public Development Assistance (APD) and extreme vulnerability to external shocks: drought, a desert locust plague, fluctuations in the terms of trade, and political crises in the subregion. This illustrates the seriousness of the challenges facing Mali if it is to ensure strong, sustainable growth and reduce poverty.

2. Despite this unfavorable environment, in recent years Mali has recorded substantial progress in the political, social and economic spheres, as shown by the levels of performance indicators in this PRSP implementation report for 2003 and 2004.

3. The political and social situation has in fact improved over the last ten-year period. Since 1992, democratic elections (presidential, legislative, municipal and communal) have been held in a peaceful and cooperative environment. In 2002, these elections led to a handing over of power with social and political stability, further abetted by quiet local elections in May 2004.

4. As regards institutional reform, since 1992 Mali has undertaken a wide-ranging decentralization and devolution process which led to a reconfigured administrative system made up of 703 communes, 49 cercles, 8 regions and 1 district. This is not to deny that there have been noticeable delays in the transfer of functions and resources from the central government to regional governments.

5. Significant reforms have been undertaken within the framework of a modernized administration, an improved judicial system, good governance, the fight against corruption and financial crime.

6. In the area of the economy and finance, since 1992 the International Monetary Fund (IMF) has provided Mali with continuous support in the form of three (3) successive ESAF/PRGF agreements, enabling it to restore macroeconomic stability, the viability of public finance and the implementation of thorough structural reforms. Mali has made significant advances in public finance management and in the macroeconomic area through implementation of a new budget and accounting nomenclature, program budgets, medium-term expenditure frameworks (ADMT) expenditure execution procedure manuals, establishing and using a macroeconomic model, and creating a Forecasting and Modeling Committee (2003). 
In the real sector, with the new series of "more comparable" GDPs, economic growth reached 4.3 percent in 2002 and 7.4 percent in 2003 . However, as a consequence of the poor 2004-2005 crop, the desert locust plague, the drop in gold production, the drop in the price of cotton, the increase in oil prices and the fluctuation of the US dollar vis-à-vis the euro/CFAF, the growth of Mali's real GDP was on the order of 2.2 percent in 2004 .

7. As regards public finance and indebtedness, as an acknowledgment of the satisfactory progress made by the government in implementing reforms, Mali became the seventh country to reach the completion point within the HIPC framework (Highly Indebted Poor Countries), after Bolivia, Burkina Faso, Mauritania, Mozambique, Tanzania and Uganda. In 2003, Mali's entire eligible debt was cancelled by the Paris Club. The amount of HIPC resources awarded in 2003 was CFAF 19 billion, compared to CFAF 24.5 billion specified in the PRSP for 2003, for a 78 percent implementation rate; in 2004, CFAF 28.8 billion were awarded out of an estimate of CFAF 29.6, for a 97 percent implementation rate. In addition, Mali's encouraging results resulted in support by partners at the Donor's Roundtable (Geneva, March 2004) confirming their intention to increase their grants of assistance for development. For the three years of the period 2004-2006, the Roundtable posted declarations of intent totaling around US\$ 2.4 billion (CFAF 1,276 billion). This 20004 assistance included budgetary assistance of CFAF 75 billion, of which CFAF 33 billion have been mobilized.

8. Moreover, the program to restructure and privatize public enterprises is well advanced. The railroads have been private since 2003, and a privatization support unit (CAP) was established for SOTELMA; the process for Mali Airports concessions and privatizing the ground handling services is ongoing. As for the cotton sector, privatization of HUICOMA has proceeded normally and privatization of the Malian Textile Development Company (CMDT) is scheduled for 2008.

9. Progress has been made in the social sectors, even if some inadequacies remain. For example, budget allocations to the education and health sectors have improved, with budget resources allotted to essential social services trending markedly favorably over the period 2001-2004.

10. The relative share of basic education in overall budget expenditures has grown from 6.68 percent in 2001 to 10 percent in 2003, a rate of increase of nearly 50 percent. As regards the budget for health, its share of overall budget expenditures rose from 6.3 percent in 2001 to 7.1 percent in 2003, a growth rate of 12.7 percent.

11. Regarding health indicators, the percentage of the population located less than $5 \mathrm{~km}$ from an operating health center rose from 44 percent in 2002 to 47 percent in 2004. The percentage of persons living within a radius of less than $15 \mathrm{~km}$ was 69 percent in 2003, versus 68 percent in 2002. The number of women benefiting from prenatal consultation increased from 54 percent in 2002 to 59 percent in 2003 and 69 percent (71 percent) in 2004; 
child bearing assisted by qualified personnel rose from 40 percent in 2002 to 42 percent in 2003 and 46 percent (47 percent) in 2004. The rate of DTCPS coverage of children under one year of age reached 79 percent in 2003, for an annual objective of 80 percent, compared to 74 percent in 2002. In 2004, this rate was boosted to 86 percent.

12. As regards education indicators, the Gross School Attendance Rate (TBS) rose from 64.3 percent in 2002 to 67 percent in 2003 and 70.5 percent in 2004. For boys the TBS was 72.5 in 2002, versus 53.7 percent for girls; in 2003, the rate was 77.9 percent for boys versus 56.4 percent for girls; in 2004, the rate for girls reached 60 percent. The average dropout rate fell markedly, to an average of 4.2 percent annually.

13. Looking now at inadequacies in these sectors, we note the poor quality of Mali's education system, the virtually stagnant rate of visitation of health centers, and problems related to quantitative and qualitative inadequacies and poor motivation of personnel in the social-health fields.

14. As for the coverage of financing needs, additional resources need to be mobilized from Mali's development partners in order to attain the PRSP objectives, especially in priority sectors such as health, education, rural development and basic infrastructure.

\section{To eliminate constraints that threaten to mortgage proper implementation of the PRSP and achievement of its objectives, the government must accelerate implementation of institutional reforms, in particular the Action Plan to improve and modernize public finance management, eventually involving direct budget assistance by technical and financial partners.}

15. The macroeconomic outlook is encouraging, with a GDP growth rate estimated at 6.1 percent in 2005 and 5.8 percent in 2006, buttressed by growth of 4 percent in the agricultural sector and an 18 percent increase in gold production in 2005 and 16.4 percent in 2006.

16. In the sectors, and in particular the health sector, the sanitation and social development program (PDSS 2005-2009) is aimed at improving the health of populations and correcting the major bottlenecks in implementing the PRODESS, designed to achieve the PRSP objectives (results-oriented management based on a Medium-Term Expenditure Framework (MTEF). 


\section{Introduction}

17. Mali is a landlocked country structurally dependent on the regional and international economies; it has been severely handicapped by a very unfavorable international business climate. Mali's economy experienced combined shocks to which the government responded energetically so as to maintain macroeconomic stability and protect vulnerable population segments. The period under study, 2003 and 2004, was marked by the crisis in Cote d'Ivoire, a drop in the price of cotton, increased prices for oil, intermittent rainfall and a locust plague.

18. Highlights of 2003:

- Political crisis in Côte d'Ivoire. Starting in September 2002, closure of the main highway to Côte d'Ivoire, Mali's biggest trade partner in the subregion, and the channel for 70 percent of Mali's trade, increased the recurrent transportation charges exponentially and reduced budget receipts.

- The international economic environment was characterized by persistent doubts regarding economic growth, especially in the United States and the euro zone. This situation was worsened by the geopolitical crisis in Iraq, together with its consequences.

- The worldwide growth rate improved slightly in 2003 as compared to 2002, inching up from 3 percent to 3.2 percent.

- In the WAEMU zone, the decline in prices begun in 2002 continued throughout 2003, creating abundant supplies of food products. This pricing trend was disturbed, however, by a rise in the price of fuels and the impact of the crisis in Côte d'Ivoire. In 2003, inflation stood at 1.8 percent, compared to 3.1 percent in 2002.

- The rebound of the world economy in 2002 continued in 2003 and resulted in improved world demand for the principal commodities and higher prices for the major inputs (oil, cotton, gold).

19. Highlights of 2004:

- Continued crisis in Côte d'Ivoire;

- The price of cotton for the 2004-2005 crop year fell by 30 percent compared to its 20032004 level as a consequence of an increase in the world production of cotton, subsidies granted by some western countries and the improved yields of genetically engineered cotton. - Higher oil prices. The price of oil on the international market surged by 30 percent in 2004 . - Unprecedented plague of desert locusts, below-average, scattered rainfall.

20. Faced with these problems, the government proceeded to:

- Diversify the country’s supply ports (Lomé, Téma, Conakry, Cotonou and Nouakchott), supported by measures to strengthen transportation, and in particular acquisition of new vehicles.

- Implement a moderate tax policy for petroleum products, resulting in stabilized domestic prices, all the while ensuring continued tax receipts from this sector, deregulated in 1992. - With the help of partners, organize an anti-locust campaign resulting in limitation of the negative effects on cereals production; a relative decline of 11.9 percent was recorded. 
- Deregulate the cotton sector and bring producer costs under control. A CMDT privatization plan was adopted, with completion of the process scheduled in 2008. To minimize future budget risks and strengthen the role of price signals from the world market for producers and processors, a new, flexible producer price mechanism was established.

21. In order to limit the impact of internal and external shocks on growth, the government is determined to accelerate structural reforms so as to increase the flexibility and efficiency of its economy while carrying on an active budgetary policy of reducing poverty within the framework of the PRSP.

22. At the macroeconomic level, the GDP growth rate plummeted from 7.4 percent in 2003 to 2.2 percent in 2004, compared to an initial forecast of 4.7 percent. This sharp decline is attributable to a drop in 2004-2005 cereals production and a drop in gold production in 2004.

23. Despite this state of affairs, the government of Mali remains determined to pursue budgetary discipline by maintaining the budget deficit in line with PRGF targets. In the medium term, strengthening the private sector and improving the efficiency of the economy will sustain GDP growth. These budget objectives are also in harmony with the framework for meeting the WAEMU convergence criteria.

24. The initial implementation report covered the period from 2002 to June 2003, while the present report, covering the whole of years 2003 and 2004, enables readjustment of the PRSP objectives to align with the objectives of the budget law; it aims to assess the results obtained by reference to the indicators employed.

25. The overall objective is to achieve strong growth over the period 2002-2006, reduce poverty and promote good governance. Specifically, the PRSP seeks to achieve the following objectives:

- Macroeconomic objectives:

o Average annual growth rate of 6.7 percent (2002-2006);

o Average annual rate of investment of 24.8 percent of GDP (2002-2006);

o Ratio of wage bill to tax receipts of 26.2 percent in 2006; annual increase of wage bill of 9.6 percent;

o Tax burden: 17 percent by 2006;

o Budget deficit: maximum of 6 percent by 2006;

- Overall poverty reduction objective:

o Lowering of incidence of poverty from 63.8 percent in 2001 to 47.5 percent in 2006;

- Sector objectives:

o School attendance: boost school attendance to 75 percent by 2006;

o Infant mortality: lower the rate of infant mortality to 90/1,000 live births by 2006. 
26. PRSP monitoring/assessment constitutes one of the major concerns of both the government of Mali and its development partners, who join in implementing Mali's development policies and strategies. This concern is linked to the growing demand for information on the results and impact of development assistance and the domestic efforts in all areas, particularly in the fight against poverty.

27. The PRSP monitoring/assessment system aims at including all concerned as participants in the process, being informed of the implementation, and verifying that the strategies adopted are effective in reducing poverty. The system uses a twin approach, operating vertically and horizontally - the latter based on a decentralized and devolved monitoring system. This mechanism is based on continuation of the participatory process used to draw up the PRSP, calling upon central and regional institutional mechanisms. 


\section{Poverty trends}

\subsection{Results of the short-form integrated household survey (ELIM)}

28. In order to measure progress made in improving the living conditions of segments of the population and draw lessons from the process to improve the effectiveness of the measures deployed, the National Statistics and Information Directorate (DNSI) undertakes a short-form integrated survey of households (ELIM) every two years based on the Malian Poverty Assessment Survey (EMEP) 2001-2002. The survey undertaken at end-2003 was the first in that series. The overall objective of the ELIM is to measure the levels and determining factors of the living conditions of the population.

29. The survey gathered a sizeable mass of pertinent information on the living conditions of households. These data relate to essential areas such as access to basic essential infrastructures (schools, health and transportation facilities, food markets, etc.), school attendance, adult literacy, the state of health of the population and employment.

30. From study of the survey results we can retain the following findings and conclusions: - The average household in Mali consists of 9 persons, headed mainly by men: 89 percent male head of household, versus 11 percent female heads.

- Household economic conditions have improved by comparison with the situation the previous year. More than two-thirds (67 percent) of households estimated that their economic condition at the time of the survey was better than the previous year. This improvement was felt more strongly in rural locations than in the cities, and more strongly in households headed by men than by women.

- Coordinated with the improved economic condition of the households between 2001 and 2003, the amount of goods owned by the households had also improved: the families possessed more arable land, more livestock, household appliances (television sets, radios, etc.) and vehicles (bicycles, motorcycles, cars) in 2003 than in 2001.

- There was a distinct improvement in certain social indicators between 2001 and 2003:

o The gross school attendance rate increased from 58 percent to 67 percent, a rise of 16 percent, and the net rate improved by 17 percent, from 41 percent to 48 percent.

0 Adult literacy rose from 21 percent to 24 percent.

0 The number of households with access to drinking water stands at 68 percent, with a clear improvement in rural areas, where the number rose from 59 percent of households to 67 percent between 2001 and 2003.

o A larger proportion of households have the use of electricity, up from 8 percent in 2001 to 13 percent in 2003.

o Household access to health facilities has improved, from 38 percent of the population to 42 percent, and the number of births at home decreased from 55 percent to 48 percent.

o One out of every two persons (56 percent) age 15 or more worked during the week preceding the survey. 
o Self-employment increased from 35 percent to 40 percent, and the rate of employment in the private sector doubled, from 5 percent to 10 percent.

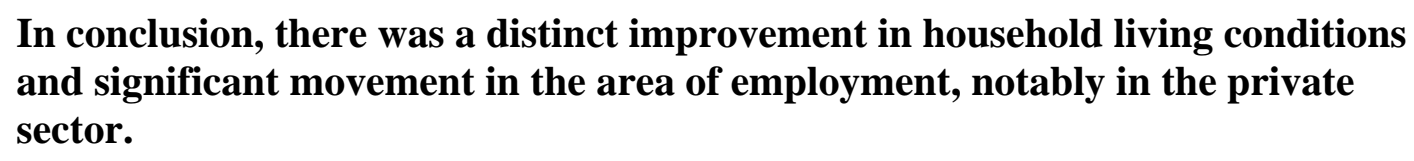

\subsection{PRSP monitoring and assessment system}

\subsubsection{System evaluation}

31. Assessment of the PRSP monitoring/assessment system since the implementation of the PRSP has identified a certain number of problems and suggested recommendations which speak volumes on the importance of problem solving that the coordination of the PRSP is called upon to address.

32. Considering the institutional mechanism for monitoring/assessment, at the end of the third year of implementation, we note that certain institutional PRSP monitoring/assessment mechanisms (Orientation Committee, thematic groups, Steering Committee, Technical Secretariat, Regional Committees) are not operating as intended. The chief problem encountered continues to be inadequate capacities of the various national sector and regional entities responsible for monitoring/assessment (PRSP Unit, DNSI, DNPD, ODHD, CPS, DRPSIAP, etc.).

33. Regarding methods, tools, instruments and indicators used, the problems encountered can be summed up as follows:

- The lack of reference situations and well defined targets among the components of the PRSP makes it difficult to adopt an adequate approach and to undertake detailed analyses of the principal strategic pillars on the basis of objectives and actions chosen for implementation.

- $\quad$ The information system remains unable to measure the performance indicators with precision, given the lack of a management culture oriented toward results, as shown by the "excessively administrative" reports generated by the thematic groups.

- The approach that consists in monitoring PRSP implementation through the program budget, used by the thematic groups, does not seem to be able to assess intermediate results, and thus cannot replace routine activities emphasized in most of the thematic groups. Moreover, it has been observed that there is little coherence between the ministerial program budgets and the PRSP strategies and objectives.

- $\quad$ The methodology used in preparing thematic group reports needs to be reviewed in light of PRSP needs and requirements. 
- The reliability and coherence of data and statistics obtained from diverse sources continues to be a serious problem.

\subsubsection{Recommendations}

34. In order to ensure improved implementation of the PRSP, the report makes the following recommendations as regards the institutional mechanism for PRSP monitoring/implementation.

35. In order for the monitoring and assessment mechanism to function properly, the following measures should be adopted:

- Clarify and simplify the PRSP monitoring/assessment mechanism, and review the roles assigned to the various participants.

- Improve leadership of the thematic groups by the PRSP Technical Secretariat and the Coordination Unit (nationally and regionally).

- Provide technical support to ODHD in generating thematic analyses on poverty based on results of the survey assessing poverty, the short-form integrated household survey and other surveys on living conditions of population groups.

- Provide adequate financial support to effective functioning of the monitoring/assessment mechanism, to induce it to plan its activities better and with transparency, and to avoid improvising as a function of the availability of financial resources.

36. As regards methods, tools, instruments and indicators used, we need to:

- Refine and update the PRSP Action Plan (prioritize the actions/projects/programs selected by component, group of components per strategic approach, indications of funding available or needed;

- Harmonize efforts with the three-year program, the special investment budget and the program budgets;

- Review the number and kind of indicators used per component and thematic domain, with a view to reducing their number and making them more pertinent;

- Develop a reference situation for the indicators selected for the PRSP monitoring/assessment system and plan studies and surveys for items not able to be generated using available statistics;

- Facilitate the circulation of information generated by the PRSP implementation process using compatible computer applications and networking the major players in the monitoring/assessment process.

\subsection{Strategy strong points and weak points}

37. The three-year experience in implementing the PRSP enables us to indicate the strong points and the weak points of the strategy, for the purpose of steering the PRSP implementation more confidently toward its overall objective. 


\subsubsection{Strong points}

- Annual framing of the PRSP to cohere with the Budget Law;

- Gradual refocusing of sector policies and strategies on PRSP approaches (e.g., PRODESS II, updated PNP, PISE II, etc.);

- $\quad$ The repetitive and participatory nature of the PRSP monitoring/assessment process is a considerable advantage allowing for flexible articulation with institutional innovations. This reference framework, refocused on a more operational institutional mechanism, enables development of poverty reduction strategies.

\subsubsection{Weak points}

- $\quad$ The choice of indicators and their monitoring by sector agencies;

- Illegible links between current environmental phenomena and the structure of the indicators;

- $\quad$ Lack of a reference situation;

- Inadequate data collection mechanisms;

- $\quad$ Problems in adoption of monitoring/assessment mechanisms by the various players;

- Lack of a working strategy for mobilizing financial resources (domestic and foreign);

- Unavailability of gender indicators in the PRSP third approach.

\section{Macroeconomic performance}

\subsection{Economic growth}

\subsubsection{Growth rate}

38. In 2003, the growth rate was 7.4 percent, compared to 4.3 percent in 2002. This strong growth is largely attributable to agriculture, which produced especially high yields in 2003, driving an 18.4 percent increase in the primary sector. The secondary sector slowed in the wake of a drop in gold production and in the output of manufacturing, dominated by shelling facilities. Gold production declined from 66.1 tons in 2002 to 53.6 tons in 2003, a drop of 18.9 percent. Growth in the tertiary sector averaged 8.3 percent, driven by trade and the start up of business by a second telephone company.

39. In 2004, the economic environment included a difficult start to the 2004-2005 crop year, in which a plague of desert locusts caused significant damage to livestock pastures and farm output in the northern regions of Mali, to which was added underperformance of mining companies.

40. Further to the situation in agriculture, the year 2004 saw a significant decrease in growth compared to initial forecasts. According to the latest estimates, the GDP growth rate was 
only 2.2 percent in 2004, whereas initial forecasts called for 4.7 percent. This sharp decline was essentially attributable to lower cereals output and lower gold production compared to 2003.

\subsubsection{Inflation rate}

41. Average inflation, measured by the changes in the Harmonized Consumer Price Index (HCPI average over 12 months) was a negative 1.3 percent in 2003, compared to 5 percent in 2002. In 2004, the annual change in the HCPI (average over 12 months) was a negative 4.3 percent. This rate is significantly below the WAEMU zone standard of 3 percent maximum. As for the GDP deflator, it stood at 2.2 percent in 2004, compared to 0.3 percent in 2003 and a negative 0.9 percent in 2002.

\subsection{Public finance}

\subsubsection{Budget-PRSP link}

42. The link between the PRSP and the budget process is made by the circular letter of the Minister of the Economy and Finance (MEF), based on the priorities and the general and sector objectives of the PRSP. The minister's letter constitutes the preparatory framework for the national budget, and in particular the program budget of each department. The PRSP monitoring/assessment mechanism identifies three central institutional pillars on which oversight of sector strategy implementation rests: ministerial departments (all the technical ministries), the Ministry of the Economy and Finance and the Ministry of the Plan and Land Use Management (MPAT), service-user interest groups and associations. The institutional pillars, their interactions and the tools used for monitoring/assessment are presented below.

43. The first institutional pillar includes the ministerial departments (at the national level) and the agencies and subagencies of these departments as decentralized. The ministerial departments are responsible for designing, implementing and monitoring sector strategies under their purview. Since 1998, this process has taken the form of design, implementation and monitoring/assessment of program budgets within each ministerial department. The program budget of a given sector reflects the entire range of medium-term measures and actions required to respond to specified objectives, including - for each component of the sector strategy, in accordance with PRSP priorities-specific quantified objectives provided with action plans and financial and budgetary needs. Furthermore, this pillar specifies the corresponding indicators, assumptions and sources of verification.

44. The second pillar of the current sector monitoring/assessment system structure is made up of the Ministry of the Economy and Finance and the Ministry of the Plan and Land Use Management. The National Budget Directorate (DNB) and the National Planning and Development Directorate (DNPD) are charged, respectively, with ensuring oversight of program budgets of all the ministerial departments and with executing the Three-Year Investment Program (PTI), whose annual tranche constitutes the Special Investment Budget (BSI). 


\subsubsection{Revenues}

46. Total revenues and grants in 2003 amounted to CFAF 536.5 billion, a 17.47 percent increase over 2002 (CFAF 456.7 billion). In 2003, tax receipts of CFAF 349.2 billion accounted for 82.78 percent of total revenues excluding grants (421.8 billion). This represents an increase of 14.25 percent over their year 2002 level of CFAF 306 billion.

47 Grants surged from CFAF 85.8 billion in 2002 to CFAF 114.8 billion in 2003, driven by exceptional grants from the European Union and the World Bank intended to soften the negative impact on revenues of the crisis in Côte d'Ivoire (a loss of CFAF 14.2 billion in 2002 and a loss of CFAF 21.4 billion in 2003).

48. In 2004, total revenues and grants reached CFAF 558 billion, compared to CFAF 536.5 billion in 2003, an increase of 4 percent. Additionally, total revenues excluding grants were CFAF 454.7 billion, including CFAF 393.3 billion in tax receipts, for an increase of 12.63 percent over the figure for 2003 (CFAF 349.2 billion).

49. Incoming funds from HIPC sources totaled CFAF 19 billion in 2003, compared to the PRSP year 2003 estimate of CFAF 24.5 billion, i.e., a 78 percent implementation rate; for 2004, comparable figures were CFAF 28.8 billion actually disbursed, out of 29.6 billion estimated, a 97.30 percent implementation rate.

50. Further to the matter of revenues, Mali's encouraging results induced the Donor Roundtable to pledge increased development support at their March 2004 meeting in Geneva. For the three-year period 2004-2006, the Roundtable recorded declarations of intention totaling about US $\$ 2.4$ billion (CFAF 1,276 billion). This assistance estimated budget aid of CFAF 75 billion in 2004, of which CFAF 33 billion have been mobilized.

In summary, revenues increased by 17.47 percent between 2002 and 2003 and by 4.01 percent between 2003 and 2004.

\subsubsection{Expenditures}

51. Total expenditures and net lending, CFAF 540.6 billion in 2002, stood at CFAF 569 billion in 2003, an increase of 5.3 percent. These expenditures represented 22.1 percent of GDP in 2003, versus 23.8 percent in 2002, a decrease of 1.7 percentage point.

52. Having been estimated at CFAF 292.1 billion in 2003, the Special Investment Budget (BSI) was 69.6 percent executed, compared to 72 percent in 2002. Executed items were 69.3 percent financed by technical and financial partners (i.e., CFAF 140.2 billion) and 30.7 percent by domestic resources (for CFAF 62.4 billion). The decline in volume and in the rate of execution of the BSI was essentially linked to the drop in the volume of external financing 
in the BSI total. The low execution rate is explained by the poor absorption rate of some departments, associated with the ponderous procedures in the bidding process, in institutional organization of mobilization of financing, and the unfamiliarity with donors' procedures.

53. As far as the wage bill is concerned, its share of GDP was 3.8 percent in 2002; it stood at 3.9 percent in 2003, a slight rise of 0.1 percentage point, due to the implementation of the Civil Service recruitment plan.

54. Total expenditures and net lending was CFAF 625.8 billion in 2004, versus CFAF 569 billion in 2003, a 10 percent increase. Current expenditures reached CFAF 349.9 billion in 2004, of which 121.7 billion went to wages. Capital expenditures totaled CFAF 242.2 billion in 2004, compared to CFAF 219.2 billion in 2003.

55. The deficit on a commitment basis, excluding grants, dropped from CFAF 151.3 billion in 2002 to CFAF 128.4 billion in 2003, an improvement of CFAF 22.9 billion. In 2004, the deficit stood at CFAF 171.1 billion. Compared to GDP, the deficit was 7.1 percent in 2004, 5.7 percent in 2003, and 7.3 percent in 2002. This improvement in the condition of public finance is attributable to a good 2003-2004 crop harvest, and to control of expenses accompanied by growth in receipts between 2002 and 2003.

In 2004, strict budget management enabled Mali to maintain an overall budget position in line with the projections of the IMF program. Current expenditures and capital expenditures were kept within the limits of the program in order to partly offset delays in disbursements of foreign assistance. Total expenditures and net lending rose to CFAF 625.8 billion in 2004, versus CFAF 569 billion in 2003. Current expenses totaled CFAF 349.9 billion in 2004, compared to CFAF 316.3 billion in 2003, and capital outlays totaled CFAF 242.2 billion in 2004, versus CFAF 219.2 billion in 2003.

\subsubsection{Budget balance}

56. One of the government's major strategic approaches as regards economic and financial reform remains the improvement of the country's financial condition through the viability of its financial operations. Official policy in this regard aims at consolidating public finances by controlling current expenditures and broadening the tax base. The ratio of base budget balance excluding HIPC to GDP rose from a negative 0.1 percent in 2002 to 1.0 percent in 2003, then returned to 0.1 percent in 2004.

\subsubsection{Public debt situation}

\section{Foreign debt}

57. As of December 31, 2003, the medium- and long-term public debt before relief was estimated at CFAF 1,798.7 billion, compared to CFAF 1,776.1 billion in 2002. Multilateral 
debt accounted for 74.5 percent of the total, or CFAF 1,339.9 billion, whereas bilateral debt represented 25.5 percent of the total, or CFAF 458.8 billion. The ratio of foreign public debt to GDP improved between 2002 and 2003, falling from 77.3 percent in 2002 to 72.1 percent in 2003. Mali is benefiting from resources disbursed under the second phase of the HIPC initiative adopted in June 1999 in Cologne by the G7 summit, since Mali reached the completion point on February 28, 2003.

58. As of December 31, 2004, the total medium- and long-term foreign public debt before relief was CFAF 1,705.25 billion, of which CFAF 436.99 billion represented bilateral debt, and CFAF 1,268.26 billion was in multilateral debt. Over the same period, relief granted under the HIPC initiative totaled CFAF 17.83 billion, compared with an annual estimate of CFAF 29.6 billion in 2004.

\section{Domestic debt}

59. As of December 31, 2003, the domestic public debt stood at CFAF 78.2 billion, compared to CFAF 107.1 billion in 2002. As of December 31, 2004, the domestic public debt fell to CFAF 55.4 billion, a decrease of CFAF 22.8 billion over the figure for 2003 . That gradual drop is attributable to the proper execution of the schedule for settling the existing stock of debt.

\subsection{Monetary survey}

On the basis of data recorded ${ }^{1}$ at end-December 2003, changes in the monetary situation compared to December 2002 included: an increase in net foreign assets (up CFAF 115.7 billion or 40.6 percent); a rise in domestic credit (up CFAF 23.8 billion or 6.2 percent) and an increase in the money supply (up CFAF 137.1 billion or 21.9 percent).

Compared to end-December 2003, the estimated monetary situation at end-December 2004 featured an improvement in net assets (up CFAF 59.7 billion or 14.9 percent), an increase in domestic credit (up CFAF 48 billion or 11.8 percent), and an increase in the money supply (up CFAF 92.6 billion or 12.1 percent).

\subsection{Performance indicators}

The indicators shown in the following tables enable assessment of the allocation of resources to priority sectors and the PRSP-budget link.

\section{Public finance indicators}

\footnotetext{
${ }^{1}$ From the note on recent changes in the monetary situation and the balance of payments, and forecasts for the year 2004/BCEAO_No.658-SC.WAD_05/03/04.
} 


\begin{tabular}{|c|c|c|c|c|}
\hline No. & Indicators & 2002 & 2003 & 2004 \\
\hline 10 & $\begin{array}{l}\text { Percentage of budget expenditures linked to poverty } \\
\text { reduction }\end{array}$ & $61.18 \%$ & $57.78 \%$ & $58.75 \%$ \\
\hline 15 & $\begin{array}{l}\text { Percentage of financial resources actually } \\
\text { transferred to local governments }\end{array}$ & & $\begin{array}{r}(2.442 \\
\text { billion }) \\
\end{array}$ & $\begin{array}{r}(2.761 \\
\text { billion }) \\
\end{array}$ \\
\hline 16 & $\begin{array}{l}\text { Percentage of financial resources transferred from } \\
\text { central administrations to decentralized agencies }\end{array}$ & & & $29.41 \%$ \\
\hline 26 & $\begin{array}{l}\text { Health budget share of the govt. budget in terms of } \\
\text { recurrent charges }\end{array}$ & $\begin{array}{l}10.70 \%(\mathrm{P}) \\
10.50 \%(\mathrm{R})\end{array}$ & $\begin{array}{l}10.80 \% \\
10.23 \% \\
\end{array}$ & $\begin{array}{l}11.00 \% \\
10.65 \%\end{array}$ \\
\hline 27 & $\begin{array}{l}\text { Rate of execution of ordinary budget allocated to } \\
\text { purchase of drugs and vaccines }\end{array}$ & $94.50 \%$ & $98.20 \%$ & $100.00 \%$ \\
\hline 30 & Education budget share of the govt. budget & $29.00 \%$ & $29.60 \%$ & $29.15 \%$ \\
\hline 31 & $\begin{array}{l}\text { Rate of execution of ordinary budget allocated to } \\
\text { purchase of teaching materials }\end{array}$ & $99.56 \%$ & $99.74 \%$ & $99.54 \%$ \\
\hline 43 & $\begin{array}{l}\text { Rate of execution of BSI (domestic financing) } \\
\text { allocated to road maintenance }\end{array}$ & $100.40 \%$ & $98.90 \%$ & $100.00 \%$ \\
\hline
\end{tabular}

Source: DNB

\section{Principal sector ratios in terms of recurrent charges}

\begin{tabular}{|l|r|r|r|}
\hline Sector & \multicolumn{1}{|c|}{$\mathbf{2 0 0 3}$} & \multicolumn{1}{|c|}{$\mathbf{2 0 0 4}$} & \multicolumn{1}{|c|}{$\mathbf{2 0 0 5}$} \\
\hline Education & 30.57 & 30.06 & 30.31 \\
\hline Health (ex. other social sectors) & 10.07 & 10.65 & 10.15 \\
\hline Social Sectors (ex. health and education) & 6.85 & 8.39 & 8.72 \\
\hline Rural Development and Environment & 4.57 & 4.74 & 5.15 \\
\hline $\begin{array}{l}\text { Equipment, Transportation, City Planning and } \\
\text { Communications }\end{array}$ & & & \\
\hline Armed Forces and Security & 3.60 & 3.92 & 3.85 \\
\hline Mines, Water Resources and Industry & 16.90 & 16.66 & 16.45 \\
\hline Public Authorities and Administration & 19.59 & 1.47 & 1.54 \\
\hline Allocated but not distributed & 6.44 & 4.37 & 20.19 \\
\hline Total & 100 & 100 & 3.64 \\
\hline
\end{tabular}

Source: DNB

Ratios in terms of the entire budget (including financing from abroad of the Special Investment Budget)

\begin{tabular}{|l|r|r|r|}
\hline Sector & \multicolumn{1}{|c|}{$\mathbf{2 0 0 3}$} & \multicolumn{1}{|c|}{$\mathbf{2 0 0 4}$} & \multicolumn{1}{|c|}{$\mathbf{2 0 0 5}$} \\
\hline Education & 13.91 & 15.13 & 15.07 \\
\hline Health (ex. other social sectors) & 7.06 & 6.79 & 6.68 \\
\hline Social Sectors (ex. health and education) & 3.65 & 5.30 & 5.81 \\
\hline Rural Development and Environment & 15.53 & 15.10 & 15.28 \\
\hline $\begin{array}{l}\text { Equipment, Transportation, City Planning and } \\
\text { Communications }\end{array}$ & 14.58 & 14.27 & 12.24 \\
\hline Armed Forces and Security & 6.59 & 7.03 & 7.40 \\
\hline
\end{tabular}




\begin{tabular}{|l|r|r|r|}
\hline Principal and interest on the debt & 10.37 & 9.68 & 9.76 \\
\hline Mines, Water Resources and Industry & 3.60 & 3.54 & 5.26 \\
\hline Public Authorities and Administration & 10.94 & 11.56 & 12.89 \\
\hline Allocated but not distributed & 13.77 & 11.60 & 9.61 \\
\hline Total & 100 & 100 & 100 \\
\hline
\end{tabular}

Source: DNB

60. The share of the government budget allocated to education rose from 11 percent in 2001 to 12 percent in 2002, and reached 14 percent in 2003. Between 2001 and 2003, Mali allocated 3.2 percent of GDP on average to its educational system. As for the recurrent budget, it represented 29.15 percent in 2004 compared to a target of 32 percent in the PRSP. The breakdown of resources among the various levels of education shows that priority is given to basic education, to enlarge the base of the pyramid and improve selectivity at the top. It is nevertheless true that allocation of a sizeable portion of the budget to this subsector encounters demographic, institutional, financial and cultural constraints that impede attainment of the objectives contemplated.

\section{Reference macroeconomic indicators in 2003 and 2004} (Percentages)

\begin{tabular}{|c|c|c|c|c|}
\hline No. & Indicators by sector/years & 2002 & 2003 & 2004 \\
\hline & Sustained rapid growth & & & \\
\hline 1 & Real GDP growth rate & 4.30 & 7.40 & 2.20 \\
\hline \multirow[t]{2}{*}{2} & Overall investment rate & 18.80 & 26.03 & 19.48 \\
\hline & Financial stability & & & \\
\hline 3 & Base budget balance/Nominal GDP & 0.10 & 1.00 & 0.10 \\
\hline 4 & Annual inflation rate & 5.00 & -1.30 & -3.10 \\
\hline 5 & $\begin{array}{l}\text { Current external balance (ex. } \\
\text { grants)/Nominal GDP }\end{array}$ & -4.20 & -9.40 & -5.70 \\
\hline 6 & Tax ratio (standard: $\geq 17$ ) & 13.40 & 15.20 & 15.40 \\
\hline \multirow[t]{2}{*}{7} & Rate of debt service/export receipts & 15.30 & 14.00 & 10.00 \\
\hline & Poverty & & & \\
\hline 8 & Degree of monetary poverty & 68.30 & -- & -- \\
\hline 9 & Degree of poor living conditions & 63.80 & -- & - \\
\hline 10 & GINI index & 40.00 & 40.00 & 40.00 \\
\hline
\end{tabular}

Source: DNSI/DNPD

\section{Sector performance}

\subsection{Approach 1: Ensure institutional development, improve governance and participation}


61. This first PRSP strategic approach aims at strengthening institutional capacities in order to ensure proper management of public affairs and conditions of peace and social stabilitywithout which no enduring development program is possible.

\subsubsection{Improve public sector performance}

62. Activities completed in 2003:

- Creation of a Ten-Year Institutional Development Program, together with its own Operational Plan, with the long-term goal of "Making Mali's administration an effective instrument for development and the fight against poverty."

- Creation and publication of a procedural manual for expenditure execution, and a new budget and accounting nomenclature that indicates expenditures on poverty reduction;

- Review of the civil service General Statutes and harmonization of the civil service grid;

- Physical control of personnel numbers for the purpose of reconciling civil service records and payroll records.

The outcome expected from these last two activities is harmonization of the various indices and grids, while preserving specificities of each branch; secondly, to have a single, reliable database for personnel management.

63. Activities completed in 2004:

- Adoption of an interim action plan to improve public finance management (20042005);

- Creation of the budgeted Operational Plan to accompany the Institutional Development Program;

- Undertaking of an organizational audit of centralized and decentralized public services;

- Reconciliation of the Central Payroll Office files with the National Civil Service Directorate files.

\subsubsection{Strengthen national capacities for development planning and management}

64. In the area of restructuring and strengthening services and agencies:

- Creation of the Committee on Forecasting and Modeling (CPM) by Decree No. 03366/PM-RM of August 29, 2003, with a mission to “undertake and harmonize Mali's macroeconomic forecasting and modeling efforts and undertake theoretical and methodological research as needed";

- Creation of the National Technical Assessment Committee on Guidelines and Summaries in Land Management and City Planning (SDAU/SSAU) by Decree No. 03-367/PM-RM of August 29, 2003; 
- Creation of the National Development Planning Directorate (DNPD) by Order No. 04-007/P-RM of March 25, 2004;

- Creation of the National Statistics and Information Directorate (DNSI) by Order No. 04-008/P-RM of March 25, 2004;

- Creation of the National Land Management Directorate (DNAT) by Order No. 04009/P-RM of March 25, 2004;

- Creation of the National Population Directorate (DNP) by Order No. 04-010/P-RM of March 25, 2004.

65. In the areas of policy and program development, improvement of tools, instruments and methods of development planning and management:

- Completed study on coordinating the various planning levels, including the validation workshop held on March 19-21, 2003;

- Development of the updated National Population Policy (PNP) adopted by the Council of Ministers on April 30, 2003;

- Development of the Manual of Procedures for programming and monitoring/assessment of Malian public investments, adopted by the Council of Ministers on July 9, 2003;

- Completion of the Methodological Guide for drawing up cercle land management and development guidelines, to include development time and space horizons;

- Completion of the study on local planning;

- Completion of the short-form integrated household survey (ELIM), whose findings were adopted by the Council of Ministers on December 15, 2004;

- Development of the 2002-2004 Priority Investment Program for Population (PPIP), adopted by the Council of Ministers on December 22, 2004.

66. In the area of strengthening national capacities:

- Organization of several seminars to pool test experiments in drawing up land management guidelines and development plans for the cercles;

- Finalization of the 2005-2007 training plan for personnel involved in development planning and management in the central administration and territorial governments (December 2004).

\subsubsection{Improve public expenditure management}

67. The interim action plan for improving public expenditure management (2004-2005) includes measures taken from the Fourth Structural Adjustment Credit (SAC IV) and from the various projects designed to modernize the Ministry of the Economy and Finance. Since reliable financial management is indispensable for achieving the objectives of the PRSP, the government has adopted an action plan for improving/modernizing public finance management as part of the actions called for by the Interim Plan 2004-2005. This new plan incorporates all the recommendations made by the Technical and Financial Partners (PTF) related to the quality of government budget preparation and execution, 
integration/interconnection of the expenditure chain and databases of tax and customs administrations, the auditing functions, the government contract bidding process and the monitoring of expenditures financed by foreign resources. The plan is organized around 5 approaches:

- Approach 1: Improve the quality of budget preparation and execution;

- Approach 2: Increase the effectiveness of tax and Treasury administrations;

- Approach 3: Incorporate external financing into the national budgetary procedures;

- $\quad$ Approach 4: Increase the efficiency and transparency of contract bidding procedures;

- Approach 5: Strengthen governance and increase transparency.

For each of these approaches, risks have been identified and measures proposed to attenuate the risks.

The outcome expected is as follows:

- Improved control of government expenditures

- Creation of the Office of General Inspector

- Increase in tax receipts

- Enlarged absorption capacity and effectiveness of assistance

- Improved oversight of expenditures for public assistance to development

- $\quad$ Greater effectiveness of the auditing system and increase in its rate of coverage

- Enhanced decentralization through budget devolution and devolution of public contract bidding procedures

- Modernization of the organization of the Ministry of the Economy and Finance and strengthening of its agents' capacities through ongoing training.

\subsubsection{Coordination and effectiveness of foreign assistance and the reduction of poverty}

68. In the area of coordination, a significant change has been observed since 2002 with respect to the monitoring and evaluation of PRSP implementation: regular meetings of the Mali-Partners Joint Commission and periodic meetings on a variety of themes in the area of social sectors, government reform, decentralization and public finance management.

69. Regarding the coherence and synergy of development activities, there is a perceptible, fresh determination on the part of the participants (government, civil society and donors) to make the PRSP the sole reference framework for development in Mali.

70. As for harmonizing procedures, we see efforts on the part of donors to improve coordination of joint monitoring procedures, expectations of co-financing and initiatives to delegate assistance efforts. Examples are the greater number of studies, increased conditionality, monitoring/assessment carried on jointly or in coordinated fashion. Despite these advances, analysis shows that the harmonization of procedures is not yet a reality. The objective will be attained by implementing a common budgetary support and the use of national execution procedures. 


\subsubsection{Consolidate the democratic, participatory and decentralizing processes}

\section{The democratization process}

71. Over the past decade, Mali’s political and social situation has improved. Since 1992, democratic elections have been organized in a consensual, peaceful political climate (presidential, legislative, municipal and communal elections). In 2002, the elections have allowed the transfer of political power with socio-political stability, further consolidated by the regular holding of communal elections in May 2004.

Rate of participation in communal elections in 2004

\begin{tabular}{|l|r|r|r|}
\hline & Enrolled voters & \multicolumn{1}{|c|}{$\begin{array}{c}\text { Participating } \\
\text { voters }\end{array}$} & $\begin{array}{c}\text { Rate of } \\
\text { participation (\%) }\end{array}$ \\
\hline Kayes region & 745,900 & 321,820 & 43.15 \\
\hline Koulikoro region & 895,240 & 391,418 & 43.72 \\
\hline Sikasso region & 963,523 & 429,644 & 44.59 \\
\hline Ségou region & 842,120 & 368,508 & 52.66 \\
\hline Mopti region & 756,247 & 398,266 & 53.55 \\
\hline Timbuktu region & 300,982 & 161,190 & 49.29 \\
\hline Gao region & 297,375 & 146,572 & 37.40 \\
\hline Kidal region & 49,506 & 18,514 & 23.30 \\
\hline Bamako district & 741,557 & 172,781 & 43.07 \\
\hline Total & $5,592,450$ & $2,408,713$ & 46.09 \\
\hline Total ex Bamako & $4,850,893$ & $2,235,932$ & \\
\hline
\end{tabular}

Source: MATCL

\section{Decentralization/devolution}

72. The government is pursuing energetically the implementation of the major reform represented by the process of decentralization initiated in 1992. Within this framework, national support programs have been designed and implemented for the new territorial governments and for institutional development. Despite persistent difficulties, this process has made progress in the major components of its implementation, especially the legal and institutional framework, the transfer of competencies and resources, measures in support of local governments, the planning and budget processes and the mobilization of resources.

73. The legal and institutional framework that emerged from the communal elections of May and June 1999 came to completion in 2002 with the establishment of the Supreme Council of Regional Governments (Haut Conseil des Collectivités Territoriales). In 2002, the judicial system benefited from three decrees in the area of transfer of jurisdictions (health, education, rural and urban water resources) and in 2003, from four implementation decrees of the General Civil Service Regulations for regional governments. 
74. With the holding of communal elections on May 30, 2004, Mali initiated its second local mandate. These elections mobilized the entire political class and led to renewal of offices in Mali's 761 regional governments (703 communes, 49 cercles, 8 regions and the District of Bamako). Henceforth, 10,777 local elected officials (versus 10,540 in 1999) will be responsible for managing local affairs. In addition, there has been a perceptible increase in the number of women elected to national office, including an increase of female mayors (from 4 to 7) and an increase in elected female officials (from 543 to 714). The participation rate in the 2004 communal elections was 43.07 percent. In 2002, the participation rate was 38.81 percent for the presidential election and 23 percent for the legislative elections.

75. The support mechanism implemented with the help of the PTFs includes two complementary components - one technical and the other financial. It was evaluated in 2004 and posted significant results, including creation of the National Coordination Unit (CCN), 48 Communal Counseling Centers (CCC) under the leadership of 27 advisors, and the establishment of the OISE database on the MATCL Internet site. The financial component enabled granting of investment subsidies for more than 2,691 investment projects distributed widely over the country and undertaken in the form of supervision by regional governments. The Regional Government Investment Fund (FICT), managed by the National Investment Agency for Regional Governments (ANICT) is an important instrumentality for regional governments. For the three-year period 2001-2003, this fund used nearly 96 percent of its allocation of CFAF 25.354 billion. Nearly all the regional governments (around 94 percent of the communes and cercles) coming under the support mechanism now have a three-year development plan and a budget. Each year the central government sets aside an allocation for the operations of the regional governments. That allocation rose from CFAF 1.40 billion in 2002 to CFAF 1.442 billion in 2003 and CFAF 1.485 billion in 2004. Available data show that the proportion of financial resources transferred from central administrations to decentralized agencies rose from 26.10 percent in 2003 to 27.9 percent in 2004, a clear sign of praiseworthy efforts made to upgrade the resources available to decentralized agencies in support of devolution.

76. Despite this notable progress, there is perceptible weakness and insufficient mobilization of financial resources going to regional governments, the result of a dysfunctional collections system, a system of local taxation not well adapted to the financing needs, the poor quality of local governance and the lack of civic spirit on the part of some taxpayers. In order to improve the implementation of reforms, the legal and institutional framework must be strengthened, the governing operations of regional entities improved, and motivation must be imparted to undertaking national, regional and local sustained and coherent development, with the central government reoriented to the task of decentralization.

77. Each year the central government sets aside an allocation for regional governmental operations ("Decision on distributing the budget allocation to regional government operations"). The allocation is divided between the oversight agencies and the regional governing entities. 


\begin{tabular}{|r|r|r|r|}
\hline Year & Oversight agency & \multicolumn{1}{c|}{ operations } & \multicolumn{1}{c|}{ Total } \\
\hline 2001 & $625,000,000$ & $725,000,000$ & $1,350,000,000$ \\
\hline 2002 & $800,000,000$ & $600,000,000$ & $1,400,000,000$ \\
\hline 2003 & $824,000,000$ & $618,000,000$ & $1,442,000,000$ \\
\hline 2004 & $848,260,000$ & $637,000,000$ & $1,485,260,000$ \\
\hline
\end{tabular}

Source: DNCT/DNB

78. The National Investment Agency for Regional Governments (ANICT) is a national public body with administrative functions, created by Law No. 00-042 of July 7, 2000. ANICT manages a fund called the Regional Government Investment Fund (FICT). Subsidies are intended for local government units, to be invested under their supervision. Over the period 2001-2003, the government (and its partners) mobilized a total of more than CFAF 25 billion.

\section{Commitments by Mali’s partners}

\begin{tabular}{|c|c|}
\hline Year & Amount (CFAF) \\
\hline 2001 & $7,913,131,758$ \\
\hline 2002 & $8,037,893,663$ \\
\hline 2003 & $9,417,863,767$ \\
\hline 2004 & $9,832,228,749$ \\
\hline Total & $35,201,117,937$ \\
\hline
\end{tabular}

Source: ANICT

79. The percentage of financial resources transferred from central administrations to decentralized agencies was 26.10 percent in 2003 and 27.91 percent in 2004. These figures indicate a growth trend in the transfer of resources from central administrations to decentralized agencies. The figures are quite significant when one realizes that the success of decentralization absolutely depends on such transfers. It must be noted, however, that problems do exist in the area of non transfer of competencies and resources. In addition, note must be taken of problems in gathering data on the indicator "Percent of financial resources transferred to Decentralized Governing Units” (PRODEC; PRODESS) for education and health, respectively.

\section{Participation of civil society}

80. Regarding the participation and contribution of civil society to development programs, the Basic Development Support Unit (CADB) estimates at CFAF 35 billion the amount of financial resources mobilized in 2004 by NGOs, for the purpose of stimulating investments on behalf of populations. This form of participation shows the ever greater importance of the role of NGOs in development activities. Nevertheless, there is a need to improve the involvement of civil society participants in both quantitative and qualitative senses, by means of broader representation of a diverse spectrum of participants, along with strengthening of their capacities. 


\section{Fight against corruption}

81. According to the 2003 report on the index of perceived corruption undertaken by Transparency International, Mali has been ranked for the first time as $78^{\text {th }}$ for corruption out of 133 countries, with an index of 3/10, in which 10 indicates a lack of perceived corruption, and less than 2 indicates perception of endemic corruption. It must nevertheless be underscored that in the case of Mali, only 3 sources of information are cited, i.e., the minimal number required, which attenuates the force of the results. Moreover, 7 out of 10 countries scored lower than 5 out of 10 in the 2003 IPC, which reflects levels of corruption of politicians and government officials.

82. The Department of Justice, in its PRODEJ project, has taken rigorous measures to strengthen transparency in the processing of affairs, and develop capacities and aptitudes of civil society organizations, and to strengthen oversight agencies. In 2003, for example, the government appointed prosecutors and consultancies to provide leadership in economic and financial areas; it established the Office of General Inspector and appointed judicial police agents, to strengthen activities in the fight against corruption. In addition, PRODEJ is earmarking CFAF 2.344 billion for the fight against corruption, or 2.5 percent of the total cost of investments contemplated.

\section{Strengthening the capacities and credibility of the justice system}

83. In the area of strengthening capacities, the jurisdictions have been provided with adequate equipment; a start was made on construction of the new court of appeals in Bamako; and the National Institute for Jurisprudential Training has been officially established.

84. Strengthening of the team of inspectors and multiple routine inspections have been initiated. The diagnostic study on corruption in the judicial sphere was completed in 2004.

85. Although still below international standards, the ratio of judges to inhabitants has improved (one magistrate for 7,000 inhabitants). In 2003, Mali had one magistrate for 29,837 inhabitants. In 1999 and 2002, the ratio stood at 1: 36,000 and 1: 32,324, respectively.

\section{Synoptic table of judicial personnel}

\begin{tabular}{|l|r|r|r|}
\hline \multicolumn{1}{|c|}{ Branch } & Legal number & $\begin{array}{c}\text { Actual } \\
\text { number }\end{array}$ & \multicolumn{1}{c|}{ Deficit } \\
\hline Supreme court & 46 & 17 & 29 \\
\hline Court of appeal, Bamako & 25 & 19 & 6 \\
\hline Court of appeal, Kayes & 12 & 6 & 6 \\
\hline Court of appeal, Mopti & 12 & 6 & 6 \\
\hline Lower courts & 250 & 147 & 103 \\
\hline DNATS & 20 & 2 & 18 \\
\hline
\end{tabular}




\begin{tabular}{|l|r|r|r|}
\hline DNATJ & 12 & 4 & 8 \\
\hline DNATPES & 9 & 1 & 8 \\
\hline INFJ & 3 & 2 & 1 \\
\hline Total & 389 & 204 & 188 \\
\hline
\end{tabular}

Source: MJ

Number of courts per inhabitant

\begin{tabular}{|l|l|l|l|}
\hline & $\begin{array}{l}2002 \\
\text { Assump. 11 million }\end{array}$ & $\begin{array}{l}2003 \\
\text { Assump. 11.2 million }\end{array}$ & $\begin{array}{l}2004 \\
\text { Assump. } 11.5 \\
\text { million }\end{array}$ \\
\hline $\begin{array}{l}\text { Number of } \\
\text { jurisdictions per } \\
\text { inhabitant }\end{array}$ & $\begin{array}{l}70 \text { jurisdictions } \\
1 \text { jurisdiction per } \\
10,507 \text { inhabitants }\end{array}$ & $\begin{array}{l}70 \text { jurisdictions } \\
1 \text { jurisdiction per } \\
11,700 \text { inhabitants }\end{array}$ & $\begin{array}{l}70 \text { jurisdictions } \\
1 \text { jurisdiction per } \\
12,500 \text { inhabitants }\end{array}$ \\
\hline
\end{tabular}

Source: Geographical Map of Jurisdictions, DNAJ 2004.

\section{Culture, religion, peace and security}

86. The creation of a climate of peace in Mali is the result of a trait specific to its society, namely "Sinankouya" along with the good governance resulting from implementation of stable political institutions. The following progress has been noted:

- Incorporation of the culture of peace in school programs;

- Enhancement of traditional mechanisms for preventing, managing and resolving conflicts, together with thorough involvement of women in the areas of peace and security, social cohesion and national unity. In 2003, the rate of conflict resolution was 7 percent, to be compared with 43 percent in 2004 (MATCL Report);

- Meetings held in Timbuktu and Kidal in 2003 and in Sadiola in 2004, to resolve disputes;

- Democratic Inquiry Forums (EID) contributed to resolving certain problems and maintaining a climate of peace.

- Youth awareness campaign to highlight traditional values of tolerance and mutual aid;

- Preservation of the secular state and consolidation of tolerance between religions and among the members of religions guaranteed by Mali's Constitution of February 25, 1992; creation by the government of the Consultative Commission on Religious Practices.

\subsection{Approach 2: Foster sustainable human development and strengthen access to basic social services}

\subsubsection{Strengthen health, nutrition and population services}


87. In 2003 and 2004, the strategies adopted and implemented within the framework of poverty reduction were either consolidated or extended to regions not yet covered. The generally considerable results recorded enabled removal of certain systematic obstacles and de facto improvement of availability, access, use, continuity and quality of the packages of services offered.

Health indicators

\begin{tabular}{|c|c|c|c|c|}
\hline & & 2002 & 2003 & 2004 \\
\hline 19 & Infant mortality rate per 1,000 , under age 5 , & 229 & 229 & 229 \\
\hline 20 & $\begin{array}{l}\text { Rate of DTCP3 vaccination coverage for children under } 1 \text { year } \\
\text { of age }\end{array}$ & $74 \%$ & $79 \%$ & $85 \%$ \\
\hline 21 & Rate of maternal mortality per 100,000 & 582 & 582 & 582 \\
\hline & Rate of childbirth assisted by trained personnel & $40 \%$ & $42 \%$ & $46 \%$ \\
\hline 22 & $\begin{array}{l}\text { Percent of the population living within a radius of } 5 \mathrm{~km} \text { of an } \\
\text { operating health center }\end{array}$ & $44 \%$ & $46 \%$ & $47 \%$ \\
\hline & Rate of prenatal consultation & $54 \%$ & $59 \%$ & $69 \%$ \\
\hline 23 & Average number of prenatal consultations per woman & 2.04 & 2 & 1.9 \\
\hline 24 & Percentage of low birth weight children under 5 years of age & $38 \%$ & $38 \%$ & $38 \%$ \\
\hline 25 & $\begin{array}{l}\text { Rate of HIV/AIDS prevalence among pregnant women } 15 \text { to } \\
24 \text { years of age }\end{array}$ & $1.9 \%$ & $1.9 \%$ & $1.9 \%$ \\
\hline
\end{tabular}

Source: CPS/santé

88. The percentage of the population located less than $5 \mathrm{~km}$ from an operating health center (CSCOM) rose from 44 percent in 2002 to 46 percent in 2004, with the creation of 55 new CSCOMs. We see a significant improvement in geographical access to care. Analysis of the implementation of activities shows the need to increase coverage of populations with essential services in order to speed up achievement of the Millennium Development Goals. Progress will depend mainly on using facilities already created (e.g., the CSCOMs), making a priority of strengthening their technical capabilities and improving the quality of services provided. To that end, the various meetings of the PRODESS monitoring committee, with the technical and financial partners of the health department in attendance, have recommended emphasizing consolidation of progress already made. In concrete terms, this means favoring the strengthening of technical capabilities and improving the quality of services offered rather than expanding the CSCOM network. Moreover, some new CSCOMs with few visitations have impacted results negatively. The objective set was reached in 2004. It must be remembered that geographical accessibility is one stage in bringing medical services closer to the people. PRODESS II, launched in January 2005, incorporated these concerns. It places the emphasis on household care, strengthening the accelerated strategy, and mobile teams - all designed to speed up attainment of the objectives.

89. In 2003, the DTCP3 vaccination coverage rate for children under 12 months of age was 79 percent, compared to 74 percent in 2002, against a target of 80 percent decided upon each year. This 80 percent objective was exceeded in 2004, when an 85 percent coverage was reached. Analysis by region (See table in the annex) shows that: 
- The Sikasso, Ségou and Mopti regions and the District of Bamako have DTCP3 coverage rates of 80 percent for children under 1 year of age - and sometimes higher rates. Progress has been noteworthy in the Kayes and Koulikoro regions, where the rates rose from 47 percent to 59 percent and 63 percent to 72 percent, respectively, from 2002 to 2003. The drop in these various rates in the northern regions of Mali, for instance in Gao (70 percent to 48 percent) and Kidal (56 percent to 18 percent), and the marginal increase in Timbuktu (from 38 percent to 42 percent), are attributable to the fact that the mobile units have not been operational because of organizational problems in carrying out the mobile strategy, together with an insufficiency of human resources to undertake the accelerated strategies. Within the PRODESS II framework, the strengthening and restarting of the accelerated strategic activities and the mobile activities will be initiated in partnership with the regional governments and the ASACOs;

- Bearing in mind the poverty perspective, each of the poor regions has experienced a significant overall improvement as regards DTCP3 vaccination coverage (Table 3). Nevertheless, problems of availability of human resources, very often linked to issues of motivation, have limited the optimal implementation of the activities.

90. Within the framework of the implementation of the second phase of the PDDSS, special attention was given to zones 1 and 2, where accelerated and mobile strategies are to be strengthened in order to raise the level of the indicators by targeting the poorest pockets.

91. The availability of adequate human resources remains essential for optimal provision of the package of healthcare services. The Ministry of Health has undertaken to plead for availability of human resources corresponding to the need, especially in the peripheral regions. Proposals containing concrete measures are also under study for submission to the decision makers.

92. The percentage of mothers benefiting from prenatal consultation has largely exceeded the objectives set for the period. It rose from 54 percent to 59 percent between 2002 and 2003, compared to the target of 56 percent. Moreover, a significant improvement in each of the poverty zones is perceptible. In 2004, the figure rose to 69 percent. Efforts were made in zone 2, where the rate of prenatal consultation is the lowest, and its rate was lifted from 35 percent in 2002 to 54 percent in 2004.

93. The number of childbirths assisted by qualified personnel rose from 40 percent to 42 percent between 2002 and 2003, and in 2004 it rose further to 46 percent. In all regions of the country there was a modest increase - occasionally a slight decrease-in the rates of assisted childbirths. It should be noted, however, that the results are largely attributable to underreporting. The data do not take into account a sizeable number of births assisted by newly trained traditional midwives, as well as childbirth in certain private facilities.

94. To make up for the above-mentioned inadequacies, PRODESS II contains plans to develop activities to strengthen the informational and collaborative link with the private 
sector. Analysis of the indicators reveals disparities between poverty zones, in large part attributable to structural problems. Nevertheless, each of the poverty zones posted significant improvement in the performance indicators, indicating a noteworthy effort on behalf of the poor. PRODESS II was developed on the basis of PRSP and MTEF principles aimed at decentralization, and is devoted to developing optimal interventions targeting the poor. It represents a fine opportunity for accelerating achievement of the Millennium Development Goals.

\subsubsection{Strengthen education and literacy services}

95. Education impacts poverty with medium- and long-term ripple effects. All the measures implemented within the framework of PRSP execution are aimed at reaching a certain number of objectives such as equal opportunity in access to education, literacy for population segments not attending schools, and improvement of the quality of formal education. Execution of the Ten-Year Education Development Program (PRODEC) is part of that strategy, and takes the form of implementing its four components, namely:

- $\quad$ The access component

- $\quad$ The quality component

- Decentralized management of the system

- Cross-disciplinary thematic issues.

PRSP monitoring indicators: estimates and achievements (Percentages)

\begin{tabular}{|l|r|r|r|r|r|r|}
\hline Indicator & \multicolumn{2}{|c|}{$\mathbf{2 0 0 2}$} & \multicolumn{2}{c|}{$\mathbf{2 0 0 3}$} & \multicolumn{2}{c|}{2004} \\
\hline & Targeted & Actual & Targeted & Actual & Targeted & \multicolumn{1}{c|}{ Actual } \\
\hline TBS $1^{\text {st }}$ cycle & 64.00 & 64.34 & 67.00 & 67.00 & 71.00 & 70.50 \\
\hline TBS $1^{\text {st }}$ cycle (girls) & 52.00 & 53.70 & 55.00 & 56.40 & 58.00 & 59.90 \\
\hline Student/teacher ratio & 74.00 & 71.00 & 67.00 & 67.00 & 60.00 & 69.00 \\
\hline \% repeating $1^{\text {st }}$ cycle & 20.00 & 20.00 & 18.00 & 19.80 & 17.00 & 19.00 \\
\hline
\end{tabular}

Source: CSP/Education

96. Analysis of this table shows that the results indicator, namely the Gross Rate of School Attendance (TBS) has improved. The value for that indicator was 70.5 percent compared to the PRSP target of 71 percent and the 70 percent target in the Education Sector Investment Program (PISE). The corresponding gender-sensitive indicator also shows that the gross rate of school attendance for girls reached 60 percent compared to the PRSP target of 58 percent and the PISE target of 56 percent, a distinct improvement over the objectives of both the PRSP and the PISE. These results are due to the fact that the voluntary character of the PRSP strongly influences the objectives set.

97. The trends set in motion must be continued if Mali is to reach the MDGs more easily. The student/teacher ratio deteriorated. Teacher recruitment efforts and the construction of additional classrooms must therefore be continued and strengthened. In general terms, 
much work remains to be done to improve the quality of the system, however. Internal efficiency followed a positive trend from 2002 to 2004. This is reflected in the percentage of pupils repeating the $1^{\text {st }}$ cycle: from 20 percent in 2002 to 19 percent in 2004. It must nevertheless be acknowledged that the figure for 2004 is slightly below the year 2004 estimates (19 percent versus a target of 17 percent in both the PRSP and the PISE). With a view to improving this indicator, steps have been taken in administering the PISE, including:

- Implementation of corrective measures involving an assessment system based on problem diagnosis;

- Assignment of experienced teachers to classes of beginners and gifted;

- More exacting remedial and catch-up courses, especially for girls;

- Use of indigenous languages in the system of formal education;

- Assignment of qualified teachers to the schools.

98. Implementation of the PRODEC was accelerated by launch of PISE, financed jointly by the central government budget and the technical and financial partners. In addition, the education sector MTEF (already adopted) is expected to improve the PRODEC steering ability, in line with the PRSP targeted objectives and the MDGs.

99. Experience in introducing indigenous languages into $1^{\text {st }}$ cycle basic education via the Convergent Pedagogy program (PC) has underscored the conspicuous improvement of the quality of teaching. The average drop out rate has decreased considerably, standing now at 4.2 percent annually on average.

100. Efforts made thus far have also improved the book/pupil ratio, formerly 1:3 in 1996, then 1:1 in 2003 and 2:1 in 2004, reflecting the government's national policy on textbooks. The Ministry of Education is undertaking implementation of an effective strategy for the distribution and use of textbooks. Classroom furniture, meanwhile, is inadequate from quantitative and qualitative points of view.

\subsubsection{Drinking water and sanitation}

101. In this sector, significant reforms have been undertaken, including:

- Creation of regional and subregional water resource and energy services within the framework of decentralization efforts (Decree No. 369 of July 19, 2002);

- Adoption of Decree No. 02-315 of June 4, 2002, detailing the competencies bearing on rural and urban water resources to be transferred from the central government to the regional governing entities;

- Modernization of the SIGMA database (Malian geographical information system) and development of the Water Map.

102. Availability of drinking water increased markedly as shown by the various indicators in the following table. In 2003, 24,562 modern water sources were identified and recorded. 
Nevertheless, rural areas continue to show poor coverage, with only 60.6 percent of the population having access to drinking water. For 2004, the total number of modern water sources stood at 25,149 and the rate of coverage of rural people's water needs was in the area of 62.5 percent.

\section{Change in drinking water indicators}

\begin{tabular}{|l|l|r|r|r|}
\hline No. & \multicolumn{1}{|c|}{ Sector indicator } & \multicolumn{1}{|c|}{$\mathbf{2 0 0 2}$} & \multicolumn{1}{|c|}{$\mathbf{2 0 0 3}$} & \multicolumn{1}{|c|}{$\mathbf{2 0 0 4}$} \\
\hline 1 & Rate of access to tap water & $7.9 \%$ & $8.3 \%$ & $8.3 \%$ \\
\hline 2 & Rate of access to water via EDM network & $12.7 \%$ & $13.4 \%$ & $15.7 \%$ \\
\hline 3 & $\begin{array}{l}\text { Rate of access to drinking water in urban } \\
\text { and semi-urban locations }\end{array}$ & $57.1 \%$ & $59.0 \%$ & $66.3 \%$ \\
\hline 4 & $\begin{array}{l}\text { Percentage of villages with at least one } \\
\text { modern water source }\end{array}$ & $84.0 \%$ & $81.4 \%$ & $83.0 \%$ \\
\hline 5 & $\begin{array}{l}\text { Rate of access to drinking water in rural } \\
\text { locations }\end{array}$ & $56.9 \%$ & $60.6 \%$ & $62.5 \%$ \\
\hline 6 & Rate of access to drinking water in Mali & $57.0 \%$ & $60.1 \%$ & $63.7 \%$ \\
\hline 7 & $\begin{array}{l}\text { Number of wells drilled and modern water } \\
\text { sources }\end{array}$ & 23,034 & 24,562 & 25,149 \\
\hline
\end{tabular}

Source: CPS/MMEE

(N.B.: the figures include data from NGOs and other non-governmental agencies)

103. The lack of data for most of the sanitation performance indicators renders unfeasible reporting on trends in this area. At the institutional level, Mali has drawn up a framework for fighting pollution and noise in the form of the National Sanitation Plan, and has created the National Sanitation, Pollution Control and Noise Abatement Directorate (DNACPN) with its subdivisions.

\subsubsection{Housing}

104. In order to improve access to decent housing for low-income persons and find solutions to the obstacles identified, the government has established a city-planning and housing policy with the following objectives: (i) increase the use of local techniques in constructing housing; (ii) increase the number of housing units available to poor people, and at lower cost; (iii) improve the sanitary conditions of unhealthy neighborhoods; (iv) facilitate poor people's access to housing loans; (v) rehabilitate improvised neighborhoods; (vi) draw up Guidelines for land management and urban planning (SDAU).

105. To reach these objectives, the government intends to employ the following strategies: (i) promote building techniques using sturdy local materials in underprivileged localities; (ii) develop local building material manufacturing industries; (iii) diversify the financial mechanisms and sources for housing; (iv) energize the real estate market to enable access to land and housing for the greatest number of citizens; (v) support real estate companies in order to promote public housing. 
106. In order to reduce construction costs, national building entities have been created and alternative technologies have been developed with enhanced use of local materials. Despite these measures, the gap between growing housing needs and the impoverishment of city dwellers continues to be wide. Faced with this situation, the government has drawn up a practical housing policy by using the National Housing Program (PNL) and creating two high-profile institutions: the Mali Housing Bank (BHM) specializing in the financing of housing, and the Mali Housing Office $(\mathrm{OMH})$, a financing facility operating in tandem with the BHM and designed to lower the cost of housing. This new state of affairs induced the government to undertake a construction program to build 3,500 units of public housing between 2003 and 2008.

107. The various projects completed by the Ministry of Housing and Urban Planning within the framework of the effort to improve the living conditions of populations in line with the PRSP objectives are the following:

- In 2003, the Mali Housing Office (OMH) constructed two experimental homes made of brick. As part of the government's policy to promote public housing, it granted facilities to real estate promoters enabling them to build 1,330 housing units in 2003.

- In 2004, 1,008 public housing units were begun in Yirimadio (Bamako).

\section{Distribution of candidates for housing by gender and professional status}

\begin{tabular}{|l|r|r|r|}
\hline Gender/professional status & \multicolumn{1}{|c|}{ Men } & \multicolumn{1}{c|}{ Women } & \multicolumn{1}{c|}{ Total } \\
\hline Wage earner & 2,037 & 1,213 & 3,250 \\
\hline Non-salaried & 740 & 633 & 1,373 \\
\hline Malians from abroad & 446 & 81 & 527 \\
\hline Total & 3,223 & 1,927 & 5,150 \\
\hline
\end{tabular}

Source: MHU

\section{Distribution of beneficiaries of public housing by gender and professional status}

\begin{tabular}{|l|r|r|r|}
\hline Gender/professional status & \multicolumn{2}{|c|}{ Men } & \multicolumn{2}{c|}{ Women } & \multicolumn{2}{c|}{ Total } \\
\hline Wage earner & 385 & 241 & 626 \\
\hline Non-salaried & 169 & 127 & 296 \\
\hline Malians from abroad & 71 & 15 & 86 \\
\hline Total & 625 & 383 & 1,008 \\
\hline
\end{tabular}

Source: MHU

Analysis of the situations of the 1,008 homes indicates that the rate of satisfaction of expressed requests was 19.6 percent. Out of 5,150 housing candidates, 1,008 were able to be placed in public housing. The majority of requesters were men (62.6 percent). The rate of 
satisfaction by gender was 19.4 percent for men and 19.9 percent for women. The distribution of housing among various professional status holders was 62.1 percent wage earners, 29.4 percent non-wage earners, and 8.5 percent Malians from abroad.

The analysis shows that great efforts remain to be made in order to satisfy the strong demand for public housing.

\subsubsection{Gender and poverty}

108. The government considers the dimension of gender to be a very important component of its poverty reduction strategy, especially since women are a more vulnerable segment of the population.

\section{Gender and participation in elections}

Rate of candidacies and elected officials in the general elections of 2002-2004

\begin{tabular}{|l|r|c|r|c|r|r|r|c|}
\hline & \multicolumn{4}{|c|}{ Candidates } & \multicolumn{4}{|c|}{ Elected officials } \\
\hline & Men & \% & Women & \% & Men & \% & Women & \% \\
\hline $\begin{array}{l}\text { Presidential } \\
\text { elections }\end{array}$ & 22 & 100 & 0 & 0 & 1 & 100 & 0 & 0 \\
\hline Legislative & 910 & 89.8 & 103 & 10.2 & 132 & 89.8 & 15 & 10.2 \\
\hline Communal & 65,592 & 87.9 & 9,080 & 12.1 & 10,030 & 93.4 & 720 & 6.6 \\
\hline
\end{tabular}

Source: CNDIFE

The number of female candidates for legislative and communal elections is not high; the percentage of elected officials is more significant in national elections than in local ones.

\section{Gender and civil service employment}

109. The following table shows that nearly all Category A civil service employees are men (90.1 percent). Female representation in the various categories decreases as the importance of the post increases, with the exception of the category "other personnel," in which women are under-represented (security personnel, drivers, orderlies). Civil service employment is a male prerogative, as more than three-fourths of civil servants are men (more exactly, 78.8 percent). Study of the following table shows that most female employees in the civil service belong to intermediate Category B2 (41.8 percent). This finding is true for men as well. Only 17.7 percent of female civil servants are in Category A, whereas male civil servants account for 20.2 percent of upper echelon management.

\section{Breakdown of civil service personnel according to employment category and gender in 2002}

\begin{tabular}{|l|l|l|r}
\hline Category & Male & Female & Total
\end{tabular}




\begin{tabular}{|l|r|c|r|r|r|c|}
\hline & Number & \multicolumn{1}{c|}{$\mathbf{~}$} & Number & \% & Number & \% \\
\hline A & 7,355 & 90.1 & 806 & 9.9 & 8,161 & 100.0 \\
\hline B2 & 13,928 & 77.3 & 4,084 & 22.7 & 18,012 & 100.0 \\
\hline B1 & 2,732 & 66.1 & 1,399 & 33.9 & 4,131 & 100.0 \\
\hline C & 3,540 & 65.1 & 1,895 & 34.9 & 5,435 & 100.0 \\
\hline Other & 8,788 & 84.7 & 1,584 & 15.3 & 10,372 & 100.0 \\
\hline Total & 36,343 & 78.8 & 9,768 & 21.2 & 46,111 & 100.0 \\
\hline
\end{tabular}

Source: MFPT

\section{Gender and microfinance}

110. Women over the age of 18, although a majority in that population segment (more than 51 percent), have considerably less access to micro-lending than do men. The male membership rate is markedly higher than that of women. However, the gap between the two rates has diminished from 2003 to 2004. The number of female members grew by 20 percent between 2003 and 2004, whereas the male membership grew by only 10 percent. This indicates that remarkable efforts have been made to increase female access to micro-lending.

Percentage of members with access to loans

\begin{tabular}{|l|lr|r|r|r|}
\hline & & \multicolumn{1}{|c|}{$\mathbf{2 0 0 3}$} & \multicolumn{1}{c|}{$\mathbf{2 0 0 4}$} & $\mathbf{2 0 0 4 / 2 0 0 3}$ \\
\hline Persons age 18 or over & Men & $2,416,057$ & $2,460,801$ & $1.85 \%$ \\
\hline & Women & & $2,657,913$ & $2,704,040$ & $1.74 \%$ \\
\hline & & Total & $\mathbf{5 , 0 7 3 , 9 7 0}$ & $\mathbf{5 , 1 6 4 , 8 4 1}$ & $\mathbf{1 . 7 9 \%}$ \\
\hline Number of members & Men & & 389,375 & 427,069 & $9.68 \%$ \\
\hline & Women & 238,496 & 286,699 & $20.21 \%$ \\
\hline & & Total & $\mathbf{6 2 7 , 8 7 1}$ & $\mathbf{7 1 3 , 7 6 8}$ & $\mathbf{1 3 . 6 8 \%}$ \\
\hline Membership rate & Men & $16.12 \%$ & $17.35 \%$ & $1.08 \%$ \\
\hline & Women & & $8.97 \%$ & $10.60 \%$ & $1.18 \%$ \\
\hline & \multicolumn{2}{r|}{ Total } & $\mathbf{1 2 . 3 7 \%}$ & $\mathbf{1 3 . 8 2 \%}$ & $\mathbf{1 . 1 2 \%}$ \\
\hline
\end{tabular}

Source: CAS-SFD/DNP

\subsubsection{Improve the living conditions of children and youth}

\section{Number of infants recorded at birth}

111. The number of infants recorded at birth increased from 223,049 in 2000 to 249,079 in 2001, a gain of 11.7 percent. The figure for 2002-246,277-represented a drop of 1.1 percent. According to data provided by Mali's vital statistics registry (figures for March 2004), the number of supplementary rulings increased from 23,857 in 2000 to 29,156 in 2001, a gain of 22.2 percent. In 2002, the 34,512 rulings represent an increase of 18.4 percent over the situation in 2001. The increase in the rate of supplementary rulings is an unsettling state of affairs, since they create a decline in recordings at birth. 


\section{Youth}

112. Over the period 2002-2004, the following major activities were undertaken:

- In 2002, training of 35 young persons in youth entrepreneurship at the Soufouroulaye Youth Camp;

- In 2003, training of 35 young persons in making sports leadership equipment;

- In 2004, official launch of Youth Camp activities. With this launch, 60 young persons were trained in three trades: automotive mechanics, metal fitting, soap manufacturing. Of the 60 participants, 43 were placed in jobs (71 percent).

\subsubsection{Employment and vocational training}

113. The Permanent Household Survey (EPAM) reveals that employment is a matter of concern in Mali, given its employment rate of about 46.8 percent. For men the rate is 58.4 percent and for women, 41.6 percent. Primary sector employment stands at 42.6 percent and tertiary sector employment is 41.6 percent, and only 15.8 percent in the secondary sector.

114. Although the proportion of regular jobs stagnated between 2001 and 2003, selfemployment increased over the same period (from 35 percent in 2001 to 40 percent in 2003). The underemployment rate plummeted from 23 percent to 5 percent between 2001 and 2003 (see ELIM 2004). The overall unemployment rate increased from 3.1 percent in 1997 to 8.8 percent in 2004, with the arrival of the phenomenon of rural unemployment. However, unemployment continues to be higher in urban settings (12 percent). The unemployment rate for graduates is around 18 percent.

115. Faced with an acute unemployment and underemployment situation, the government has developed a national action program for employment to reduce poverty (PNA/ERP), and a youth employment program (PEJ) was started in 2004 for the purpose of offering young people the maximum of employment opportunities in both the salaried domain and in selfemployment.

116. The 1-2-3 Survey of the informal sector (2001) confirms the image of a labor market in deep difficulties, characterized by massive underemployment and a gulf between the demand for work and its supply.

\subsubsection{Social solidarity and security}

117. The area of social protection and solidarity contributes to improved sector performances through its contribution to the building of social infrastructures, and by improvement to accessibility via stronger incomes, the strengthening of capacities of its beneficiaries and coverage of social risks of populations. Over the period 2002-2004, implementation of strategies in the area of social solidarity and social security achieved the following results:

118. In the area of social security 
Situation of persons insured and working population enrolled in the INPS

\begin{tabular}{|l|r|r|r|}
\hline Category & $\mathbf{2 0 0 2}$ & $\mathbf{2 0 0 3}$ & \multicolumn{1}{c|}{$\mathbf{2 0 0 4}$} \\
\hline Insured & 246,704 & 249,875 & 219,213 \\
\hline Working population & 154,622 & 157,416 & 120,741 \\
\hline Allocations & 63,260 & 67,325 & 58,826 \\
\hline New registrants & 2,123 & 2,059 & 6,843 \\
\hline Pensioners & 26,911 & 28,156 & 37,782 \\
\hline Annuitants & 1,911 & 2,288 & 1,864 \\
\hline
\end{tabular}

Source: INPS

119. As regards mutual insurance, Mali currently has 75 mutual associations, 39 of which are certified. If all levels of benefits are considered, these mutual associations cover around 80,000 persons (about 0.6 percent of the population); around 40,000 persons are covered for sickness risk (about 0.3 percent of the population). As regards cooperative societies, there are 2,545 registered in accordance with Law no. 01-076. These cooperative societies are essentially: craft-oriented, multifunctional, farming/livestock raising, agricultural, industrial, housing, services, crop-promotional, fishing, etc. As for associations, there are currently 8,000 associations registered with the MATCL.

120. In the area of social solidarity, the years 2003 and 2004 were marked by the following major events:

- The organization of the Faso Dambé operation, a campaign to collect funds for Malians returning from Côte d'Ivoire: CFAF 362 million were collected;

- Organization of a televised fundraiser that collected nearly CFAF 40 million for the mentally ill;

- Breast cancer diagnosis benefiting 300 women, with 12 patients taken into care;

- Assignment of 1,000 units of public housing to their beneficiaries;

- Financial assistance to victims of fires occurring at the Sévaré market and at the Badalabougou fishing camp;

- Organization of the $9^{\text {th }}$ and $10^{\text {th }}$ solidarity months.

\subsection{Approach 3: Develop basic infrastructure and the productive sectors}

The development of infrastructures and support for productive services have as their objective to improve the economic environment and thereby increased profitability of production factors, so as to attract investments, create jobs, distribute (and redistribute) incomes, accumulate wealth and push back poverty.

\subsubsection{Develop basic infrastructure}

\section{Transportation infrastructures}


Road infrastructures

121. In order to improve the living conditions of populations in Mali and reduce poverty, the government has undertaken wide-ranging reforms in the transportation subsector. The results of the implementation of the PRSP for 2003 and 2004 are encouraging, with the indicators trending favorably in the area of providing internal and external access.

\begin{tabular}{|l|r|r|r|}
\hline \multicolumn{1}{|c|}{ Indicators } & \multicolumn{1}{c|}{$\begin{array}{c}\text { Completed } \\
\text { in 2002 }\end{array}$} & $\begin{array}{c}\text { Completed } \\
\text { in 2003 }\end{array}$ & \multicolumn{1}{c|}{$\begin{array}{c}\text { Completed } \\
\text { in 2004 }\end{array}$} \\
\hline Number of km of asphalt roads rehabilitated & 136 & 282 & 160 \\
\hline Number of km of modern dirt roads & 100 & 8 & 185 \\
\hline Number of tracks cleared & & 246 & 232 \\
\hline Number of km of asphalt roads maintained & 3,024 & 3,028 & 3,437 \\
\hline $\begin{array}{l}\text { Number of km of modern dirt roads } \\
\text { maintained }\end{array}$ & 5,976 & 6,012 & 6,059 \\
\hline
\end{tabular}

Source: CPS/MET

122. The low completion rate observed in 2003 in work on modern dirt roads (5.84 percent) was due to excessive delays in executing the Kita-Krouninkoto projects $(99 \mathrm{~km})$ and the Didiéni Goumbou-Nara projects $(176 \mathrm{~km})$. The companies charged with undertaking this work lacked heavy equipment (earth movers) and qualified personnel. The low rate of completion of modern dirt road construction in 2004 was due to the cancellation of the Niono-Nara contract (for $242 \mathrm{~km}$ ) in the wake of the business failure of one of the team of companies responsible for undertaking the construction.

123. Significant institutional reforms have been enacted by the authorities since 2002 in order to ensure creation of access to the interior of Mali and to countries outside, thereby facilitating the movement of persons and goods. Among the reforms are:

- Creation of the National Roads Directorate (DNR) and the Roads Data Service (SDR);

- Completion of a study on classification of Mali's road network;

- Establishment of the Roads Authority, formalizing the privatization of road maintenance by eliminating road construction by a centralized government entity; upkeep of roads also devolves to the private sector.

124. Generally speaking, road building and maintenance projects have a significant impact on Mali's economy. In addition to the increased tax and customs receipts generated for public finance, the various road projects participate broadly in Mali's fight against poverty. Although statistics are not available, each project may generate a hundred or so jobs, on average, indeed several hundred directly and indirectly related jobs. 
125. Moreover, road construction has enabled peasants in the various regions impacted to sell their agricultural produce in consumption centers, thereby contributing to their own purchasing power. The health and educational level of rural populations is improved because of the gain in proximity to health centers and schools.

126. The growing number of road accident victims points to the need to strengthen road safety mechanisms.

\section{Air transportation infrastructures}

127. The process of restructuring Mali Airports (ADM) as concessions is ongoing, as is the creation of a national air transport company, together with privatization of ground handling services.

\section{Railroad infrastructures}

128. Conversion of the government railroad company (Régie du Chemin de Fer) has been completed in a joint operation with Senegal. A restructuring plan has been adopted and its financing has been ensured by the state budget and the World Bank (IDA). A private Franco Canadian consortium, the concession holder for a period of 25 years, has already taken over operations of the rail line. It is committed to increasing the annual tonnage transported (now 300,000 tons/year) and to improve substantially the quality and safety of services offered to its clientele.

129. Whereas the number of passengers transported in 2003 was 405,842, the figure for 2004 is estimated at 343,490. This downward movement is explained by problems encountered when launching the new concession, a shortage of rolling stock (locomotives and cars) and the poor condition of the rail bed, notably on the Senegal portion of the line (frequent derailments starting in the first quarter of 2004). By contrast, the tonnage of transported goods in 2004 grew by 4 percent over 2003 (253,148 tons versus 243,130 tons in 2003).

130. The legislation establishing AGEROUTE was adopted in 2004. The sector strategies designed to provide road access both internally and externally exhibit some weaknesses. If the Road Authority is created, it should be noted that the financing of road maintenance using funds designated in the legislation (axle load fees on vehicles using the roadways, taxes on petroleum products, road use tolls, weigh station fees) is not yet entirely assured. In addition, numerous deficiencies of an organizational and operational nature prevent the diligent implementation of selected reforms. Examples include:

- Delays in the acquiring a shallow-draft boat to cope with the continual silting up of the bed of the Niger river;

- Ponderous procedures in the acquisition of locomotives and rail cars to improve passenger transportation;

- $\quad$ Problems linked to the Mali Airports concession process;

- Poor service coverage of domestic airlines; 
- High cost of transportation on domestic lines.

\section{Communications infrastructures}

131. In 2004, Mali counted 3.37 telephone lines per 100 inhabitants. With the automation and digitizing of the entire SOTELMA network, together with the government's sector deregulation policy, which made way for the arrival of a second telecommunications company, the number of phone lines per 100 inhabitants rose from 1.02 in 2002 to 2.81 in 2003 and 3.37 in 2004. The deregulation policy also had a positive impact on the cost of telephone use, with a noticeable drop in calling costs starting in January 2003. The decreases in international communications rates went from 20 percent to 78 percent, for intercity calls a decrease from 12 percent to 87 percent, and for local calls, 40 percent. Nevertheless, the telecommunications coverage of the country continues to be uneven, with a distinctly low ratio of telephone lines per inhabitant in rural areas ( 0.07 percent). Substantial efforts must be deployed to ensure access to the telephone for a maximum number of citizens. The percentage of the population covered by radio grew between 2003 and 2004, from 76 percent to 95 percent. The annex provides a picture of changes in the principal sector indicators.

Changes in audio-visual indicators

132. The percentage of the population covered by radio increased between 2003 and 2004, from 76 percent to 95 percent. The improvement is explained by the combined efforts of people purchasing radios (about 1 million new receivers purchased between 2003 and 2004) and local radio stations, whose frequency outpaced forecasts by more than 100 percent. As regards localities covered by television broadcasts, the percentage remains low. Between 2003 and 2004 the change in this situation was only 6 percent. This finding is explained by the high cost of digital equipment together with the low level of resources allocated to the audio-visual sector.

\begin{tabular}{|l|r|r|r|r|}
\hline Indicator & \multicolumn{2}{|c|}{ Values in 2003 } & \multicolumn{2}{c|}{ Values in 2004 } \\
\hline & Target & \multicolumn{1}{|c|}{ Actual } & \multicolumn{1}{c|}{ Target } & \multicolumn{1}{|c|}{ Actual } \\
\hline $\begin{array}{l}\text { Number of radio receivers in } \\
\text { existence }\end{array}$ & $1,500,000$ & $1,600,000$ & $2,100,000$ & $2,000,000$ \\
\hline $\begin{array}{l}\text { Number of communes covered by } \\
\text { rural radio (having a local station) }\end{array}$ & 175 & 200 & 230 & 220 \\
\hline $\begin{array}{l}\text { Percentage of population reached } \\
\text { by broadcast radio }\end{array}$ & $80 \%$ & $76 \%$ & $90 \%$ & $95 \%$ \\
\hline $\begin{array}{l}\text { Percentage of localities covered by } \\
\text { broadcast television }\end{array}$ & $80 \%$ & $70 \%$ & $85 \%$ & $76 \%$ \\
\hline
\end{tabular}

Source: MCNT

Changes in NTIC indicators 
133. Since the creation of the National Internet Node by SOTELMA in 1997, bandwidth, the number of ISPs, cyber cafés, Internet protocols and web browsers have all grown incessantly, although the phenomenon is more urban than rural. In addition, the narrow bandwidth available does not yet favor use of the Internet for business purposes. Overall, Mali's communication networks and services exhibit the following characteristics:

- Low density of telephone ownership;

- Low rate of penetration of rural areas;

- Uneven telecommunications service coverage between urban and rural areas;

- Low rate of Internet connectivity.

\section{NTIC indicators}

\begin{tabular}{|l|r|r|r|r|}
\hline Indicator & \multicolumn{2}{|c|}{ Values in 2003 } & \multicolumn{2}{c|}{ Values in 2004 } \\
\hline & Target & \multicolumn{1}{|c|}{ Actual } & Target & Actual \\
\hline Internet bandwidth (Mb) & NA & 6 & & 39 \\
\hline Number of ministries connected & & & 5 & 5 \\
\hline Number of agencies connected & & & 5 & 5 \\
\hline Number of technicians trained & & & & 10 \\
\hline Number of communes connected & & & & 27 \\
\hline Number of cyber cafés & & & & 75 \\
\hline Number of TCPs & NA & 13 & NA & 20 \\
\hline Number of ISPs & & & & 2 \\
\hline Number of CMCs & & & & 13 \\
\hline Number of CLICs & & & & 50,000 \\
\hline Number of Internet users & & & & 300 \\
\hline Number of web sites created & & & & 2 \\
\hline
\end{tabular}

Source: MCNTI

134. In the area of postal services, as of December 31, 2004, the National Postal Service (ONP) had a network of 78 post offices. The national postal service density is 1 point of contact for every 121,495 inhabitants. The postal reform now under way is a profitable investment for Mali's economy, in that the reform strategy is intended to transform the public entity into a customer service-oriented enterprise.

\section{Development of the energy sector}

135. The state electrical grid coverage expanded from 12 percent in 2002 to 13 percent in 2003. This increase is explained in part by the growth in the number of new subscribers and in part by the power installed by the Interconnected networks (RI) and the Decentralized Services Companies (SSD) and self-producers. The increase is also explained by directives issued by the Utilities Regulatory Commission (CREE) in order to reduce significantly the charges for electricity by 10 percent in 2003 and by 8.6 percent in 2004 (subsidized basic rate). 
136. Emphasis was placed on enhancing the potential of hydroelectric power and improving the institutional environment for attracting other operators. In 2003, hydroelectric output increased by 21.7 percent compared to 2002, thanks to the boost in the Manantali hydroelectric facility's output. In 2003, the share of hydroelectric power in the total production of electricity was 61.93 percent, versus 50.4 percent in 2002 . The share of thermal power in total electricity output is on the decline, down from 49.59 in 2002 to 38.07 percent in 2003.

137. Also noteworthy is the improved overall operating yield of EDM SA, from 72.8 percent in 2002 to 73.6 percent in 2003, achieved by preventing losses. The quantity of butane gas rose slightly because this product is subsidized. Activities undertaken in 2003 bore on: (1) liquidation of butane gas subsidy amounts owed to private operators (Total, Mobil, Sodigaz); (2) creation of AMADER, charged with implementing the entitled Domestic Energy and Access to Basic Services in Rural Locations Project, including a major component designed to promote domestic energy.

138. The launch of the Domestic Energy and Access to Basic Services in Rural Locations Project (PEDASB) in rural locations, with these objectives: accelerate the use of modern energy types in rural areas and areas on the periphery of cities; promote forest management on a community basis; strengthen the reform processes of the energy sector and allied institutions.

139. The constraints to energy development include the absence of a unified energy policy, national standards - with the exception of standards for domestic electrical installations - and a formal framework for cooperation between the participants in the sector.

\subsubsection{Develop productive sectors}

\section{The environment}

140. Article 15 of the Constitution of Mali states: “All persons have the right to a healthy environment. The defense and protection of the environment and the promotion of quality of life are a duty for all and for the state.” According to Law No. 01-020 of May 30, 2001 (Pollution and nuisances), the environment is "perceived as a unified system in a given space and time, made up of physical, chemical, biological and social factors able to have a direct or indirect effect, immediately or in the long term, on the human species and its activities and on the animal and plant species.” Against that background, Mali signed and ratified 30 or so international agreements, accords and treaties related to the environment. In the context of these various engagements, Mali has designed and implemented environmental policies and strategies. The chief policies, entrusted to the Ministry of the Environment and Sanitation for implementation, are as follows:

- National environmental protection policy

- National policy on management of natural resources 
- National wetlands policy

- National decentralization policy

- National public health policy.

141. In addition, Mali has drawn up a national strategy on conservation of biodiversity, together with its own action plan, and a domestic energy strategy. Despite the cross-

disciplinary nature of the environment, its incorporation into the various sector policies, strategies and programs remains modest. For example, assessment procedures do not always make it possible to grasp the entire range of effects resulting from the policies adopted and the interrelations between the various sectors.

\section{Sector indicators}

142. The indicators used in the third approach, and appearing on the agreed upon list are:

- Reforested surfaces expressed in hectares. this indicator provides a grasp of the ongoing reforestation efforts. It provides information on the community forest land and the degree of involvement of populations in forest activities (village, urban, cityperipheral plantations, reforestation campaigns, etc.). Reforested surfaces under the guidance of the DNCN were estimated at 2,283 ha in 2003 and 1,706 ha in 2004;

- Number of rural firewood markets created. The number of rural firewood markets created in 2003 was 253, and in 2004, 22. The small number of markets in 2004 is explained by the cessation of the Combustible Wood Unit project. A new facility was established - the Malian Agency for Development of Rural Electrification—which includes domestic energy strategy among its concerns;

- Proportion of forested zones. At the present time, the rate of national forest cover is estimated at 2.6 percent. This figure falls well below the international standard (FAO) of at least 15 percent of the national territory. Changes in this indicator will be estimated on the basis of data from forest inventories (5-10 years);

- Consumption of energy wood by the stere (cubic meter). In 2003, Mali's consumption of energy wood was 7,000 steres, compared to 4,000 in 2004. These data are taken from DNCN statistics on quantities indicated on permits issued.

\section{Agriculture}

143. The authorities have placed the emphasis on development of the rural sector by the following means: (1) intensification of hydro-agricultural management; (2) adoption of the Government Management Program for 50,000 hectares between 2003 and 2007; (3) initiation of the Support Program for Agricultural Sectors and Peasant Organizations (PASAOP); (4) implementation of the National Rural Infrastructure Program (PNIR); (5) creation and establishment of the Agency for Construction of Rural Infrastructure and Equipment (AGETIER). 
144. As of early 2003, the financial ceiling on support to the agricultural sector via projects and programs was evaluated at CFAF 336 billion, including CFAF 44 billion in national contributions via the BSI.

145. Simultaneously, substantial reforms have been undertaken within the framework of the cotton sector restructuring, intended in the long term to consolidate and rehabilitate the Malian Textile Development Company (CMDT), by refocusing its activities, opening its capital to national and foreign private investors, and controlling its producer prices. Within the framework of the reform, a mechanism has been adopted to determine producer prices, to disengage the CMDT from public service missions, and apply a restructuring plan, etc.

146. With a view to improving production, processing and exportation conditions for meat, construction has been completed of a slaughterhouse on the right bank of Bamako (Missabougou) with a capacity of 10,000 tons of meat per year, financed by Japanese foreign assistance at a cost of CFAF 460 million.

147. Within the framework of the sale and/or privatization of slaughterhouses, the management of that slaughterhouse was granted a five-year concession, contracted to a private operator as the result of a bidding process undertaken by the Ministry of State Domains, Real Property Affairs and Housing.

148. In the area of agriculture, the principal incentives for cultivating greater land surfaces have been the creation of favorable watering conditions for crops and government distribution of seeds in areas with low yields. The surfaces managed with total water control rose by 37 percent between 2002 and 2003, and by 21 percent between 2003 and 2004. In 2003, cereals production totaled 3,402,221 tons, compared to 2,583,816 tons in 2002, for an increase of 32 percent. In 2004, cereals production fell 16 percent from its 2003 level, to 2,844,902 tons. Cotton fiber production declined from 111,918 tons in 2002 to 85,173 tons in 2003 (down 24 percent) and 111,284 tons in 2004 (an increase of 31 percent over 2003).

\section{Changes in agriculture sector indicators}

\begin{tabular}{|l|r|r|r|}
\hline \multicolumn{1}{|c|}{ Sector indicators } & \multicolumn{1}{c|}{$\mathbf{2 0 0 2}$} & \multicolumn{1}{c|}{$\mathbf{2 0 0 3}$} & \multicolumn{1}{c|}{$\mathbf{2 0 0 4}$} \\
\hline Cereals production (tons) & $2,583,816$ & $3,402,221$ & $2,844,902$ \\
\hline Surfaces under total management (ha) & 5,157 & 7,048 & 8,498 \\
\hline Cotton fiber production (tons) & 111,918 & 85,173 & 111,284 \\
\hline
\end{tabular}

Source: CPS/MA

149. In 2003, the government drew up the institutional framework for managing food security, from the level of the commune to the national level, and assigned a greater role to regional governments and civil society.

150. In 2004, by virtue of Decree 150-PRM dated May 14, there was created in the office of the Presidency of the Republic, a Food Security Commission charged with drawing up and 
ensuring the implementation of the food security policy, an expression of the often stated determination of the highest authorities to ensure food and nutritional security.

151. The state of execution of the government's hydro-agricultural management program in 2004 can be summed up as follows: the government management program involves 64,279 hectares, including 50,000 hectares under total water control, and 14,279 hectares under partial control. The funding mobilized enabled management of 70 percent of the surfaces, or 44,710 hectares, of which 31,431 under total water control and 13,569 under partial control. Funding still needed bears on 30 percent of the surfaces, or 19,569 hectares, of which 18,569 under total water control and 1,000 hectares under partial control, both the subject of funding requests.

152 Overall, it appears that significant reforms have been made or are in the process of being made with regard to the three PRSP strategic approaches. Moreover, considerable financial contributions have been provided from the government budget to improve the expenditure ratios in priority sectors such as education, health, rural development, equipmenttransportation-city planning.

\section{Livestock and fishing domains}

153. The 2003-2004 campaign was especially marked by creation of a national development policy on livestock raising, adopted by the government in January 2004.

Livestock production

154. At end-2003, the number of cattle was estimated as follows: 7,312,000 cows, 19,413,000 sheep and goats, 710,000 camels and 25,000,000 head of fowl.

Livestock and meat exports

155. The main audited exports of live animals in 2003 involved cows $(115,831)$, sheep and goats $(235,617)$, donkeys $(681)$, camels $(7,384)$, fowl $(328,197)$ and reptiles $(8,188)$.

Generally speaking, there were fewer cows and sheep-goats exported in 2003 than in 2002. The decline was due essentially to the crisis in Côte d'Ivoire, and to the condition of the livestock as a result of the deficiency of fodder during the dry season. The drop in exports of animals on the hoof was partly offset by a significant increase in meat exports. $50,070 \mathrm{~kg}$ of beef were exported to Senegal and 7,637 kg of lamb were exported to Gabon and Morocco.

\section{Number of cattle by species (head)}

\begin{tabular}{|l|c|c|c|c|c|c|c|}
\hline Campaign & Cows & Sheep & Goats & Horses & Donkeys & Camels & Pigs \\
\hline 2002 & $7,099,384$ & $7,648,451$ & $10,857,328$ & 220,452 & 726,035 & 664,654 & 68,119 \\
\hline 2003 & $7,312,366$ & $8,030,873$ & $11,400,194$ & 242,916 & 741,936 & 747,669 & 68,868 \\
\hline 2004 & $7,757,700$ & $8,854,038$ & $12,568,714$ & 294,944 & 774,788 & 946,101 & 70,392 \\
\hline
\end{tabular}




\section{Source: OMBEVI}

156. Contrasting with the preceding situation, and marked by exceptional rain and flooding conditions, the year 2004 fishing campaign was a good one. However, the size of the catches was average to small, since fishing is based on the juveniles of the then current year, given the deficiency of the 2002 campaign.

\section{Mining}

157. In the area of mining, the overall objective is to increase substantially the share of mining production in GDP and to contribute to poverty reduction, especially in mining areas. The specific objectives include:

- Promote, intensify, diversify and transform the products of mining and petroleum research;

- Participate in the implementation, monitoring and auditing/evaluation of mining and oil activities, projects and programs;

- Provide leadership and organization to artisanal mining and strengthen the capacities of the various participants;

- Identify the cause of geological phenomena (Bourakébougou fumaroles, M’Bouna heat escape);

- Consolidate the hydrocarbon market.

\subsubsection{Industry, crafts and tourism}

Faced with the low level of development of activities in industrial, artisanal and touristic production, the government intends to favor a strategy focused on attracting investment and development of private enterprise, within the framework of the PRSP.

Industry

158. In 2003, completed projects concerned: (1) continued execution of the multifunctional platform project, with the installation of 433 platforms out of the 450 scheduled in 2004, a completion rate of 98 percent; (2) study of the integrated framework for competitiveness and decentralization of industrial activities and propose solutions for their recovery; (3) completion of 16 industrial projects including Fabrique Malienne d'Aliments pour Bétail (Malian animal feed company FAMAB S.A.) and Société Malienne des Oléagineux (Malian Oil Pressing Company, SMO S.A.).

159. In 2004, completed projects included: (1) Markala sugar project (the donors' roundtable for this project has met); (2) rehabilitation of ITEMA, newly purchased by a Malian economic operator; (3) development in process of the national program to install 5,000 multifunctional platforms over the period 2005-2014; (4) development of the national program to restructure and update enterprises; (5) completion of a few industrial projects, 
including Sud Coton et Textile (South Cotton and Textile, Sucotex Sarl) in Kignan, and Fils et Tissus Naturels d'Afrique (Natural Yarn and Fabric of Africa Fitina S.A.) in Banankoro.

160. We must note the disproportion between the existing potential in the industrial sector and the actual results, especially as regards job creation and value added. Theoretically, industry should be the principal channel of activities generating jobs and income. The share of Mali’s industrial sector in GDP has remained virtually constant since 1998.

Crafts

161. Noteworthy in 2003 were: training of 414 master craftsmen and 1,500 apprentices in technical and/or managerial matters; CFAF 149.9 million in investments mobilized on the line of credit of the Crafts Sector Development Project (PDSA) to benefit various artisanal projects. In addition, Mali participated in the Smithsonian Folklife Festival in Washington, D.C., from June 25 to July 6, 2003.

162. In 2004, completed projects concerned the mobilization/investment of CFAF 398.6 million on the line of credit of the Crafts Sector Development Project; the reduction of delays in obtaining artisanal plots and construction permits; the opening of regional craft promotion centers (CRPA) in Sikasso, Ségou and Mopti; the opening of a center for craft resources in Mopti.

163. In the area of strengthening leadership facilities, we note the construction of a headquarters for the District of Bamako commune III chamber of handicrafts; finally, provision of computer and office automation equipment to all existing handicrafts chambers.

Tourism

164. In 2003, completed projects included: updating of laws related to the organization of the profession of travel agent, the vacation booking profession, and the travel guide profession; negotiations with France to finalize the agreement in principle exchanged during the world tourism summit in Paris; support to certain traditional activities (collective fishing in Bamba, crossing of the oxen in Dialoubé) as well as certain festivals (Essakane, Hombori, Yelen Festival, etc.); initiation of project to "promote tourism and conserve touristic and archeological sites"; creation of a tourist information counter at the Bamabko-Sénou airport; participation in several international trade shows.

165. In addition, we note in 2003: CFAF 1.931 billion in tourism investments; CFAF 20 billion in receipts; and 2,097 jobs created in lodging establishments.

166. All activities in the domain of tourism were executed by more than 80 percent. For example, arrivals of international visitors rose from 95,581 in 2002 to 110,365 in 2003 and 112,654 in 2004, a growth rate of 20 percent. During the same period, tourism receipts increased significantly, from CFAF 18.3 billion in 2002 to more than 19.5 billion in 2003, a rate of increase of nearly 10 percent. Employment - a very important indicator in the fight 
against poverty-rose from 4,000 in 2002 to nearly 5,000 in 2003, a rate of increase of nearly 20 percent.

167. Activities programmed in 2004 were executed at a rate approaching 80 percent. Arrivals of international visitors reached 80,000. The number of jobs created rose thanks to the reopening of certain major hotels, and by the construction of numerous bars-restaurants in Bamako as well as the interior of the country.

168. Weighing these findings, it appears that tourism is one of the most reliable sectors for the fight against poverty, since it reaches almost every branch of the economy. It is one of the sectors that creates the most jobs, because-as specialists tell us-one direct job in tourism can create 2 to 3 indirect jobs by the multiplier effect. Tourism is also one of the sectors that has a high impact on the balance of payments, because of the flow of foreign currencies it generates.

169. For 2004, investment in tourism rose to CFAF 2.469 billion, created 2,736 jobs in hotels and similar services, 2,736 jobs in bars-restaurants, night clubs and leisure activity venues, and 346 jobs in travel agencies.

\section{Trade}

170. The following activities were undertaken:

- Development of the Trade Integration Diagnostic Study in the context of the technical assistance to trade of the integrated framework process;

- $\quad$ Launch and implementation of the joint program of assistance to trade (JITAP);

- $\quad$ Launch and implementation of the Trade Mali Project, to promote exports of certain targeted products: mango, potatoes, red meat, rice, shea nuts;

- Cleansing the business climate. Actions taken concerned the fight against fraud, regular cooperation and involvement of economic operators in decisions of concern to them.

171. At the international level, the cotton sector initiative launched by four African countries including Mali, directed to the WTO, received a favorable response from the member countries. A cotton subcommittee was created to pursue rapid consideration of this issue. The initiative aims to eliminate all forms of cotton subsidies and to indemnify the victim countries.

\section{Stimulate development of the private sector}

172. For more than two decades Mali has undertaken a vast program of macroeconomic and structural reforms, including the gradual withdrawal of the state from the productive sectors, retaining only a regulatory mission. The result has been a larger private sector accounting for 87 percent of Mali's GDP. Closer analysis of the GDP reveals the following composition: 
- Primary sector, 35.8 percent

- Secondary sector, 21.2 percent

- $\quad$ Tertiary sector, 43.3 percent.

173. This composition of GDP, with only 21.2 percent coming from the secondary sector, mirrors the weakness of productive investment and consequently the low level of job creation and economic development pure and simple. Hence, the PRSP assigns a large role to stimulation of private sector development. Government participation follows these approaches:

- Strengthen the partnership and collaboration mechanisms between the government and the private sector;

- Consolidate and develop infrastructures and support services to business;

- Build a solid, high-performance financial system;

- Develop the spirit of enterprise, promote SMEs and create facilities and the capacities required for competitiveness;

- Coordinate and harmonize the programs supported by Mali’s development partners.

174. Assessment of the activities undertaken under these various approaches reveals strong points as well as some major weaknesses. Generally speaking, Mali's private sector currently possesses genuine advantages in terms of both its structure and the efforts deployed to improve its environment and its management (support), to which the government and its development partners have devoted and continue to devote enormous energy.

175. As regards the private sector, in recent years organizations have devoted serious efforts to strengthening their capacities and their own organization. Since the General Assembly of March 2002, when proposal groups were created in 11 business sectors, the National Business Leadership Council (CNPM) has positioned itself to act efficiently and effectively in his field of activity. The recent creation of a current and updated database (Internet site) on economic and trade issues at the General Secretariat of the CNPM, the establishment of a partnership with the BIT and the support program for business competitiveness and productivity — are so many obvious manifestations of the determination on the part of business leaders to meet the challenges of integration and globalization of Mali's economy. Moreover, the recent creation of the Union of consular chambers, bringing together the CCIM, APCAM and APCMM, is eloquent expression of the commitment of these various private sector organizations to harmonize their strategies in order to come up to the high expectations of their members.

176. REAO's projected creation of an agency to develop services to businesses and CNPM's project to create a national subcontracting and partnership marketplace (BNSTP) are signs of forward-looking initiatives taken by the various participants to provide better support to Mali's SMEs.

177. As regards the business environment and leadership, various studies of profitable business segments undertaken with the assistance of Mali's development partners, led to 
adoption by the government of a genuine action plan for profitable business segments that now constitutes an inexhaustible source of opportunities in Mali. The current hopes generated by all the initiatives on behalf of the private sector are due in part to the government's technical guidance agencies, which have deployed efforts to restructure and strengthen internally, undertaking everything possible to meet the high expectations of the private sector. Also worthy of mention are the efforts made in the direction of improving the legal and regulatory environment in which businesses operate, through revision of various legislative documents in the direction of greater liberality, placing businesses in a position to deal with competition. The start-up of OHADA and SYSCOA is a response to that concern.

178. Regarding weaknesses, it should be emphasized that the process of reviewing legislative and regulatory documents by the private sector development committee (CDSP) and the national economic coordination committee (CNCE) - part of the state/private sector partnership process begun almost two years ago-is still not completed. Also delayed is the review of codes in the area of strengthening the institutional and regulatory basis of markets. The privatization process has encountered serious problems in the form of poorly prepared dossiers, problems in negotiating and in finding partners, as well as delays in selling off assets. The problem of financing the private sector remains whole and entire. There remains a long road to the establishment of a private sector guarantee fund, despite promising initiatives and actions taken by the steering committee; the national investment fund has not advanced beyond the validation of the conclusions of the study devoted to it. In the area of infrastructures, we note the creation of AZI SA charged with overseeing programs to outfit and rehabilitate industrial zones. Some studies have demonstrated that nearly 40 percent of the costs of an investment project are only for the preparation of the site.

179. Finally, we note that the ten-year private sector development project, intended to marshal all these initiatives, is seriously late in getting started. In light of the preceding, the government and its private sector partners are committed to:

- $\quad$ Accelerate the implementation of the ten-year private sector development project;

- Establish a private sector guarantee fund, by bringing their complete support to the steering committee created for that purpose, and by mobilizing the resources needed from the development partners;

- $\quad$ Bring to completion the latest action plan (1999-2002) for privatizing public enterprises;

- Develop strategies to privatize public enterprises as a function of the medium- and long-term benefits to be gained;

- Provide substantial support to private sector organizations and intermediation agencies in their efforts to strengthen capacities.

180. With a view to sustaining these actions, the government will:

- (industry): give priority to the program to update and rehabilitate enterprises (Ministry of Industry and Trade); 
- (trade): increase exports and competitiveness of exporting companies, emphasizing as a strong point the need to promote and process raw materials and primary resources so as to create local value added.

- (AGR): strengthen the use of high-performance analytical tools to assess the quality of the national economy and its competitiveness vis-à-vis certain neighboring countries; pursue the active policy to monitor/evaluate the PRSP in order to provide greater stimulus to mobilizing domestic and foreign financing resources by negotiating lines of credit, organizing and training resource persons (focal points) among the partners, to energize the follow-up of PRSP actions (study of impacts).

- (private sector promotion): given the findings in this regard, energize the ongoing and dynamic state/private sector collaboration framework and study the multiple opportunities for socio-economic and cultural development.

- Create modern infrastructures, the indispensable foundations of a stable and effective economic environment required for access to basic service by business operators (industrial zones, trade expansion zones, handicraft zones, large-scale agricultural expansion zones; agribusinesses on surfaces of 100 to 1,000 hectares, mechanized and modernized); finally, the selection of appropriate technologies is the basis for reducing production factor costs, providing Mali's products with reliable comparative advantages.

- Create a dense, functional road network to open the country to the outside and its subregion; improve the rail network and restore its performance; research high-level port and river services and undertake thoroughgoing expansion of an airport system.

- Strengthen the competencies and qualifications of human resources and create a legislative and regulatory framework that is responsive, innovative, and continually self-improving, in a legal environment substantially improved in the direction of helping businesses rise to stiffer national and international competition and new opportunities.

\section{Outlook}

\subsection{Macroeconomic outlook}

181. After a slow-down in economic growth in 2004, owing essentially to a lack of rainfall, the desert locust plague and the drop in gold production, Mali's economy will resume sustained growth in 2005 and 2006, with GDP growth rates of 6.1 percent and 5.8 percent, respectively, compared to the 2004 figure of only 2.2 percent. This economic outlook is supported by the return of normal rainfall, which will provide the agricultural sector with an average growth of 4 percent, and an 18 percent increase in gold production in 2005 and 16.4 percent in 2006.

182. Analysis of the various macroeconomic accounts in recent years shows that Mali's economy features a strongly fluctuating agricultural output dependent on rainfall. It is insufficiently diversified and has a heavy dependency on foreign financing because of inadequate domestic saving, and is subject to fluctuations in the prices of raw materials 
(especially cotton and gold). Mali's economy is also marked by a certain predominance of taxes on exports in government receipts. Macroeconomic and structural measures must be adopted to promote strong and sustainable growth, ensure the financial viability of the state and fight poverty effectively.

183. Viewed from that point of view, a number of paths of study must be followed, first of all relative to adopting measures to improve the competitiveness of Mali's economy, and secondly measures to promote foreign direct investment. Adequate treatment of concerns linked to the search for new sources of growth for Mali's economy involves a variety of actors and requires continuous monitoring over time. Resolving problems and alleviating constraints calls for appropriate short-, medium- and long-term measures.

\subsection{Sector outlook}

\section{Approach 1}

184. Regarding the challenges of decentralization, the advent of budget assistance and the adoption of a results-oriented management system, there is agreement on introducing new mechanisms. The action plan has set an ambitious objective whose strategic challenge is to prepare the structures, the functions and the systems for the transition from project assistance to budget support.

185. Finally, the government's action plan is part of the PRSP strategy framework and therefore an essential component of the Institutional Development Program (PDI), which incorporates modernized public finance into its objectives and actions through restructuring of the central government around strategic missions and modernization of management and control methods and procedures of public services.

186. With regard to provisions made for budgetary support, we note:

- A draft Mali/PTF framework agreement on budgetary support, in the process of finalization;

- A draft protocol agreement on sector budgetary support for the health and social development sectors, also in the process of finalization;

- $\quad$ Ongoing preparation of a sector budgetary support program on behalf of PDI and decentralization implementation (PARAD: Program in Support of Administrative Reform and Decentralization);

- Awareness campaign for DAFs, CPSs and central administration directors regarding the challenges and implications of budgetary support, with strengthening of their capacities.

\section{Approach 2}

187. Seven parts based on lessons derived from PRODESS and from the PRSP are used in the new framework establishing a link between the objectives, the indicators and the budget. 
The first five parts listed below are designed to eliminate bottlenecks in household health, communities and the care system; the last two are aimed at creating an environmental policy necessary for reaching the assigned sector objectives.

- $\quad$ Part 1: Improve physical access to the packages of health services;

- Part 2: Increase availability of qualified human resources;

- Part 3: Availability of drugs and consumables;

- $\quad$ Part 4: Improve the quality of health services; increased demand and fight against sickness;

- $\quad$ Part 5: Financial accessibility to healthcare and participation;

- Part 6: Reform hospitals and research institutions;

- $\quad$ Part 7: Strengthen institutional capacities, including decentralization.

The department outlook aims at improving the principal indicators by carrying out the department's medium-term action plan.

\section{Approach 3}

188. The major strategic approaches for cotton sector development as set forth in the cotton sector Strategic Development Framework are as follows:

- $\quad$ Continue the fight against subsidy practices in certain countries of the West;

- Strengthen the sector's competitiveness;

- Protect revenues generated by the cotton sector from the baneful effects of volatile international prices;

- Manage the cotton industry cooperatively;

- $\quad$ Promote cotton's presence in new market segments (organic cotton and fair trade);

- Increase the rate of national cotton crop processing;

- Develop private participation in the cotton sector.

189. Regarding the other sectors related to this approach, the following are noteworthy:

- Approval and implementation of the Agriculture Law

- $\quad$ Start-up in the very near future of the Project in Support of Growth Sources, of which tourism is a component;

- Development of a master plan for touristic development and a marketing plan in collaboration with the World Bank and the World Tourism Association;

- Development of master guidelines for handicraft development;

- Strengthened capacities of artisans and leadership personnel in the crafts sector;

- Facilitation of access to credit by artisans;

- Enhanced savings of Malians abroad;

- Census of Malians living abroad. 


\section{Recommendations}

In order to ensure enhanced implementation of the PRSP and attain the development and anti-poverty objectives, the reports by the various PRSP thematic groups were used as the basis for the following recommendations:

\subsection{Macroeconomic recommendations}

190. It should be emphasized that the PRSP framework was drawn up based on a voluntarist and optimistic scenario. The results of the first two years of implementation of the PRSP enable us to assess the realistic nature of this scenario out to the year 2006, and to propose corrective measures for the new phase of the PRSP (review). Compared to the 2006 objectives, the results of the first two years of implementation of the PRSP show that some objectives can be reached, while reaching others seems difficult.

191. It appears that most of the indicators, especially the growth rate, the rate of public investment, the tax burden ratio, the wage bill ratio as a percentage of tax receipts, the ratio of debt to GDP, are all difficult to reach (given the structure of our economy, with its strong correlation between economic activity and factors not easy to control, on the one hand, and the basis of comparison on the other hand). The gaps between objectives set and actual accomplishments enables us to appreciate the efforts and inadequacies involved in formulating suggestions/recommendations aimed at reorienting action. These actions include:

- Pursuing the operational phase of the PRSP action plan, while orienting more of the available financial resources toward the social sectors and mobilizing additional external financing in line with the recommendations of the donors' roundtable in Geneva (March 2004);

- Ensuring regular monitoring/assessment of implemented anti-poverty activities arising out of the PRSP by strengthening the PRSP Unit;

- $\quad$ Reviewing and updating the PRSP indicators with reference to the "more comparable” GDP of WAEMU; initiating a study of the WAEMU more comparable GDP nomenclature and its implications for the production of economic and financial statistics, as well as macroeconomic analysis and forecasting;

- Strengthening and accelerating the hydro-agricultural management program as well as the mechanization of agriculture, to develop irrigated crops and off-season crops able to reduce the vulnerability of the primary sector to climactic uncertainties;

- Establishing an ongoing mechanism for monitoring and fighting predators, especially migrating crickets, grain-eating birds, etc.;

- Taking steps to reduce the cost of factors (water, electricity, telephone, transportation, etc.) so as to attract foreign investors to sectors such as textiles, food processing, cement and sugar, and encourage national private investment in all domains;

- Maintaining and strengthening Mali's image of socio-political stability, good governance, and transparency in the management of public affairs; 
- Underscoring the need to control deficits impacting the debt situation by favoring efficiency in the use of resources;

- Strengthening the technical and human resources of the agencies charged with macroeconomic analysis and forecasting, by recruiting agents and improving their working conditions and updating of their skills;

- Establish a centralized system of economic, financial and social statistics and strengthen the capacities of the Forecasting and Modeling Committee recently established.

\subsection{Sector recommendations}

\section{Approach 1}

192. The principal recommendations for action under this approach are:

- Strengthen capacities at all levels;

- Strengthen partnerships between the state, civil society, the private sector and regional governments;

- Strengthen the legal and institutional framework in terms of decentralization;

- Improve the functioning of regional governments;

- Establish the agency charged with implementing and coordinating measures contained in the government action plan for improving and modernizing public finance management;

- Adopt the government/partner protocol aimed at using national budget execution procedures within the framework of a common budgetary support so as to optimize completion of activities designed to reduce poverty;

- Strengthen the capacities of the DAFs, CPSs and central administrative directors so as to optimize programming, completion and auditing of activities within the framework of the PRSP implementation;

- Strengthen and improve the quality of management of financial, material and human resources.

\section{Approach 2}

193. The principal recommendations under this approach are:

- Improve the quality of basic social services (health, education, drinking water, etc.);

- Boost the effectiveness of regional governments' exercise of powers in the sectors transferred to their oversight;

- Strengthen the national capacities in the area of gender, to take gender into account systematically in Mali's development policies and strategies;

- Support the implementation of employment policies and programs, including the Youth Jobs Program (PEJ), the Multisector Investment Program with a high percentage of rural jobs (PROMIEER) and the Local Urban Employment Initiative Program (PILE). 


\section{Approach 3}

194. The principal recommendations under this approach are:

- Managing of bottom lands and small irrigated agricultural plots in low-yield zones;

- Establishing a natural disaster fund and a system of agricultural insurance for profitable crop segments;

- $\quad$ Continuing the process of privatizing the cotton sector;

- Undertaking an awareness campaign of the large scale use of new and renewable energy sources;

- Adopting a national information and communications technologies policy and a national strategic plan, together with incentives for attracting investments to the NTIC area. 


\section{Conclusion}

195. The initial PRSP implementation report covered the period from 2002 to the first half of 2003, thereby not providing a basis for a pertinent analysis of the results obtained and corrections to be undertaken to increase the effectiveness of the actions for improving the fight against poverty specified in the budget law.

196. The 2003-2004 report showed Mali's determination to make the fight against poverty its own priority, thus facilitating harmonizing the PRSP objectives with the budget law. This second PRSP monitoring/assessment report showed that the discrepancies between PRSP objectives and their achievement in the course of the first two years of PRSP implementation are not yet satisfactory, especially the growth rate, the public investment rate, the overall investment rate, the ratio of debt to GDP, the tax burden, and certain sector indicators whose levels, while close to the estimates, have not fully attained the objectives set.

197. In 2003, Mali's economy posted strong growth, with a real rate of 7.4 percent. This recovery was made possible by a dynamic agricultural sector. By contrast, the economic environment in 2004 was marked by less impressive agricultural results due to poorly distributed rainfall, a drop in the price of cotton, and the consequences for crops of a desert locust plague, together with underperformance of mining companies and an increase in oil prices. In 2004, Mali's economy grew at a rate of only 2.2 percent.

198. Encouraging results may be noted thanks to the various actions undertaken to create a participatory process for designing, executing and implementing the PRSP, enabling all levels of society to become aware of problems in the areas of health, education and rights, and to organize themselves to improve their living conditions.

199. One of the noteworthy results of the process of social dialogue has been that the government and its social partners have gradually learned to listen to one another, so as to understand each other better and to better understand their respective constraints. The partners are ever more able to get past group interests in order to analyze problems with the government and look for compromise solutions acceptable to all. These good practices of social dialogue have formed the basis of a relatively peaceful social climate that has favored the attainment of certain of the government's economic objectives, such as the growth rate.

200. In addition, the introduction of results-oriented management in government agencies, the completion of the program reviews, and the establishment of evaluation and selfevaluation tools to assess regional government performance, constitute so many encouraging signs that will reinforce the PRSP monitoring mechanisms in the long term.

201. However, in order for Mali to attain the objectives it has set for the PRSP by 2006 and reach the Millennium Development Goals (MDGs), it must find appropriate solutions to certain recurrent problems and meet a certain number of future challenges, in line with the 
recommendations and suggestions made above. Before 2006, major efforts must be deployed to consolidate and intensify anti-poverty activities, for example:

- Establish a National Steering Committee to Transfer Competencies from the central government to regional governments, as well as a support program based on a clear assessment of the human, material and financial resources required;

- Design and implement a national disaster management policy;

- Fund the rural mechanization program presently being prepared so as to raise the equipment level of peasant farmers;

- $\quad$ Promote oil prospecting;

- $\quad$ Adopt the contemplated National Plan for Access to Water for the period 2004-2015, aimed at creating 10,000 new modern water sources, with priority given to regions not yet provided with them;

- Prior to end-2004, establish the Road Maintenance Agency (AGEROUTE), and in 2005, establish twelve (12) fee collection stations and penalties for overcharging;

- Diversify Mali's supply sources by expanding its depots in Togo, Mauritania and Senegal, and implement the Transportation Corridor Improvement Project (20042008) with a total allocation of US\$ 48.7 million;

- Implement an updated National Population Policy, adopted in April 2003, by developing in the course of 2004 the Priority Population Investment Program, and by taking up population issues in all development projects, programs and strategies. 
Annex 1. Macroeconomic framework, 2004-2007

Principal economic and financial indicators

\begin{tabular}{|c|c|c|c|c|c|}
\hline & 2002 & 2003 & 2004 & 2005 & 2006 \\
\hline Nominal GDP & 2,330 & 2,574 & 2,602 & 2,753 & 3,049 \\
\hline Growth in real terms (in volume terms) (\%) & 4.3 & 7.4 & 2.2 & 5.8 & 5.8 \\
\hline GDP deflator & 1.0 & 2.9 & -1.0 & 0.0 & 4.7 \\
\hline Revenue and grants & 456.7 & 536.5 & 565.4 & 648.3 & 660.6 \\
\hline Total revenue & 370.9 & 421.8 & 446.5 & 502.7 & 572.9 \\
\hline Tax receipts & 306.0 & 349.2 & 390.9 & 434.1 & 483.4 \\
\hline Total expenditure and net lending & 540.6 & 569.0 & 644.4 & 744.4 & 793.5 \\
\hline Current expenditure & 308.7 & 316.3 & 355.8 & 388.2 & 443.0 \\
\hline Wages & 93.5 & 106.2 & 122.0 & 140.2 & 146.7 \\
\hline Capital expenditure & 203.1 & 219.2 & 259.1 & 282.7 & 312.9 \\
\hline Domestically funded investment & 62.7 & 78.3 & 90.0 & 97.5 & 117.2 \\
\hline Deficit, commitment basis, ex. grants & -169.7 & -147.2 & -184.8 & -241.7 & -220.6 \\
\hline $\begin{array}{l}\text { Deficit, commitment basis, ex. grants/GDP in } \\
\%\end{array}$ & -7.3 & -5.7 & -7.1 & -8.8 & -6.9 \\
\hline Basic budget balance & -29.4 & -6.3 & -15.8 & -56.5 & -24.9 \\
\hline Net Government position (NGP) & -8.8 & -48.6 & 15.2 & -17.2 & -12.1 \\
\hline Stock of debt & $1,746.1$ & $1,765.9$ & $1,666.0$ & $1,737.6$ & $1,763.6$ \\
\hline Total imports & 492.8 & 560.2 & 585.4 & 631.3 & 657.6 \\
\hline Total exports & 624.6 & 552.8 & 582.1 & 555.0 & 622.7 \\
\hline Trade balance & 131.8 & -7.4 & -3.3 & -76.3 & -34.9 \\
\hline Current account balance & -100.0 & -178.6 & -166.1 & -248.3 & -232.3 \\
\hline Overall financing balance & -96.3 & -92.6 & -33.9 & 14.6 & 18.7 \\
\hline \multicolumn{6}{|l|}{ Convergence criteria } \\
\hline \multicolumn{6}{|l|}{ First-tier criteria } \\
\hline Basic budget balance/GDP (standard $\geq-3 \%$ ) & -1.3 & -0.2 & -1.1 & -2.1 & -0.6 \\
\hline Average annual inflation rate (standard $\leq-3 \%$ ) & 5.0 & -1.3 & -3.0 & 2.5 & 2.5 \\
\hline Stock of debt/GDP (standard $\leq 70 \%)$ & 76.0 & 70.8 & 62.3 & 59.3 & 55.1 \\
\hline Change in domestic arrears (standard $\leq 0$ ) & 0.0 & 0.0 & 0.0 & 0.0 & 0.0 \\
\hline Change in external arrears (standard $\leq 0$ ) & 0.0 & 0.0 & 0.0 & 0.0 & 0.0 \\
\hline \multicolumn{6}{|l|}{ Second-tier criteria } \\
\hline Wage bill/tax receipts (standard < 35\%) (\%) & 30.6 & 30.4 & 31.2 & 32.5 & 28.0 \\
\hline $\begin{array}{l}\text { Domestically funded investment/tax receipts } \\
\text { (standard } \geq 20 \% \text { ) (\%) }\end{array}$ & $20 \%$ & $27 \%$ & $23 \%$ & $24 \%$ & $24 \%$ \\
\hline $\begin{array}{l}\text { Current external deficit ex. grants/GDP } \\
\text { (standard } \leq 5 \% \text { ) }\end{array}$ & -4.3 & -6.9 & -6.4 & -9.0 & -7.0 \\
\hline Tax burden (standard $\geq 17 \%$ ) & 13.4 & 14.2 & 15.2 & 15.7 & 15.9 \\
\hline
\end{tabular}


Major commodities

\begin{tabular}{|c|c|c|c|c|c|c|}
\hline Product & 2002 & 2003 & 2004 & 2005 & 2006 & $\begin{array}{c}\text { Average } \\
2004-2006\end{array}$ \\
\hline \multicolumn{7}{|l|}{$\begin{array}{l}\text { Volume } \\
\text { in tons }\end{array}$} \\
\hline $\begin{array}{l}\text { All food } \\
\text { crops }\end{array}$ & $2,333,367$ & $3,107,086$ & $2,951,675$ & $3,108,485$ & $3,273,690$ & $3,111,283.3$ \\
\hline Millet & 715,631 & $1,010,665$ & 889,385 & 933,854 & 980,547 & $934,595.5$ \\
\hline Sorghum & 577,579 & 687,315 & 604,837 & 635,079 & 666,833 & $635,582.8$ \\
\hline Rice & 639,401 & 870,465 & 922,693 & 978,054 & $1,036,737$ & $979,161.4$ \\
\hline Maize & 334,539 & 468,516 & 468,516 & 491,942 & 516,539 & $492,332.7$ \\
\hline Cotton & 419,421 & 608,717 & 600,012 & 624,013 & 648,973 & $624,332.8$ \\
\hline Gold & 66.1 & 54.1 & 53.6 & 57.4 & 69.3 & 60.1 \\
\hline \multicolumn{7}{|l|}{$\begin{array}{l}\text { Value in } \\
\text { CFAF } \\
\text { millions }\end{array}$} \\
\hline $\begin{array}{l}\text { Total food } \\
\text { crops }\end{array}$ & 336,729 & 462,497 & 474,022 & 514,069 & 579,121 & $522,403.8$ \\
\hline Millet & 79,674 & 115,334 & 109,613 & 117,971 & 133,779 & $120,454.5$ \\
\hline Sorghum & 55,592 & 67,808 & 64,445 & 69,359 & 78,653 & $70,818.6$ \\
\hline Rice & 77,314 & 107,885 & 123,507 & 134,190 & 153,621 & $137,105.9$ \\
\hline Maize & 26,010 & 37,338 & 40,325 & 43,400 & 49,215 & $44,313.2$ \\
\hline Cotton & 248,541 & 239,800 & 315,004 & 380,433 & 406,143 & $367,193.4$ \\
\hline Gold & 340,793 & 376,656 & 414,458 & 509,259 & 413,268 & $445,661.7$ \\
\hline
\end{tabular}


Share of various sectors in GDP

\begin{tabular}{|c|c|c|c|c|c|c|}
\hline & 2002 & 2003 & 2004 & 2005 & 2006 & $\begin{array}{c}\text { Average } \\
2004-2006\end{array}$ \\
\hline Primary sector & 740.3 & 924.9 & 951.7 & $1,035.0$ & $1,116.9$ & $1,034.5$ \\
\hline Secondary sector & 564.8 & 516.6 & 585.5 & 711.3 & 798.4 & 698.4 \\
\hline Tertiary sector & 992.3 & $1,052.9$ & $1,137.6$ & $1,185.2$ & $1,283.5$ & $1,202.1$ \\
\hline GDP & 2,297 & 2,494 & 2,675 & 2,932 & 3,199 & $2,935.0$ \\
\hline \multicolumn{7}{|l|}{ As a percentage of GDP } \\
\hline Primary sector & 32.2 & 37.1 & 35.6 & 35.3 & 34.9 & 35.3 \\
\hline Secondary sector & 24.6 & 20.7 & 21.9 & 24.3 & 25.0 & 23.7 \\
\hline Tertiary sector & 43.2 & 42.2 & 42.5 & 40.4 & 40.1 & 41.0 \\
\hline Gross capital formation & 431.5 & 630.9 & 555.2 & 648.6 & 706.7 & 636.8 \\
\hline Gross fixed capital formation & 439.5 & 446.0 & 457.5 & 472.4 & 481.0 & 470.3 \\
\hline Private & 267.0 & 269.2 & 276.3 & 286.6 & 290.5 & 284.5 \\
\hline Public & 172.5 & 176.8 & 181.2 & 185.8 & 190.4 & 185.8 \\
\hline Investment rate (\%) & 18.8 & 25.3 & 20.8 & 22.1 & 22.1 & 21.6 \\
\hline
\end{tabular}


Annex 2. PRSP basic framework for 2002-2006

\section{Principal economic and financial indicators (2002 projections) (Percentages)}

\begin{tabular}{|c|c|c|c|c|c|c|c|}
\hline & 2001 & 2002 & 2003 & 2004 & 2005 & 2006 & $\begin{array}{l}2002 / \\
2006\end{array}$ \\
\hline \multicolumn{8}{|l|}{ Growth } \\
\hline GDP at constant prices & 1.5 & 9.3 & 7.4 & 5.9 & 5.6 & 5.3 & 6.7 \\
\hline Of which, primary sector & -13.4 & 19.5 & 3.7 & 4.4 & 4.4 & 4.6 & 7.3 \\
\hline \%GDP & 37.9 & 41.5 & 40.0 & 39.5 & 39.0 & 38.8 & 39.8 \\
\hline Contribution & -6.0 & 7.4 & 1.5 & 1.8 & 1.8 & 1.8 & 2.8 \\
\hline Secondary sector & 31.0 & -2.6 & 17.9 & 6.3 & 4.8 & 4.4 & 6.2 \\
\hline \%GDP & 23.7 & 21.1 & 23.2 & 23.3 & 23.1 & 22.9 & 22.7 \\
\hline Contribution & 5.7 & -0.6 & 3.8 & 1.5 & 1.1 & 1.0 & 1.4 \\
\hline Tertiary sector & 1.2 & 5.9 & 4.5 & 6.6 & 6.7 & 5.8 & 5.9 \\
\hline \%GDP & 31.8 & 30.8 & 30.0 & 30.2 & 30.5 & 30.7 & 30.4 \\
\hline Contribution & 0.4 & 1.9 & 1.4 & 2.0 & 2.0 & 1.8 & 1.8 \\
\hline DTI contribution & 1.4 & 0.6 & 0.7 & 0.7 & 0.7 & 0.7 & 0.7 \\
\hline Verification & 0.0 & 0.0 & 0.0 & 0.0 & 0.0 & 0.0 & 0.0 \\
\hline GDP deflator & 7.8 & 3.2 & -2.7 & 2.2 & 0.8 & 0.6 & 0.8 \\
\hline Growth in imports (volume) & 13.3 & 11.4 & 9.1 & 7.3 & 6.9 & 6.6 & 8.3 \\
\hline Growth in exports (volume & 19.1 & 9.4 & 16.4 & 6.1 & 3.6 & 2.7 & 7.7 \\
\hline Overall investment rate & 21.1 & 20.7 & 23.4 & 23.0 & 23.3 & 23.1 & 22.7 \\
\hline Public investment rate & 7.0 & 7.6 & 8.3 & 8.1 & 8.2 & 8.8 & 8.2 \\
\hline Domestic saving rate & 16.6 & 16.2 & 19.0 & 18.4 & 47.6 & 15.8 & 17.4 \\
\hline \multicolumn{8}{|l|}{ Government finance (\% of GDP) } \\
\hline Total revenue & 16.6 & 18.1 & 18.0 & 18.3 & 18.8 & 19.8 & 18.6 \\
\hline Tax receipts & 14.6 & 15.5 & 15.6 & 16.1 & 16.7 & 17.8 & 16.4 \\
\hline Total expenditures and net lending & 27.6 & 28.4 & 27.8 & 27.2 & 27.2 & 28.1 & 27.7 \\
\hline Domestic financing of investment & 3.2 & 3.5 & 4.5 & 4.7 & 5.3 & 6.7 & 4.9 \\
\hline Current expenditure & 12.6 & 13.4 & 12.2 & 12.0 & 11.9 & 11.9 & 12.3 \\
\hline Wage bill & 4.2 & 4.2 & 4.2 & 4.1 & 4.1 & 4.1 & 4.1 \\
\hline Development outlays & 13.2 & 12.3 & 13.5 & 13.2 & 13.3 & 14.4 & 13.3 \\
\hline Current deficit including grants & 7.7 & 7.0 & 6.8 & 7.3 & 7.9 & 6.0 & 7.0 \\
\hline Primary deficit & -5.1 & -5.7 & -5.6 & -4.9 & -4.5 & -4.7 & -5.1 \\
\hline Basic balance & -2.0 & -1.9 & -1.3 & -0.9 & -0.7 & -0.9 & -1.1 \\
\hline Basic balance ex. HIPC & -1.2 & -0.5 & -0.4 & 0.1 & 0.3 & -0.2 & -0.1 \\
\hline Budget deficit, commitment basis & -5.8 & -6.6 & -6.4 & -5.7 & -5.3 & -5.3 & -5.9 \\
\hline Deficit, commitment basis, ex. grants & -11.0 & -10.3 & -9.8 & -8.9 & -8.3 & -8.5 & -9.2 \\
\hline Budget deficit, cash basis & -5.8 & -6.6 & -6.4 & -5.7 & -5.3 & -5.3 & -5.9 \\
\hline \multicolumn{8}{|l|}{$\begin{array}{l}\text { Gross fixed capital formation } \\
\text { (GFCF) rate }\end{array}$} \\
\hline GFCF, total & 17.7 & 17.6 & 18.3 & 18.3 & 18.7 & 19.6 & 18.5 \\
\hline GFCF, public & 6.8 & 7.3 & 7.9 & 7.7 & 7.6 & 8.1 & 7.7 \\
\hline GFCF, private & 10.9 & 10.4 & 10.4 & 10.6 & 11.1 & 11.6 & 10.8 \\
\hline $\begin{array}{l}\text { Share of current expenditure/total } \\
\text { expenditure }\end{array}$ & 45.7 & 47.1 & 44.0 & 44.1 & 43.8 & 42.2 & 44.2 \\
\hline Share of development & 44.3 & 41.7 & 46.9 & 47.0 & 47.6 & 49.9 & 46.6 \\
\hline
\end{tabular}




\begin{tabular}{|l|r|r|r|r|r|r|r|}
\hline expenditure/total expenditure & & & & & & & \\
\hline Wage bill & 29.1 & 27.0 & 26.6 & 25.3 & 24.7 & 23.3 & 25.4 \\
\hline Domestic financing of investment & 22.0 & 22.3 & 28.7 & 29.5 & 31.7 & 37.5 & 29.9 \\
\hline Service of direct debt & 22.69 & 24.77 & 22.72 & 21.55 & 19.94 & 17.82 & 21.4 \\
\hline -Interest & 5.2 & 6.3 & 5.2 & 4.9 & 4.5 & 3.5 & 4.9 \\
\hline - Principal repayment & 12.9 & 12.9 & 12.4 & 11.9 & 11.8 & 11.9 & 12.2 \\
\hline -IMF repurchase & 4.6 & 5.6 & 5.2 & 4.8 & 3.6 & 2.4 & 4.3 \\
\hline Debt relief & 0.0 & 0.0 & 1.1 & 8.2 & 8.8 & 4.6 & 4.5 \\
\hline Deficit, cash basis & -39.8 & -42.7 & -41.1 & -35.2 & -31.6 & -29.9 & -36.1 \\
\hline BOP (\% of GDP) & & & & & & & \\
\hline Trade balance & -0.1 & 1.4 & 5.4 & 4.8 & 3.7 & 2.0 & 3.5 \\
\hline Services balance (net) & -11.0 & -9.7 & -9.8 & -9.7 & -9.6 & -9.5 & -9.7 \\
\hline Income Balance (net) & -5.1 & -4.2 & -4.8 & -4.7 & -4.4 & -3.9 & -4.4 \\
\hline Of which, interest & -0.7 & -0.9 & -0.8 & -0.8 & -0.7 & -0.6 & -0.8 \\
\hline Public transfers & 7.2 & 5.7 & 4.9 & 4.6 & 4.3 & 4.1 & 4.7 \\
\hline Private transfers & 2.0 & 1.6 & 1.6 & 1.7 & 1.7 & 1.8 & 1.7 \\
\hline Current balance & -11.9 & -10.3 & -7.1 & -7.4 & -8.2 & -9.3 & -8.5 \\
\hline Current balance ex. public transfers & -14.2 & -10.9 & -7.6 & -7.9 & -8.6 & -9.7 & -8.9 \\
\hline As a percentage of GDP & & & & & & & \\
\hline Primary sector & 37.9 & 41.5 & 40.0 & 39.5 & 39.0 & 38.8 & 39.8 \\
\hline Secondary sector & 23.7 & 21.1 & 23.2 & 23.3 & 23.1 & 22.9 & 22.7 \\
\hline Tertiary sector & 31.8 & 30.8 & 30.0 & 30.2 & 30.5 & 30.7 & 30.4 \\
\hline Import duties and taxes & 6.6 & 6.6 & 6.8 & 7.0 & 7.3 & 7.7 & 7.1 \\
\hline Verification & 100.0 & 100.0 & 100.0 & 100.0 & 100.0 & 100.0 & 100.0 \\
\hline Imports & 32.6 & 33.3 & 33.8 & 34.3 & 34.7 & 35.1 & 34.2 \\
\hline Exports & 34.0 & 34.1 & 37.0 & 37.0 & 36.3 & 35.4 & 36.0 \\
\hline Source
\end{tabular}

Source: 2002-2006 PRSP

\section{Real sector data in volumes (2002 projections)}

\begin{tabular}{|c|c|c|c|c|c|c|}
\hline $\begin{array}{l}\text { Volumes of production } \\
\text { (in thousands of tons) }\end{array}$ & 2001 & 2002 & 2003 & 2004 & 2005 & 2006 \\
\hline Millet & 722.0 & 776.4 & 815.3 & 856.0 & 898.8 & 943.8 \\
\hline Sorghum & 553.0 & 625.4 & 656.6 & 689.5 & 724.0 & 760.1 \\
\hline Maize & 205.0 & 402.3 & 422.4 & 443.5 & 465.7 & 489.0 \\
\hline Rice & 670.0 & 756.0 & 809.0 & 865.6 & 926.2 & 991.0 \\
\hline Cotton & 250.1 & 575.0 & 575.0 & 600.0 & 625.0 & 650.0 \\
\hline Peanuts & 166.0 & 174.6 & 192.0 & 201.0 & 210.0 & 220.0 \\
\hline Gold (in tons) & 53.6 & 48.6 & 64.1 & 68.2 & 69.4 & 69.4 \\
\hline
\end{tabular}




\section{Annex 3. Comparative table of PRSP objectives and results}

WAEMU indicators and standards

\begin{tabular}{|c|c|c|c|c|}
\hline WAEMU indicators and standards & $\begin{array}{c}\text { 2002-2006 PRSP } \\
\text { objectives }\end{array}$ & \multicolumn{3}{|c|}{ Results } \\
\hline & & 2002 & 2003 & 2004 \\
\hline Real GDP growth rate & 6.7 & 4.3 & 7.4 & 2.2 \\
\hline Of which: & & & & \\
\hline Primary sector & 7.3 & -3.6 & 18.4 & -4.7 \\
\hline Secondary sector & 6.2 & 18.4 & -8.6 & 2.7 \\
\hline Tertiary sector & 5.9 & 1.1 & 7.6 & 7.5 \\
\hline Basic budget balance/GDP & -1.1 & -1.3 & -0.2 & -1.1 \\
\hline Basic budget balance ex. HIPC/GDP & -0.1 & 0.1 & 1.1 & -0.1 \\
\hline Overall investment rate & 22.7 & 18.6 & 25.6 & 18.9 \\
\hline Public investment rate & 8.2 & 7.0 & 6.8 & 8.0 \\
\hline Domestic savings rate & 17.4 & 18.5 & 20.0 & 14.0 \\
\hline Inflation rate $\leq 3 \%$ & $<3 \%$ & 5.0 & -1.3 & -3.0 \\
\hline Tax burden $\geq 17 \%$ & $>=16.4 \%$ & 14.7 & 14.5 & 14.3 \\
\hline Wage bill as $\%$ of tax receipts $\leq 35 \%$ & $<=35 \%$ & 30.6 & 30.4 & 31.2 \\
\hline Current BOP balance/GDP $\leq-5 \%$ & $<-8.5 \%$ & -4.3 & -6.9 & -6.4 \\
\hline Stock of debt/GDP $\leq 70 \%$ & $\leq 68.6$ & 90.2 & 72.6 & 69.3 \\
\hline
\end{tabular}

Sources: PRSP/DNP/DNSI/BCEAO

Rate of HIPC resource use in CFAF billions and in percentage

\begin{tabular}{|c|c|c|c|c|c|c|c|c|c|}
\hline \multirow{2}{*}{ Priority sectors } & \multicolumn{3}{|c|}{2002} & \multicolumn{3}{|c|}{2003} & \multicolumn{3}{|c|}{2004} \\
\hline & $\begin{array}{c}\text { PRSP } \\
\text { goal }\end{array}$ & Actual & $\begin{array}{r}\text { Gap } \\
\text { in \% }\end{array}$ & $\begin{array}{l}\text { PRSP } \\
\text { goal }\end{array}$ & Actual & $\begin{array}{r}\text { Gap } \\
\text { in \% }\end{array}$ & $\begin{array}{c}\text { PRSP } \\
\text { goal }\end{array}$ & Actual & $\begin{array}{l}\text { Gap } \\
\text { in \% }\end{array}$ \\
\hline Health and population & 4.6 & 3.6 & -22 & 3.3 & 0.5 & -85 & 3.6 & & \\
\hline Education/literacy & 11.2 & 14.6 & 30 & 11.2 & 7.1 & -37 & 11.8 & & \\
\hline $\begin{array}{l}\text { Employment and } \\
\text { vocational training }\end{array}$ & 1.5 & 1.1 & -27 & 0.5 & 0.6 & 20 & 0.3 & & \\
\hline $\begin{array}{l}\text { Basic infrastructure for } \\
\text { development }\end{array}$ & 0.9 & 1.7 & 85 & 0.5 & 5.7 & 1,040 & 0.5 & & \\
\hline $\begin{array}{l}\text { Rural development and } \\
\text { natural resources }\end{array}$ & 2.9 & 3.3 & 14 & 3.3 & 2.0 & -39 & 3.5 & & \\
\hline $\begin{array}{l}\text { AGR, solidarity and } \\
\text { social security }\end{array}$ & 3.1 & 0.8 & -7 & 3.8 & 0.1 & -97 & 3.8 & & \\
\hline $\begin{array}{l}\text { Environment and } \\
\text { living standards }\end{array}$ & 0.8 & 0 & 100 & 1.9 & 0.3 & -84 & 1.9 & & \\
\hline Governance and & -- & & & -- & & -- & & & \\
\hline
\end{tabular}




\begin{tabular}{|c|c|c|c|c|c|c|c|c|c|}
\hline institutions & & & & & & & & & \\
\hline $\begin{array}{l}\text { Culture/religion/peace } \\
\text { and security }\end{array}$ & -- & & & -- & & -- & & & \\
\hline $\begin{array}{l}\text { PRSP implementation/ } \\
\text { poverty monitoring } \\
\text { and analysis }\end{array}$ & 0.3 & & & 0.3 & & & 0.3 & & \\
\hline Total & 25.3 & 30.9 & 22 & 24.5 & 19.0 & -22 & 24.7 & 29.6 & 20 \\
\hline
\end{tabular}

Sources: PRSP document and TOFE 


\section{Annex 4. Simplified diagram of the PRSP monitoring/assessment mechanism}

202.

203.

[Left column]

Orientation committee

Steering committee

Semi-annual reports

National technical committee and 13 thematic groups

[Center column]

Joint Commission Mali-Partners

Annual summary report

[Right column]

Policymaking (CAFPD)

Capacity building (PRECAGED)

DNP (PRSP Technical Secretariat): Summary semi-annual reports/Annual and bi-annual reports/Monitoring macroeconomic planning and programming of public investments

MEF/PRSP Unit

(Coordination)

ODHD: Monitoring of indicators, impact assessment MDSSPA
DNB: Monitoring MTEF

DGDP: Monitoring HIPC resources

IF: Monitoring anti-corruption

DNSI: production of monitoring indicators/ surveys

Sector ministries

CPS/DAF: sector indicators

Regional and subregional technical offices: spatial data 


\section{Annex 5. PRSP monitoring and assessment mechanism}

\begin{tabular}{|c|c|}
\hline \multicolumn{2}{|c|}{ Roles of the main technical entities involved in PRSP monitoring } \\
\hline Entity & Role \\
\hline PRSP unit & $\begin{array}{l}\text { - Ensure coordination of all PRSP implementation, monitoring and } \\
\text { assessment activities; } \\
\text { - Ensure the strengthening of the main structures of administration, } \\
\text { civil society, and private sector to successfully conduct PRSP } \\
\text { implementation, monitoring and assessment process }\end{array}$ \\
\hline DNP & $\begin{array}{l}\text { - Monitor implementation of the action plan through projects and } \\
\text { programs adopted in the context of poverty reductions efforts; } \\
\text { - Monitor the status of and update macroeconomic planning; } \\
\text { - Ensure consistency between partner strategies and interventions } \\
\text { and those of the PRSP; } \\
\text { - Produce and publish an annual monitoring report with assessment } \\
\text { and recommendations to ensure satisfactory progress for the PRSP } \\
\text { as needed; } \\
\text { - Produce a bi-annual assessment report within a framework of } \\
\text { rolling three-year planning and programming; } \\
\text { - Contribute to the development of an evaluation capacity as a tool in } \\
\text { decision-making and a means of improving the efficiency of the } \\
\text { public sector. }\end{array}$ \\
\hline DNSI & $\begin{array}{l}\text { - Ensure that the information system allows for regular fine-tuning of } \\
\text { the PRSP implementation; } \\
\text { - Produce data related to the monitoring of PRSP performance; } \\
\text { - Conduct small-scale surveys or collected passive data needed for } \\
\text { PRSP monitoring/assessment. }\end{array}$ \\
\hline DNB & $\begin{array}{l}\text { - Monitor the implementation of the Medium-Term Expenditure } \\
\text { Framework (MTEF) and program-budget. }\end{array}$ \\
\hline DGDP & $\begin{array}{l}\text { - Monitor the progress of HIPC Initiative resources; } \\
\text { - Mobilize concessional financing for implementation of the PRSP } \\
\text { action plan; } \\
\text { - Provide management of domestic and foreign debt. }\end{array}$ \\
\hline IF/MEF & $\begin{array}{l}\text { - Monitor issues linked to the "fight against corruption and financial } \\
\text { crime." }\end{array}$ \\
\hline DCI & $\begin{array}{l}\text { - Support the various entities in seeking and mobilizing external } \\
\text { financing with development partners. }\end{array}$ \\
\hline CPS of sector ministries & $\begin{array}{l}\text { - Undertake the development, implementation and } \\
\text { monitoring/assessment of projects and programs initiated in their } \\
\text { respective sector departments. }\end{array}$ \\
\hline ODHD & $\begin{array}{l}\text { - Coordinate the PRSP monitoring/assessment component and } \\
\text { provide the monitoring of performance indicators and analysis of } \\
\text { impact indicators for poverty reduction; } \\
\text { - Produce and disseminate Sustainable Human Development reports } \\
\text { (SHD) from data generated by the national statistics system and } \\
\text { other information sources. }\end{array}$ \\
\hline
\end{tabular}




\section{Annex 6. Trends in Mali's principal macroeconomic indicators}

Trends in Mali's principal macroeconomic indicators according to the "more comparable” GDP approach, 2000 to 2004

\begin{tabular}{|c|c|c|c|c|c|}
\hline Indicators & 2000 & 2001 & 2002 & 2003 & 2004* \\
\hline \multicolumn{6}{|l|}{ Convergence indicators } \\
\hline \multicolumn{6}{|l|}{ First tier } \\
\hline Basic budget balance ex. HIPC/nominal GDP (in \%) & -0.8 & -0.6 & -0.1 & 0.9 & 0.4 \\
\hline $\begin{array}{l}\text { Annual inflation rate (change in average indices in } \\
\% \text { ) }\end{array}$ & -0.7 & 5.2 & 5.0 & -13 & -4.3 \\
\hline $\begin{array}{l}\text { Ratio of stock of total public debt to nominal GDP } \\
\text { (in \%) }\end{array}$ & 92.3 & 84.2 & 81.1 & 69.9 & 70.0 \\
\hline Change in payment arrears (in CFAF billions) & 1.6 & 0.0 & 0.0 & 0.0 & 0.0 \\
\hline Accumulation of payment arrears & 0.0 & 0.0 & 0.0 & 0.0 & 0.0 \\
\hline Accumulation of domestic payment arrears & 0.0 & 0.0 & 0.0 & 0.0 & 0.0 \\
\hline Accumulation of external payment arrears & 0.0 & 0.0 & 0.0 & 0.0 & 0.0 \\
\hline Reduction of payment arrears & 0.0 & 0.0 & 0.0 & 0.0 & 0.0 \\
\hline Reduction in domestic payment arrears & 0.0 & 0.0 & 0.0 & 0.0 & 0.0 \\
\hline Reduction in external payment arrears & 0.0 & 0.0 & 0.0 & 0.0 & 0.0 \\
\hline $\begin{array}{l}\text { Change in domestic payment arrears (in CFAF } \\
\text { billions) }\end{array}$ & 1.6 & 0.0 & 0.0 & 0.0 & 0.0 \\
\hline $\begin{array}{l}\text { Change in external payment arrears (in CFAF } \\
\text { billions) }\end{array}$ & 0.0 & 0.0 & 0.0 & 0.0 & 0.0 \\
\hline \multicolumn{6}{|l|}{ Second tier } \\
\hline Wages and salaries as a \% of tax receipts & 32.4 & 31.5 & 30.6 & 30.4 & 31.2 \\
\hline $\begin{array}{l}\text { Domestically funded capital expenditure as a \% of } \\
\text { tax receipts }\end{array}$ & 23.2 & 19.4 & 20.5 & 22.4 & 25.5 \\
\hline Tax receipts/GDP as \% & 11.9 & 12.3 & 13.4 & 14.2 & 15.2 \\
\hline \multicolumn{6}{|l|}{ National accounts } \\
\hline Nominal GDP (in CFAF billions) & 1,891 & 2,212 & 2,286 & 2,461 & 2,699 \\
\hline GDP in volume (1985 constant prices) & 989 & 1,106 & 1,153 & 1,239 & 1,257 \\
\hline GDP growth rate in volume terms & -3.3 & 12.0 & 4.3 & 7.4 & 2.2 \\
\hline \multicolumn{6}{|l|}{ Monetary survey } \\
\hline Net foreign assets & 167.7 & 198.1 & 271.6 & 400.4 & 468.0 \\
\hline Domestic credit & 247.0 & 323.5 & 411.5 & 482.8 & 489.4 \\
\hline Money supply & 408.5 & 487.2 & 626.3 & 763.4 & 813.5 \\
\hline \multicolumn{6}{|l|}{ Foreign trade and balance of payments } \\
\hline Imports FOB & 421.5 & 538.6 & 492.8 & 560.2 & 585.4 \\
\hline Exports FOB & 388.1 & 531.6 & 624.6 & 552.8 & 582.1 \\
\hline Trade balance FOB-FOB & -33.4 & -7.0 & 131.8 & -7.4 & -3.3 \\
\hline Current balance & -181.2 & -227.3 & -103.7 & -117 & -138 \\
\hline Overall balance & 70.8 & 28.0 & 96.3 & 92.6 & 33.9 \\
\hline Rate of cover in $\%$ & 92.1 & 98.7 & 126.8 & 98.7 & 99.4 \\
\hline Current balance as \% of GDP & -9.6 & -10.3 & -4.3 & -6.9 & -6.4 \\
\hline \multicolumn{6}{|l|}{ External debt } \\
\hline Stock of external debt & $1,701.6$ & $1,767.0$ & $1,746.1$ & $1,646.7$ & $1,725.0$ \\
\hline External debt service & 51.0 & 60.4 & 60.8 & 63.5 & 63.2 \\
\hline External debt as \% of GDP & 92.3 & 84.2 & 90.2 & 72.6 & 70.2 \\
\hline
\end{tabular}

Sources: DNPD/DNSI/CNPE

*Estimates for 2004. 
Annex 7. Structure of “more comparable” GDP for 2000-2007

\section{Structure of “more comparable” GDP, 2000-2007 (Percentages)}

\begin{tabular}{|c|c|c|c|c|c|c|c|c|}
\hline Source of GDP & 2000 & 2001 & 2002 & 2003 & 2004 & 2005 & 2006 & 2007 \\
\hline Primary sector & -10.4 & 11.3 & -3.2 & 19.5 & -4.1 & 8.2 & 5.5 & 4.4 \\
\hline Of which, informal & -10.4 & 11.3 & -3.2 & 19.5 & -4.1 & 8.2 & 5.5 & 4.4 \\
\hline Agriculture & $\begin{array}{l}-19.8 \\
\end{array}$ & 19.0 & -7.9 & 32.8 & -10.7 & 11.5 & 9.6 & 5.4 \\
\hline Of which, informal & -19.8 & 19.0 & -7.9 & 32.8 & -10.7 & 11.5 & 9.6 & 5.4 \\
\hline Livestock & 3.6 & 2.8 & 3.1 & 4.5 & 7.3 & 4.6 & -1.4 & 3.0 \\
\hline Of which, informal & 3.6 & 2.8 & 3.1 & 4.5 & 7.3 & 4.6 & -1.4 & 3.0 \\
\hline Fishing, forestry & 2.5 & 2.5 & 2.6 & 2.6 & 2.6 & 2.6 & 2.6 & 2.6 \\
\hline Of which, informal & 2.5 & 2.5 & 2.6 & 2.6 & 2.6 & 2.6 & 2.6 & 2.6 \\
\hline Secondary sector & 4.6 & 20.3 & 18.9 & -8.6 & 2.7 & 6.8 & 15.2 & -11.3 \\
\hline Of which, informal & 3.2 & -5.0 & 16.9 & -4.6 & 10.9 & 5.9 & 4.2 & -0.1 \\
\hline Extractive industries & 11.1 & 85.1 & 22.5 & -18.8 & -15.2 & 15.5 & 24.5 & -21.2 \\
\hline Of which, informal & 2.9 & -1.4 & 0.5 & -15.7 & 53.0 & $\begin{array}{c}-0.6 \\
\end{array}$ & -0.8 & 0.8 \\
\hline Manufacturing & -2.2 & -14.1 & 24.2 & -5.6 & 19.0 & -3.9 & 19.0 & -11.4 \\
\hline Of which, informal & -1.2 & -16.7 & 33.7 & -11.2 & 8.9 & 2.7 & 10.2 & -5.3 \\
\hline Energy & 21.7 & 9.6 & 15.1 & 11.0 & 11.6 & 11.2 & 1.4 & -1.1 \\
\hline \multicolumn{9}{|l|}{ Of which, informal } \\
\hline $\begin{array}{l}\text { Construction/public } \\
\text { works }\end{array}$ & 5.3 & 6.9 & 4.4 & 4.4 & 8.0 & 10.3 & -0.1 & 4.5 \\
\hline Of which, informal & 8.5 & 7.3 & 4.9 & 4.0 & 8.3 & 10.0 & -0.2 & 4.7 \\
\hline $\begin{array}{l}\text { General tertiary } \\
\text { sector }\end{array}$ & -0.3 & 8.4 & 3.1 & 8.0 & 7.4 & 6.4 & 7.5 & 3.5 \\
\hline Tertiary sector & 2.8 & & -0.4 & 8.2 & 8.3 & 5.0 & 8.6 & 3.0 \\
\hline Of which, informal & 2.7 & 6.3 & -0.5 & 8.3 & 8.6 & 5.8 & 9.4 & 4.0 \\
\hline $\begin{array}{l}\text { Transportation and } \\
\text { telecommunications }\end{array}$ & 4.9 & 6.3 & -2.7 & 10.6 & 14.7 & 16.1 & 17.4 & 13.6 \\
\hline Of which, informal & 5.1 & 5.6 & -2.6 & 11.4 & 15.4 & 17.1 & 18.7 & 14.3 \\
\hline Commerce & 3.7 & 10.8 & -1.6 & 9.2 & 6.1 & 1.2 & 7.4 & -1.9 \\
\hline Of which, informal & 3.7 & 10.8 & -1.6 & 9.2 & 6.1 & 1.2 & 7.4 & -1.9 \\
\hline Banks and insurance & 4.8 & 1.0 & 0.3 & 7.7 & 10.7 & 7.2 & 4.0 & 3.0 \\
\hline \multicolumn{9}{|l|}{ Of which, informal } \\
\hline Other services & -0.2 & 0.5 & 3.3 & 4.9 & 7.8 & 3.7 & 4.1 & 2.6 \\
\hline Of which, informal & -0.6 & 0.0 & 2.8 & 4.7 & 7.5 & 3.5 & 3.6 & 2.3 \\
\hline $\begin{array}{l}\text { Noncommercial } \\
\text { services }\end{array}$ & 8.5 & 3.7 & 4.1 & 3.5 & 3.9 & 7.9 & 1.2 & 3.6 \\
\hline Of which, informal & 22.5 & -0.3 & 7.1 & -20.5 & -7.7 & 3.2 & 4.4 & 4.9 \\
\hline PISB & 4.9 & 1.1 & 1.3 & 7.8 & 11.2 & 8.6 & 4.3 & 4.3 \\
\hline GDP at factor cost & -1.8 & 11.0 & 3.5 & 7.2 & 1.6 & 6.9 & 8.3 & 0.0 \\
\hline Of which, informal & -5.1 & 7.9 & -0.4 & 13.1 & 1.2 & 7.1 & 6.6 & 3.8 \\
\hline $\begin{array}{l}\text { Domestic DTI and } \\
\text { VAT }\end{array}$ & -20.3 & 23.5 & 14.5 & 12.5 & 8.8 & 9.3 & 10.2 & 4.9 \\
\hline GDP at market prices & -3.3 & 11.9 & 4.3 & 7.6 & 2.2 & 7.1 & 8.4 & 0.5 \\
\hline Of which, informal & -5.1 & 7.9 & -0.4 & 13.1 & 1.2 & 7.1 & 6.6 & 3.8 \\
\hline Final consumption & -0.3 & 6.8 & -0.2 & 7.2 & 5.5 & 3.0 & 11.1 & -3.1 \\
\hline Households & 0.2 & 7.0 & -0.8 & 4.7 & 4.9 & 1.9 & 13.6 & -4.5 \\
\hline
\end{tabular}




\begin{tabular}{|l|r|r|r|r|r|r|r|r|}
\hline Government agencies & -2.8 & 5.6 & 2.4 & 18.5 & 7.8 & 7.1 & 1.6 & 2.8 \\
\hline Gross capital formation & -33.5 & 91.0 & -22.3 & 55.7 & -32.8 & 46.9 & -4.6 & -0.2 \\
\hline $\begin{array}{l}\text { Gross fixed capital } \\
\text { formation }\end{array}$ & 2.6 & 14.8 & 0.3 & 7.0 & 7.9 & 8.8 & -1.2 & 4.4 \\
\hline Private & 8.9 & 5.4 & 1.6 & 2.5 & 4.6 & 7.6 & -2.7 & 3.7 \\
\hline Public & -7.6 & 32.5 & -1.6 & 14.0 & 12.5 & 10.2 & 0.7 & 5.2 \\
\hline Change in inventories & 869.6 & 144.8 & 201.9 & 325.0 & 183.8 & 135.6 & -55.3 & 147.5 \\
\hline Exports & 6.5 & 14.1 & 20.3 & -6.8 & 14.4 & 0.3 & 5.1 & 5.0 \\
\hline Imports & -2.5 & 28.3 & -8.3 & 13.1 & -1.5 & 6.7 & 4.0 & -4.5 \\
\hline
\end{tabular}

Source: DNSI 
- 73 -

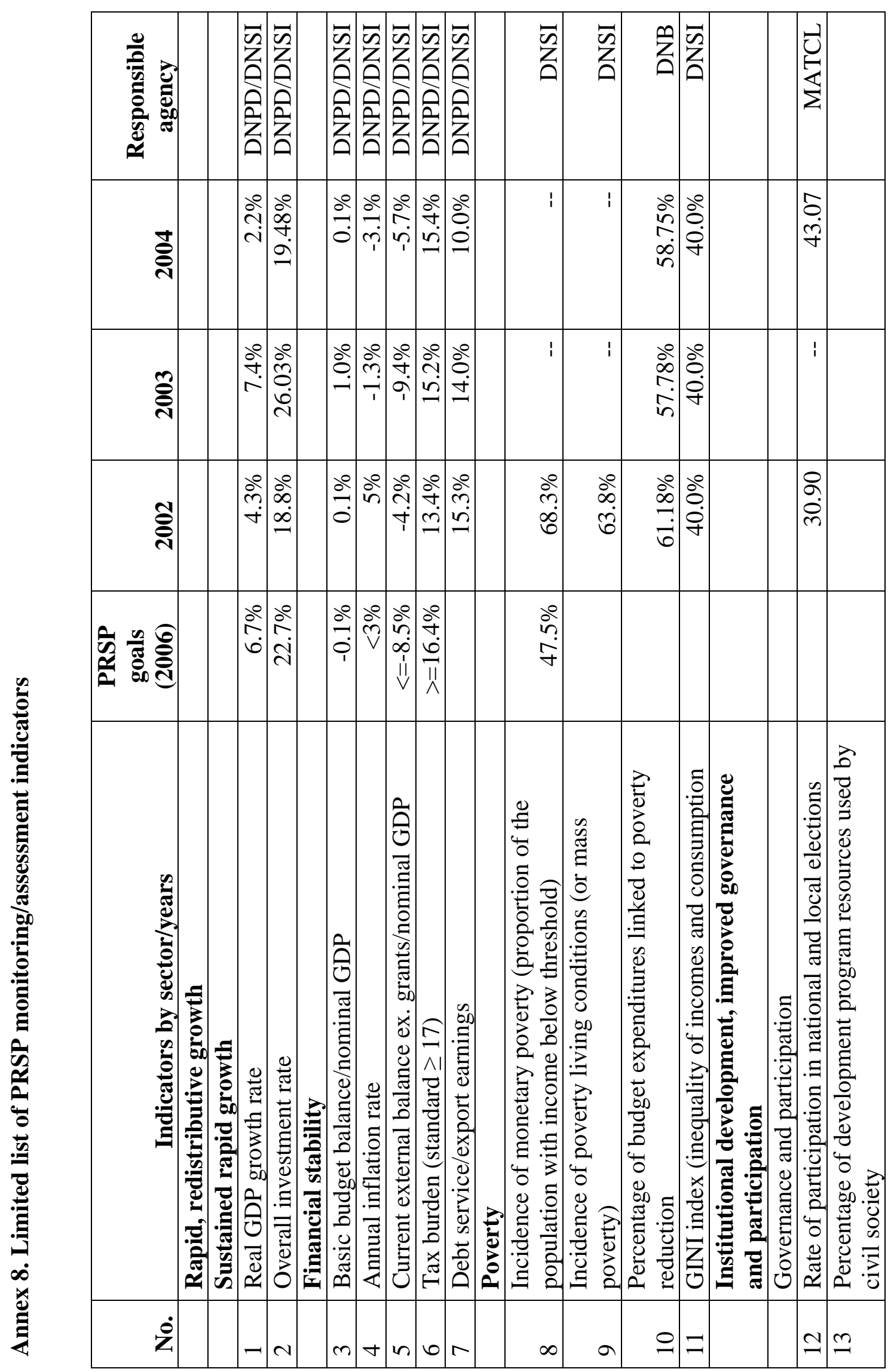




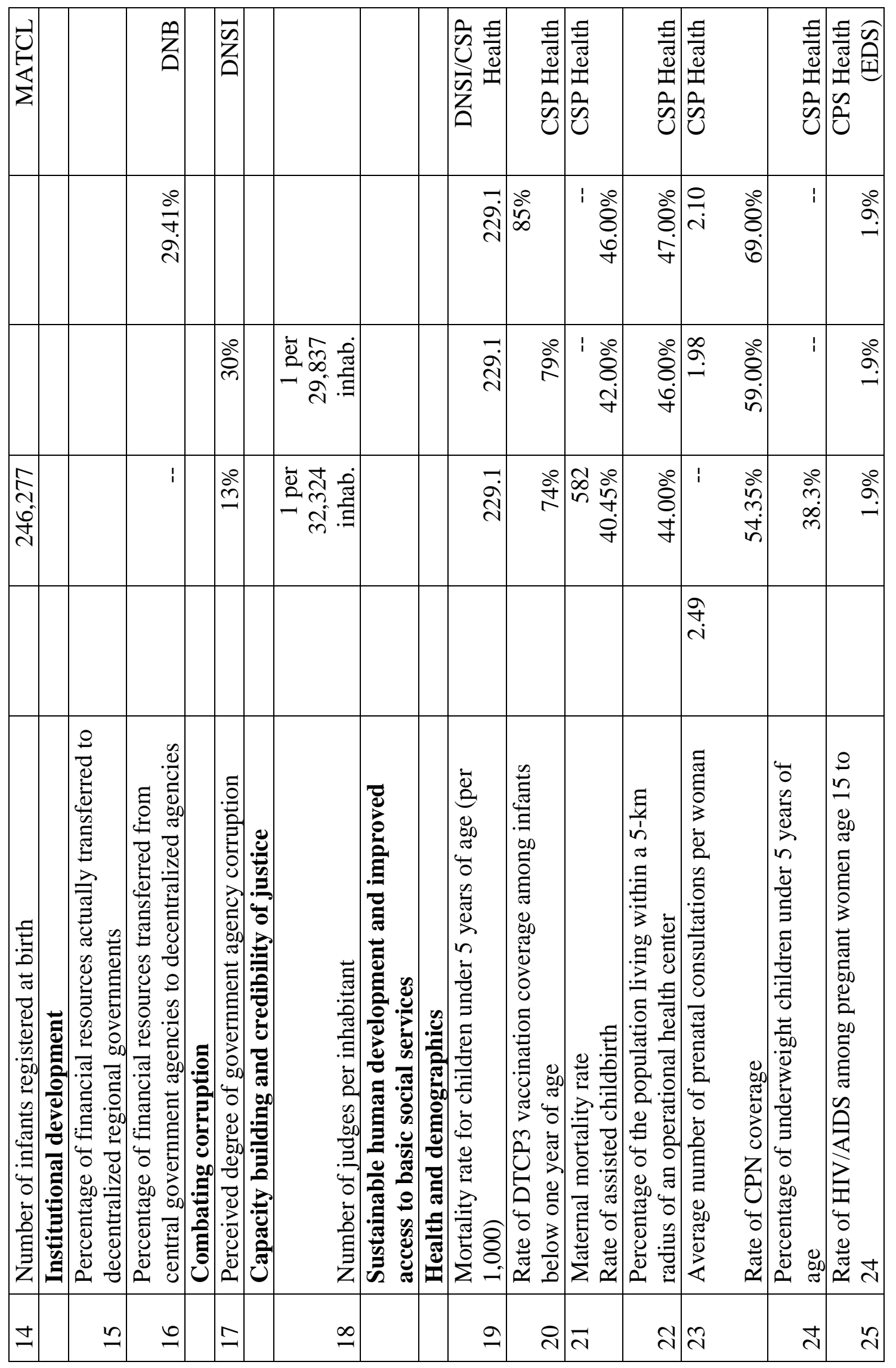




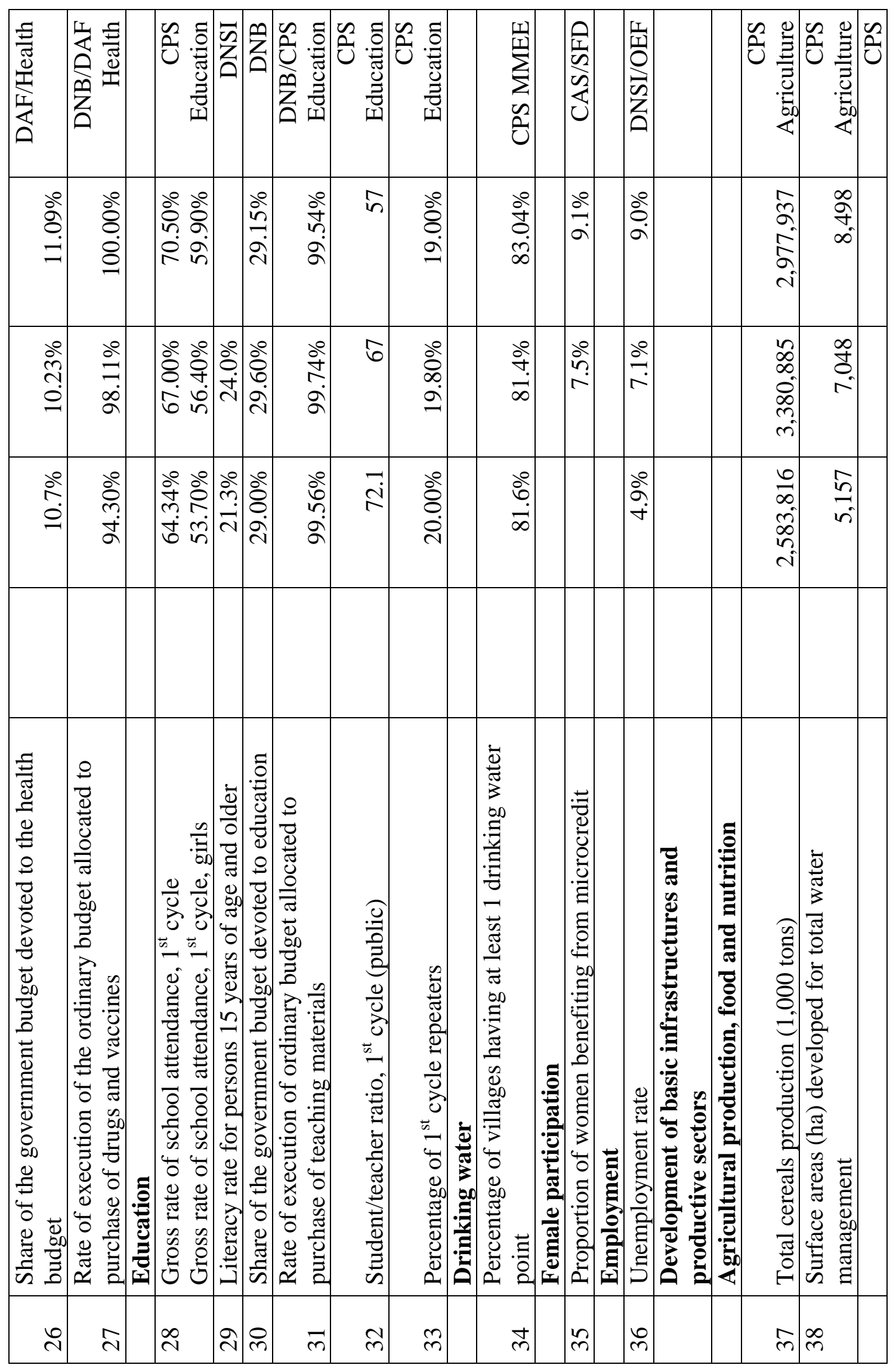




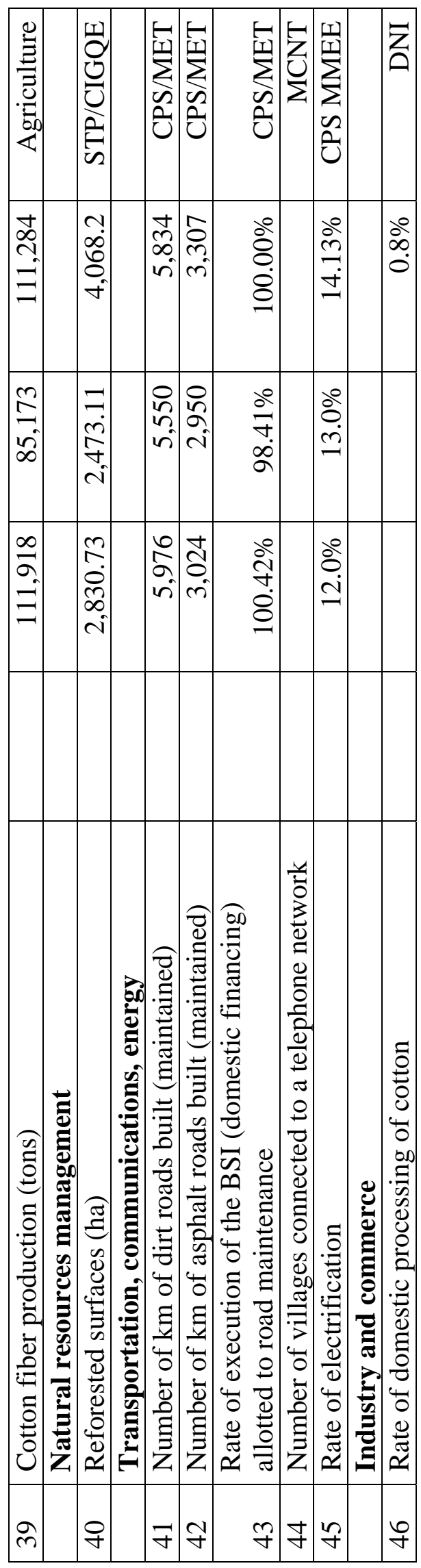



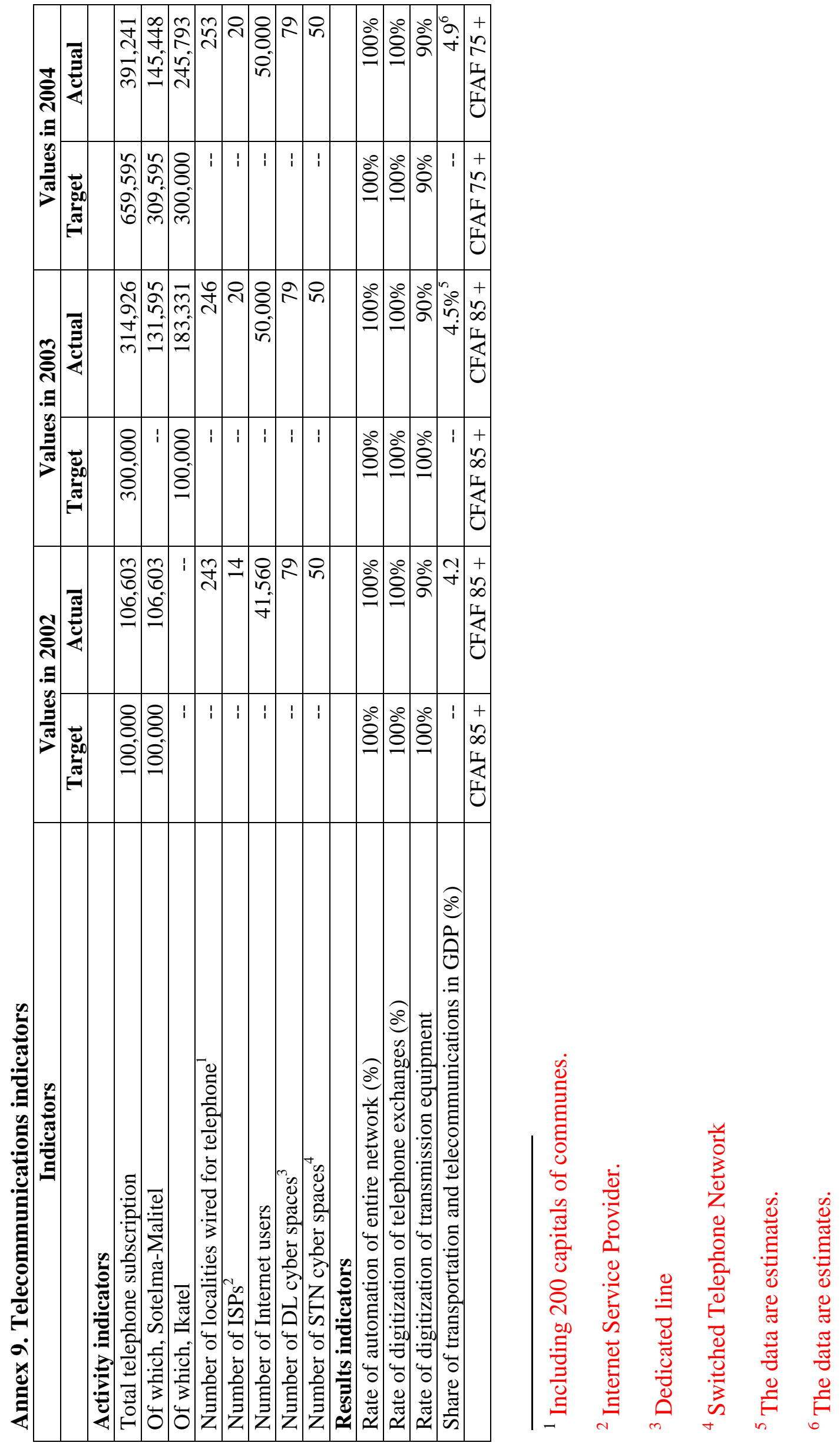


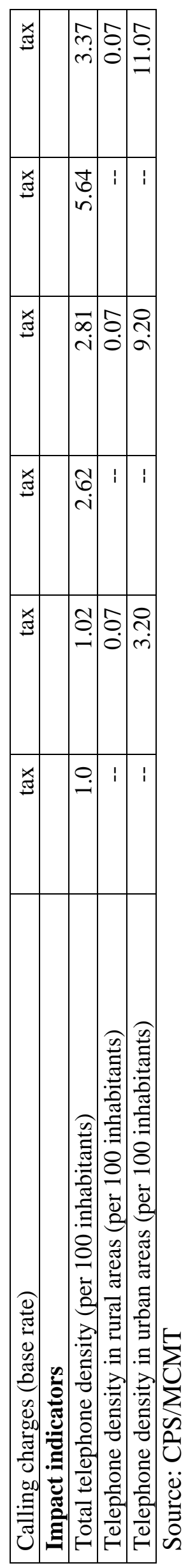


Annex 10. Trends in the budget law.

Breakdown of revenues by budget

(in billions of CFAF)

\begin{tabular}{|l|r|r|r|r|}
\hline \multicolumn{1}{|c|}{ Budget name } & $\mathbf{2 0 0 3}$ & \multicolumn{1}{c|}{$\mathbf{2 0 0 4}$} & \multicolumn{1}{c|}{$\mathbf{2 0 0 5}$} & \multicolumn{1}{c|}{$\begin{array}{c}\text { 2005/2004 } \\
\text { (\%) }\end{array}$} \\
\hline National budget & 417.527 & 458.304 & 510.511 & 11.39 \\
\hline $\begin{array}{l}\text { Supplemental budgets, special } \\
\text { accounts and funds }\end{array}$ & & & & 17.52 \\
\hline Regional budgets & 4.794 & 3.871 & 4.552 & -- \\
\hline Special Investment Budget & 0.234 & -- & -- & -1.93 \\
\hline Total & 229.471 & 237.125 & 232.539 & 6.91 \\
\hline
\end{tabular}

Source: DNB

Breakdown by type of expenditure budget

(in billions of CFAF)

\begin{tabular}{|l|r|r|r|r|}
\hline \multicolumn{1}{|c|}{ Budget name } & & & & \multicolumn{1}{c|}{$\begin{array}{c}\text { Change } \\
\text { as \% } \\
\mathbf{2 0 0 5 / 2 0 0 4}\end{array}$} \\
\hline National budget & $\mathbf{2 0 0 3}$ & $\mathbf{2 0 0 4}$ & $\mathbf{2 0 0 5}$ & 8.30 \\
\hline $\begin{array}{l}\text { Supplemental budgets, special } \\
\text { accounts and funds }\end{array}$ & 422.926 & 460.818 & 499.088 & 17.52 \\
\hline Regional budgets & 4.794 & 3.874 & 4.552 & 5.63 \\
\hline Special Investment Budget & 10.607 & 14.194 & 14.993 & 3.01 \\
\hline Total & 297.197 & 308.313 & 317.598 & 6.23 \\
\hline
\end{tabular}

Source: DNB

Breakdown by type of expenditure

(in billions of CFAF)

\begin{tabular}{|l|r|r|r|r|}
\hline \multicolumn{1}{|c|}{$\begin{array}{c}\text { Economic } \\
\text { Code }\end{array}$} & $\begin{array}{c}\text { Supplementary } \\
\text { budget } \\
\mathbf{2 0 0 3}\end{array}$ & $\begin{array}{c}\text { Budget } \\
\text { law } \\
\mathbf{2 0 0 4}\end{array}$ & \multicolumn{1}{c|}{$\begin{array}{c}\text { Budget } \\
\text { law } \\
\mathbf{2 0 0 5}\end{array}$} & $\begin{array}{c}\text { Change } \\
\mathbf{2 0 0 5 / 2 0 0 4} \\
\mathbf{( \% )}\end{array}$ \\
\hline Personnel & 100.029 & 111.140 & 123.438 & 11.07 \\
\hline HIPC personnel & 5.591 & 10.884 & 16.752 & 53.91 \\
\hline Equipment & 37.525 & 44.511 & 50.368 & 13.16 \\
\hline HIPC equipment & 0.731 & -- & 0.240 & -- \\
\hline Travel & 22.100 & 23.705 & 26.477 & 11.69 \\
\hline Communications/energy & 20.503 & 25.500 & 28.244 & 10.76 \\
\hline $\begin{array}{l}\text { Other expenses + transfers and } \\
\text { subsidies }\end{array}$ & & & & 25.42 \\
\hline HIPC transfers and subsidies & 90.011 & 97.714 & 122.549 & -40.20 \\
\hline Elections expenses & 7.176 & 10.856 & 6.492 & -50.60 \\
\hline Scholarships & 1.000 & 6.868 & 3.187 & 0.00 \\
\hline Supplemental budgets & 5.640 & 5.640 & 5.640 & 17.52 \\
\hline $\begin{array}{l}\text { Regular liability liquidation }+ \\
\text { exchange losses }\end{array}$ & 4.794 & 3.874 & 4.552 & \\
\hline
\end{tabular}




\begin{tabular}{|l|r|r|r|r|}
\hline Capital equipment & 83.000 & 108.836 & 109.763 & 0.85 \\
\hline HIPC capital equipment & 21.224 & 7.857 & 7.734 & -1.57 \\
\hline Public enterprise restructuring & 20.000 & 11.000 & 0.000 & -100.00 \\
\hline Principal/interest on debt & 76.489 & 76.248 & 83.286 & 9.23 \\
\hline BSI (external financing) & 219.471 & 227.125 & 232.539 & 2.38 \\
\hline Settled liabilities & 15.000 & 13.000 & 12.700 & -2.13 \\
\hline Total & 732.524 & 787.198 & 838.231 & 6.23 \\
\hline
\end{tabular}

Source: DNB

Main sector ratios compared to recurrent charges

\begin{tabular}{|l|r|r|r|}
\hline \multicolumn{1}{|c|}{ Sector } & \multicolumn{1}{c|}{$\mathbf{2 0 0 3}$} & $\mathbf{2 0 0 4}$ & \multicolumn{1}{c|}{$\mathbf{2 0 0 5}$} \\
\hline Education & 30.57 & 30.06 & 30.31 \\
\hline Health (ex. other social sectors) & 10.07 & 10.65 & 10.15 \\
\hline Social sectors (ex. health and education) & 6.85 & 8.39 & 8.72 \\
\hline Rural development and environment & 4.57 & 4.74 & 5.15 \\
\hline $\begin{array}{l}\text { Equipment, Transportation, City Planning } \\
\text { and Communications }\end{array}$ & & & \\
\hline Armed forces and security & 3.60 & 3.92 & 3.85 \\
\hline Mining, water resources and industry & 16.90 & 16.66 & 16.45 \\
\hline Public authorities and govt. agencies & 1.41 & 1.47 & 1.54 \\
\hline Allocated but not distributed & 19.59 & 19.74 & 20.19 \\
\hline Total & 6.44 & 4.37 & 3.64 \\
\hline
\end{tabular}

Source: DNB

Ratios compared to entire budget (including external financing of the BSI)

\begin{tabular}{|l|r|r|r|}
\hline \multicolumn{1}{|c|}{ Sector } & 2003 & $\mathbf{2 0 0 4}$ & \multicolumn{1}{c|}{$\mathbf{2 0 0 5}$} \\
\hline Education & 13.91 & 15.13 & 15.07 \\
\hline Health (ex. other social sectors) & 7.06 & 6.79 & 6.68 \\
\hline Social sectors (ex. health and education) & 3.65 & 5.30 & 5.81 \\
\hline Rural development and environment & 15.53 & 15.10 & 15.28 \\
\hline $\begin{array}{l}\text { Equipment, Transportation, City Planning } \\
\text { and Communications }\end{array}$ & 14.58 & 14.27 & 12.24 \\
\hline Armed forces and security & 6.59 & 7.03 & 7.40 \\
\hline Principal and interest on debt & 10.37 & 9.68 & 9.76 \\
\hline Mining, water resources and industry & 3.60 & 3.54 & 5.26 \\
\hline Public authorities and govt. agencies & 10.94 & 11.56 & 12.89 \\
\hline Allocated but not distributed & 13.77 & 11.60 & 9.61 \\
\hline Total & 100.00 & 100.00 & 100.00 \\
\hline
\end{tabular}

Source: DNB 
Annex 11. Gender

Gender and decision-making positions

\begin{tabular}{|c|c|c|c|c|}
\hline Period & Position/agency & Women & Men & Total \\
\hline \multicolumn{5}{|c|}{ Second Republic } \\
\hline \multirow[t]{8}{*}{$\begin{array}{l}1990 \text { ( } 3^{\text {rd }} \\
\text { Legislature) }\end{array}$} & Deputy & 5 & 77 & 82 \\
\hline & Mayor & 0 & 19 & 19 \\
\hline & Prime Minister & 0 & 1 & 1 \\
\hline & Minister & 1 & 21 & 22 \\
\hline & Staff director & 0 & 22 & 22 \\
\hline & Chief of staff & 1 & 20 & 21 \\
\hline & Governor & 0 & 9 & 9 \\
\hline & Commanding Officer & 0 & 46 & 46 \\
\hline \multirow[t]{8}{*}{$\begin{array}{l}1991-1992 \\
\text { (CTSP) }\end{array}$} & CTSP (Executive bureau) & 1 & 25 & 26 \\
\hline & Special Delegate & 2 & 17 & 19 \\
\hline & Prime Minister & 0 & 1 & 1 \\
\hline & Minister & 3 & 15 & 18 \\
\hline & Staff Director & 0 & 18 & 18 \\
\hline & Chief of Staff & 0 & 18 & 18 \\
\hline & Governor & 1 & 8 & 9 \\
\hline & Commanding Officer & 0 & 46 & 46 \\
\hline \multicolumn{5}{|c|}{ Third Republic } \\
\hline \multirow[t]{15}{*}{$\begin{array}{l}1992-1997\left(1^{\text {st }}\right. \\
\text { Legislature })\end{array}$} & Deputy & 3 & 113 & 116 \\
\hline & Mayor, urban com. & 0 & 19 & 19 \\
\hline & Mayor, rural com. & 5 & 677 & 682 \\
\hline & Prime Minister & 0 & 1 & 1 \\
\hline & Minister & 6 & 16 & 22 \\
\hline & Staff Director/Secretary General & 1 & 22 & 23 \\
\hline & Chief of Staff & 2 & 18 & 20 \\
\hline & High Commissioner & 0 & 9 & 9 \\
\hline & GRM Delegate & 0 & 46 & 46 \\
\hline & Constitutional Court & 2 & 7 & 9 \\
\hline & CESC member & 3 & 47 & 50 \\
\hline & Supreme Court & & & \\
\hline & APCAM & & & \\
\hline & CCIM & & & \\
\hline & State’s Mediator & 0 & 1 & 1 \\
\hline \multirow[t]{2}{*}{$\begin{array}{l}1997-2002\left(2^{\text {nd }}\right. \\
\text { Legislature) }\end{array}$} & Deputy & 18 & 129 & 147 \\
\hline & Mayor, urban com. & 0 & 19 & 19 \\
\hline
\end{tabular}




\begin{tabular}{|c|c|c|c|c|}
\hline & Mayor, rural com. & 5 & 677 & 682 \\
\hline & Communal Counselor & 424 & 10,116 & 10,540 \\
\hline & Prime Minister & 0 & 1 & 1 \\
\hline & Minister & 4 & 16 & 20 \\
\hline & State's Mediator & 1 & 0 & 0 \\
\hline & Secretary General & 0 & 20 & 20 \\
\hline & Chief of Staff & 2 & 18 & 20 \\
\hline & High Commissioner & 0 & 9 & 9 \\
\hline & GRM/cercle Delegate & 0 & 49 & 49 \\
\hline & Constitutional Court & 3 & 6 & 9 \\
\hline & CESC Member & 3 & 44 & 47 \\
\hline & High CCT & 6 & 63 & 69 \\
\hline & APCAM & 1 & 30 & 31 \\
\hline & CCIM & 13 & 227 & 240 \\
\hline $\begin{array}{l}\text { Starting June } \\
2002\left(3^{\text {rd }}\right. \\
\text { egislature }\end{array}$ & Deputy & 15 & 132 & 147 \\
\hline & Mayor, urban com. & 0 & 19 & 19 \\
\hline & Mayor, rural com. & 5 & 677 & 682 \\
\hline & Communal Counselor & 424 & 692 & 1,116 \\
\hline & Prime Minister & 0 & 1 & 1 \\
\hline & Minister & 4 & 20 & 24 \\
\hline & State's Mediator & 1 & 0 & 1 \\
\hline & Secretary General & 0 & 28 & 28 \\
\hline & Chief of Staff & 4 & 20 & 24 \\
\hline & High Commissioner & 0 & 9 & 9 \\
\hline & Prefect & 1 & 48 & 49 \\
\hline & Constitutional Court & 3 & 6 & 9 \\
\hline & CESC & 3 & 44 & 47 \\
\hline & High CCT & 6 & 63 & 69 \\
\hline & APCAM & 1 & 30 & 31 \\
\hline & CCIM & 13 & 227 & 240 \\
\hline & Minister & 5 & 22 & 27 \\
\hline & Secretary General & 0 & 27 & 27 \\
\hline & Chief of Staff & 3 & 25 & 28 \\
\hline & Technical Counselor & 19 & 121 & 140 \\
\hline & Mission Chief & 14 & 69 & 83 \\
\hline & Staff Attaché & 2 & 26 & 28 \\
\hline & DAF & 2 & 26 & 28 \\
\hline
\end{tabular}

Sources: DNSI (Le Mali en chiffres, 1997-2001; CNDIFE database Women/Public Life, 2002.) 


\section{Annex 12. Health}

Number of CSCOMs per region in 2002, 2003,2004

\begin{tabular}{|l|c|c|c|}
\hline \multicolumn{1}{|c|}{ Region } & Level at end-2002 & Level at end-2003 & Level at end-2004 \\
\hline Kayes & 89 & 94 & 97 \\
\hline Koulikoro & 82 & 85 & 85 \\
\hline Sikasso & 136 & 141 & 141 \\
\hline Ségou & 106 & 123 & 125 \\
\hline Mopti & 83 & 94 & 94 \\
\hline Timbuktu & 25 & 31 & 31 \\
\hline Gao & 31 & 37 & 39 \\
\hline Kidal & 5 & 5 & 8 \\
\hline Bamako & 48 & 50 & 50 \\
\hline All Mali & $\mathbf{6 0 5}$ & $\mathbf{6 6 0}$ & $\mathbf{6 7 0}$ \\
\hline
\end{tabular}

Source: Health group report

Rate of completed DTCP3 vaccination of infants under 12 months of age, 2002, 2003 and 2004

\begin{tabular}{|l|c|c|c|}
\hline \multicolumn{1}{|c|}{ Region } & Level at end-2002 & Level at end-2003 & Level at end-2004 \\
\hline Kayes & 47 & 59 & 68 \\
\hline Koulikoro & 63 & 72 & 71 \\
\hline Sikasso & 91 & 91 & 85 \\
\hline Ségou & 60 & 86 & 76 \\
\hline Mopti & 71 & 80 & 70 \\
\hline Timbuktu & 38 & 42 & 32 \\
\hline Gao & 70 & 48 & 53 \\
\hline Kidal & 56 & 18 & 17 \\
\hline Bamako & 91 & 109 & 83 \\
\hline All Mali & $\mathbf{7 4}$ & $\mathbf{7 9}$ & $\mathbf{7 2}$ \\
\hline
\end{tabular}

Source: Health thematic group report 


\section{Annex 13. Livestock}

\section{Audited exports by species (Number of head)}

\begin{tabular}{|l|r|r|r|r|}
\hline \multicolumn{1}{|c|}{ Species } & \multicolumn{1}{c|}{$\mathbf{2 0 0 1}$} & \multicolumn{1}{c|}{$\mathbf{2 0 0 2}$} & $\mathbf{2 0 0 3}$ & $\mathbf{2 0 0 4}$ \\
\hline Cows & 226,819 & 106,792 & 93,011 & \\
\hline Sheep/goats & 425,209 & 252,395 & 165,279 & \\
\hline Camels & 2,704 & 2,433 & 3,533 & \\
\hline Fowl & 783,086 & 333,789 & 18,082 & \\
\hline Wild birds & 687,038 & 257,434 & 170,997 & \\
\hline Donkeys & 96 & 71 & 746 & \\
\hline Reptiles & 32,176 & 34,333 & 8,188 & \\
\hline
\end{tabular}

Source: DGRC, 2003

Audited meat exports

(in Kg)

\begin{tabular}{|c|r|r|c|}
\hline Product & $\mathbf{2 0 0 2}$ & $\mathbf{2 0 0 3}$ & $\mathbf{2 0 0 4}$ \\
\hline Fresh meat & 62,089 & 57,722 & \\
\hline
\end{tabular}

Source: DGRC, 2003

Audited exports of hides and skins

(in Kg)

\begin{tabular}{|l|r|r|r|r|}
\hline \multicolumn{1}{|c|}{ Species } & $\mathbf{2 0 0 1}$ & $\mathbf{2 0 0 2}$ & $\mathbf{2 0 0 3}$ & $\mathbf{2 0 0 4}$ \\
\hline Cowhide & 348,310 & $1,947,000$ & $2,436,600$ & \\
\hline $\begin{array}{l}\text { Sheepskins, } \\
\text { goatskins }\end{array}$ & 782,527 & $1,888,000$ & $2,120,266$ & \\
\hline Snakeskins & 2,300 & 10,000 & 3,185 & \\
\hline
\end{tabular}

Source: DGRC, 2003 


\section{Annex 14. Sources and bibliographic references}

\section{Sources and bibliographic references}

1. Poverty Reduction Strategy Paper (PRSP), May 2002

2. Monitoring/evaluation system for implementation of the Poverty Reduction Strategy Paper (PRSP), preliminary version of November 18, 2002

3. First report on the monitoring/evaluation of the PRSP

4. Report on the Economic \& Social Situation of Mali in 2003 - 2004 Outlook

5. Validated reports of the PRSP Thematic Working Groups

6. Government Budget, 2002, 2003 and 2004

7. Report of the 2004 Program Budget (Volumes I and II)

8. World Bank Country Assistance Strategy (CAS), (provisional), March 2003

9. Year 2002 report on Mali-World Bank Partnership

10. UNDP 2003 Human Development Report

11. Report on the multiyear convergence program (WAEMU), for stability, growth, and stability (2005-2007) in Mali

12. Cooperation Strategy and National Indicative Program 2003-2007 Mali-European Union, 2002 provisional report

13. Aide-mémoire of the ex-post evaluation mission by the IMF on the results obtained as part of ESAF/PRGF programs, November 2004

14. Aide-mémoires of the Education Sector Investment Program (PISE) joint monitoring missions from February and July 2003

15. CDI: Institutional Development Program (IDP), provisional report, January 2003

16. DNP: Implementation Reports of the Special Investment Budget (BSI) 2002 and 2003

17. DNB: Report on execution of domestically funded expenditures in the government budget, 2002 and 2003 fiscal year (mid-term)

18. CPS/Education: Statistical Yearbook 